\title{
Treatment of solid wood with silanes, polydimethylsiloxanes and silica sols
}

\author{
Dissertation \\ zur Erlangung des mathematisch-naturwissenschaftlichen Doktorgrades \\ „Doctor rerum naturalium“ \\ der Georg-August-Universität Göttingen \\ im Promotionsprogramm "Wood Biology and Wood Technology" \\ der Georg-August University School of Science (GAUSS)
}

\author{
vorgelegt von \\ Malte Pries \\ aus Vechta
}

Göttingen, 2013 


\section{Betreuungsausschuss:}

PD Dr. Carsten Mai, Abteilung Holzbiologie und Holzprodukte, Georg-August Universität Göttingen

Professor Dr. Holger Militz, Abteilung Holzbiologie und Holzprodukte, GeorgAugust Universität Göttingen

\section{Mitglieder der Prüfungskommission:}

PD Dr. Carsten Mai, Abteilung Holzbiologie und Holzprodukte, Georg-August Universität Göttingen

Professor Dr. Holger Militz, Abteilung Holzbiologie und Holzprodukte, GeorgAugust Universität Göttingen

Professor Dr. Franitišek Hapla, Abteilung Holzbiologie und Holzprodukte, GeorgAugust Universität Göttingen

Professor Dr. Ursel Kües, Abteilung Molekulare Holzbiotechnologie und Technische Mykologie, Georg-August Universität Göttingen

Professor Dr. Stefan Schütz, Abteilung Forstzoologie und Waldschutz, GeorgAugust Universität Göttingen

PD Dr. Martin Worbes, Abteilung Tropischer Pflanzenbau, Georg-August Universität Göttingen

Tag der mündlichen Prüfung: 20.1.2014 


\section{Acknowledgment}

This work could not have been completed without the help of several people. I want to first and foremost thank Carsten Mai, my advisor, for his continuous support and fruitful discussions as well as for the constant revision on all things printed. Holger Militz, my professor, was an important guide throughout my thesis helping me remain on track, focus on the important things and work towards my goals, thank you.

I received great help from the whole department of Wood Biology and Wood Products in planning, preparing and carrying out my experiments as well as the analysis of my results. I thank them all for being great and fun colleagues.

My project was financed by Momentive Performance Materials. I thank Momentive, for giving me the opportunity to work on this project. Particularly I want to thank Karl-Heinz Kaesler, Roland Wagner, Jos Delis and Egbert Klaassen, who have all been very supportive and pleasant to work with. 


\section{Table of Contents}

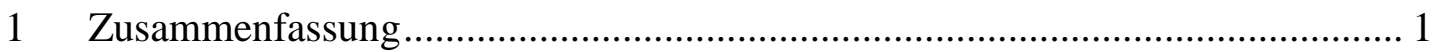

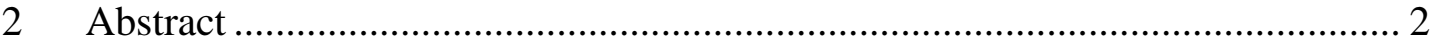

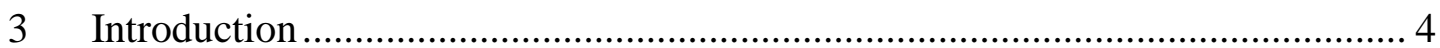

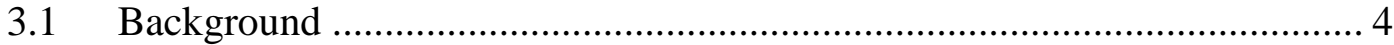

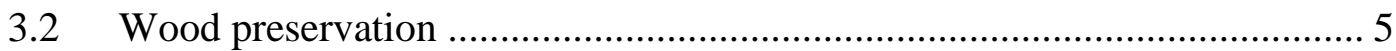

3.3 Wood modification systems …........................................................... 5

$4 \quad$ Wood modification by acetylation and with silicon compounds ........................ 9

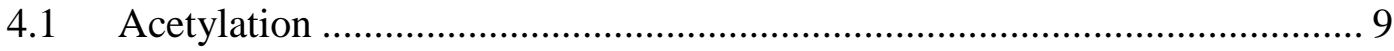

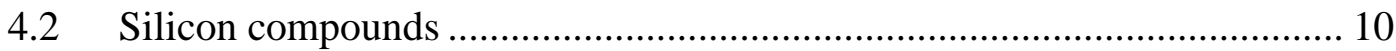

4.2.1 Inorganic silicon compounds ........................................................ 10

4.2.2 Organic silicon compounds ........................................................... 14

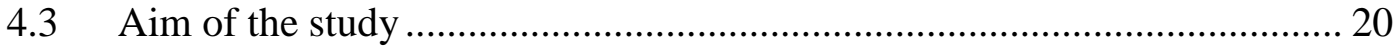

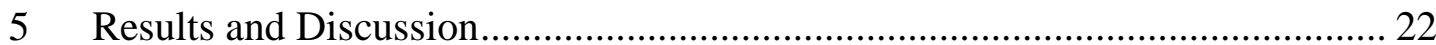

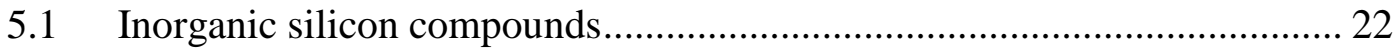

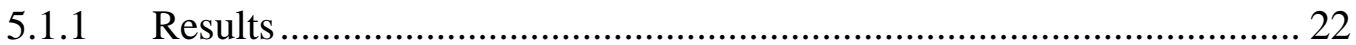

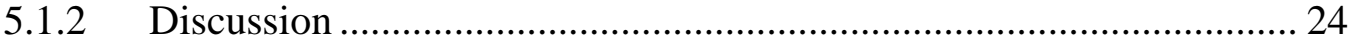

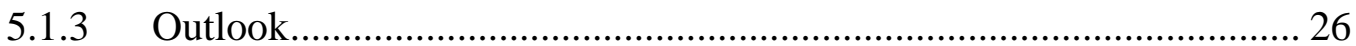

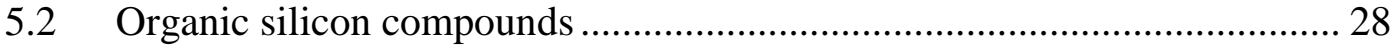

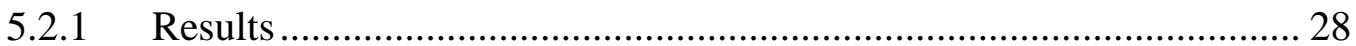

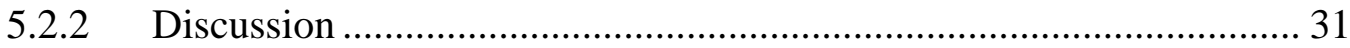

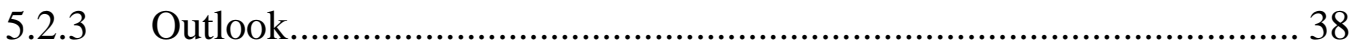

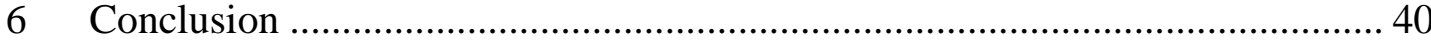

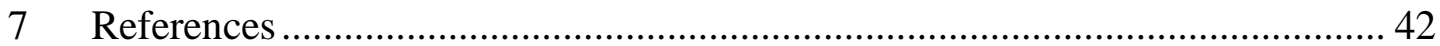

8 Appendix

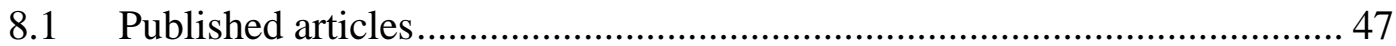

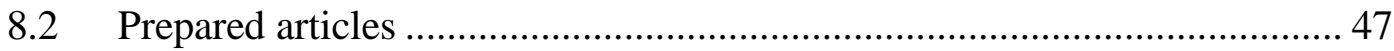

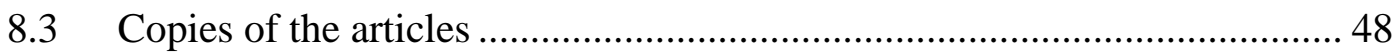




\section{Zusammenfassung}

Diese Arbeit besteht aus drei Teilen. Im ersten Teil wurde Holz mit verschiedenen, kommerziell erhältlichen Kieselsolen behandelt, die unterschiedliche pH-Werte und Oberflächenmodifikationen aufwiesen. Basische Kieselsole vermochten nicht in das Holz einzudringen, da ihr pH-Wert während des Eindringens absinkt und es zur Ausfällung des Kieselsols im Holz kommt. Neutrale und saure Kieselsole hingegen konnten problemlos in das Holz eingebracht werden. Eines der sauren Kieselsole, welches mittels Aluminumoxychlorid kationisch modifiziert war, reduzierte die Wasseraufnahme und den pilzlichen Abbau durch die Braunfäule Coniophora puteana (Kiefer) und die Weißfäule Trametes versicolor (Buche). Im Bläuetest zeigte sich ein verminderter Befall durch Aureobasidium pullulans, allerdings kein kompletter Schutz gegen diesen Pilz. Auch die kleinsten verfügbaren Partikelgrößen für Kieselsole ergaben keinerlei Zunahme des Zellwandvolumens (chemische Quellung, Bulking), was darauf hinweist, dass eine Eindringung in die Zellwand nicht stattfand. Es erscheint daher nicht möglich, Kieselsole in die Zellwand einzubringen und die Dimensionsstabilität des Holzes zu verbessern. Da Kieselsol lediglich in die Lumen der Holzzellen eingebracht werden kann, kann die Behandlung nicht als wirkliche Holzmodifizierung angesehen werden.

Wegen der vielversprechenden Ergebnisse in den Wasseraufnahmeversuchen und den Pilztests wurde mit dem kationischen Kieselsol behandeltes Holz thermogravimetrisch und in einem Brandtest untersucht. Im thermogravimetrischen Test zeigte sich eine leicht verminderte Pyrolysetemperatur (eine übliche Wirkung von Feuerschutzmitteln), die Holzkohlemenge war jedoch nicht erhöht. Dies zeigt, dass die Menge an brennbaren Gasen, die während der Pyrolyse freiwerden, durch das Kieselsol nicht vermindert wurde. Auch zeigte die resultierende Holzkohle gleiche Oxidationseigenschaften wie die Holzkohle der Kontrollen. Im Brandtest wurden die Branddauer, die Brandgeschwindigkeit und der Gewichtsverlust vermindert. Das Nachglühen der Holzkohle wurde komplett unterbunden. Alle diese Effekte waren jedoch relativ klein verglichen mit den Effekten eines kommerziell erhältlichen Feuerschutzsalzes, welches ebenfalls als Referenzbehandlung getestet wurde.

Im zweiten Teil der Arbeit wurden acetoxyfunktionelles Silan und verschiedene Polydimethylsiloxane (PDMS) mit Acetanhydrid kombiniert, um Holz zu acetylieren. Die PDMS hatten die folgenden Funktionalitäten: Amino, Acetoxy, Hydroxy und nicht-funktionell. Die beste Hydrophobierung des acetylierten Holzes wurde durch die Kombination mit acetoxyfunktionellem PDMS erreicht, welches anschließend in verschiedenen Konzentrationen getestet wurde. Eine Konzentration 
von $1 \%$ in Acetanhydrid zeigte bereits eine maximale Hydrophobierung, welches darauf schließen lässt, dass die inneren Oberflächen des Holzes mit dem PDMS belegt und hydrophobiert wurden. Die Pilzresistenz des behandelten Holzes wurde durch die Kombination mit dem PDMS nicht beeinflusst. Bei Wasserlagerung zeigte sich eine leichte Überquellung des Holzes, welches mit der Kombination von Acetanhydrid und PDMS acetyliert worden war. Untersuchungen der Biegefestigkeit und Bruchschlagarbeit ergaben jedoch keinen Einfluss.

Im dritten Teil der Arbeit wurden wasserbasierte Emulsionen von funktionellen PDMS zur Imprägnierung von Holz eingesetzt. Es wurde untersucht, ob Resistenz gegen pilzlichen Abbau und Hydrophobierung wie auch erhöhte Dimensionsstabilität mit dieser Behandlung erreicht werden kann. Die $\alpha-\omega$-gebundenen Funktionalitäten der PDMS waren: Amino, Carboxy, Epoxy und Carbobetain. Die stärkste Hydrophobierung wurde mit dem carbobetain-funktionellen PDMS erreicht, allerdings ergab diese Behandlung keine verbesserte Pilzresistenz gegenüber einem Abbau durch Coniophora puteana und Trametes versicolor. In dieser Hinsicht die beste Wirkung zeigte die Behandlung mit carboxy-funktionellem PDMS. Dieses Material verminderte jedoch die Wasseraufnahmerate nur ungenügend und wurde außerdem stark ausgewaschen. Daher wurden in der Folge amino-funktionelles und carboxy-funktionelles PDMS kombiniert, um durch eine Salzbildung der beiden Funktionalitäten eine verbesserte Fixierung des carboxy-funktionellen Siloxans zu erreichen. Die Kombination zeigte bei einem Überschuss an amino-funktionellem PDMS eine gute Fixierung, jedoch ansonsten keine Synergieeffekte. Die Dimensionsstabilität des Holzes wurde durch die Behandlungen nur sehr geringfügig verbessert. Hierfür müsste eine gute Eindringung der Chemikalien in die Zellwand erfolgen und ein dauerhaftes Bulking erzielt werden. Die Eindringung der Chemikalien in die Zellwand war jedoch in allen Fällen nur gering.

\section{Abstract}

The study can be divided into three sections. In the first section, wood was treated with different commercially available silica sols of varying $\mathrm{pH}$ and surface modification. While alkaline silica sols could not be impregnated into the wood due to lowering of $\mathrm{pH}$ and precipitation, neutral and acidic silica sols showed good penetration. One of the tested silica sols with an acidic $\mathrm{pH}$ value and cationic surface modified with aluminum-oxychloride reduced water uptake and fungal decay due to incubation with the brown rot fungus Coniophora puteana (pine sapwood) and the white rot fungus Trametes versicolor (beech wood) in a fungal decay test according to EN 113. Blue stain test revealed some inhibition of staining by the fungus Areobasidium pullulans, but no absolute resistance if wood had been treated with this 
silica sol. Even the smallest available particle sizes of the silica sols did not result in positive increase in cell wall volume (chemical swelling, bulking), indicating, that silica sols cannot penetrate the cell wall of wood and induce increased dimensional stability. Since silica sols are not able to penetrate the cell wall and are solely deposited in the lumens of the cell, the treatment cannot be regarded as a real wood modification.

Due to the promising results in water uptake and fungal decay test, wood treated with cationic silica sol was further investigated in a thermo gravimetric analysis (TGA) and burning test. In the TGA the silica sol revealed reduced thermal degradation temperature (a common feature of fire retardant salts), but only to a minor extent. The charcoal yield after pyrolysis was not increased, indicating no reduction of flammable volatiles released during pyrolysis. Furthermore oxidation behavior of the charcoal was similar to the control. In the burning test, the burning duration, burning speed and mass loss of the samples were reduced. Glowing of the charcoal was completely prevented. All these effects were, however, small if compared to a commercially available fire retardant.

In the second part of the study, acetoxy-functional silane and PDMS with amino-, acetoxy- and hydroxy-function as well as non-functional PDMS were tested in combination with acetic anhydride for the acetylation of wood. Best water repellence was obtained with acetoxy-functional PDMS, which was further investigated in different concentrations. An addition of $1 \%$ proved to be sufficient for maximum water repellence, which indicated coverage of the inner surfaces of the wood rendering them water repellent. Decay resistance was only governed by acetylcontent of the acetylated wood; the PDMS did not show an influence. Even though the PDMS treated samples showed a slight over-swelling in water, bending strength and impact bending strength were not affected by the combined treatment.

In the third section of the study, water based emulsions of functional PDMS were tested for their suitability to improve decay resistance and water related properties of wood. The $\alpha-\omega$ attached functionalities were: amino, carboxy, epoxy and carbobetain. While best results in reducing water uptake were obtained using carbobetain-functional PDMS, decay by Coniophora puteana and Trametes versicolor was most effectively reduced by carboxy-functional PDMS. This material, however, showed no proper reduction in water uptake and additionally exhibited high leaching. Combining carboxy- and amino-functional PDMS will result in salt formation of the two functionalities and was thought to increase fixation of carboxyfunctional siloxane. However, the combination did not show promising synergistic effects. Dimensional stability was hardly achieved by the treatments with PDMS 
emulsions. The PDMS did not penetrate the cell walls of wood sufficiently and did not cause a high and stable bulking, which is needed for dimensional stabilization.

\section{Introduction}

\subsection{Background}

Wood is a widely used and important renewable resource. Although it has been substituted by other materials in some areas, wood will likely be a scarce resource in the future due to increasing demand for energy production as well as in the construction sector. More than half the world's wood harvest is still used for cooking and heating purposes today (Rowell, 2005) and this demand is likely to increase if fossil fuels become more expensive. Another aspect of increasing demand of wood is an increasing environmental awareness accompanied with the idea of green building, which increases the demand for wood in construction as a renewable, $\mathrm{CO} 2$ binding resource with a low level of embodied energy (Falk, 2010). To meet all these goals, it will become very important in the future to increase service life of wood in use and thus decrease the demand.

Wood has a unique structure, which gives it high strength combined with low weight, favorable appearance and color. But there are certain drawbacks to wood which limit its application. Most important, wood is broken down by organisms such as fungi, insects and marine borers. While this is a valuable feature for disposal of wood, it reduces service life considerably in applications, where it will be exposed to such organisms. Furthermore, wood can be deteriorated by physical, mechanical and chemical means depending on the surroundings of its application. Other disadvantages of wood are its shrinking, swelling and its anisotropy (Kollmann, 1951).

Natural durability offers a certain degree of resistance, but especially home grown timber species such as spruce, pine, larch, Douglas fir or hardwoods do not show sufficient natural durability and cannot be used in outside applications or in marine environments without further protection. Large amounts of durable tropical timber were therefore used in the last decades in European industry to avoid these problems. This wood was mainly applied in use classes 3 and 4 (EN 335, 2006), for example for use in windows, doors and with ground contact (Militz et al., 1997). Tropical timbers in many cases show higher natural durability, good quality and fine appearance compared to home grown timber. Use of tropical timber, however, often has a strong environmental impact because it is harvested from old growth forests and its use is therefore not sustainable. Additionally, the quality of tropical wood on the market has declined while it is becoming scarcer and besides that, the public 
regards the utilization of tropical woods very critical due to devastation of the rain forests. Although many plantations will produce tropical woods sustainably in the future, these factors have led to a decline of consumption of tropical woods in many European countries (Militz et al., 1997).

\subsection{Wood preservation}

Alternatively to natural durability, the drawbacks of home grown timber can be overcome by treatment of wood. Wood preservation is known since ancient times and research has resulted in many chemical wood preservatives nowadays, which increase service life and are preferably relatively harmless to humans and nature. These treatments do not change properties such as moisture sorption and swelling or shrinkage of wood, but only protect the wood against biological degradation. Biocides, however, are currently regarded more critically due to environmental and health concerns. The trend is going to low toxicity products; many effective wood preservatives have been forbidden due to their toxicity to humans or the environment. Another important aspect of wood treatments in the future will be the disposal or reuse of treated wood (Falk and Mc Keever, 2004). Nowadays, most wood is incinerated to produce energy and avoid disposal on landfills. Inorganic salts, used as biocidal wood preservatives are concentrated in the ash which afterwards has to be treated as hazardous waste. Therefore treatments which do not result in toxic residues such as ash or gases are preferred. Reuse of wood will become more important in the future due to rising costs of the raw material. Solid wood can be chipped and used for the production of particle boards or other wood composites. For these usages it is important that the wood is not treated with harmful biocides.

\subsection{Wood modification systems}

The alternative to biocidal treatment of wood can be found in the field of wood modification. While the principles of wood modification are known since many decades (see for example Kollmann, 1955), it has drawn considerable interest in recent years due to the reasons mentioned above. The goal of wood modification is, different from the biocidal treatment, to change the basic chemistry or structure of the wood substrate itself, and by this approach overcome undesired properties (Militz et al., 1997). The main difference between preservative treatment of wood and modification of wood is therefore the mode of action. If wood is protected from decay by a preservative, the decay is prevented by biocidal action on the decay organism. The preservative, however, does usually not act specifically on the target organisms, but can also affect other organisms or even humans. If, on the other hand, the wood is protected by means of modification, the wood substrate is changed in a 
way that material properties are improved (for example durability and dimensional stability), but the wood remains nontoxic and no release of toxic substances takes place, neither during service, nor during disposal or recycling. (Hill, 2006).

Goals of wood modification include increased resistance of wood to biological and physical degradation, increased dimensional stability, reduction of moisture sorption and improved mechanical properties. Wood modification systems can be divided into several different mechanisms. Treatment of wood can either affect the cell walls (Figure 1a) or lumens of wood (Figure 1b). While deposition of chemicals in the lumens can certainly affect many properties of wood, such as water uptake rate or hardness, sorption properties or dimensional stability are usually not changed. Treatments with polymers, which are deposited in the lumens only, are therefore not considered as "real" modifications (Mai, 2010). Modifications can further be classified into active modifications, which involve the altering of the chemical nature of wood (Figure 1d,e), and passive modifications, where the treatment does not alter the woods chemistry (Figure 1c). By far the most abundant reactive sites in wood are the hydroxyl groups on cellulose, hemicelluloses and lignin. Most chemical modifications involve the reaction of these functional groups (Rowell, 1983) and result in either blocking of the hydroxyl groups (Figure 1d) or in the crosslinking of two or more hydroxyl groups (Figure 1e). Acetylation, which involves the linkage of an acetyl group to a hydroxyl group of the cell wall, is an example of blocking of hydroxyl groups (Figure 1d). Each hydroxyl group reacts with one separate molecule to form an ester (Hill, 2006). Other chemicals, for example formaldehyde, can react with two (or even more) hydroxyl groups to form an acetal and crosslink the cell wall (Figure 1e) (Stamm, 1959). The deposition of chemicals into the cell wall usually leads to cell wall bulking, a permanent increase in volume of the treated wood. 


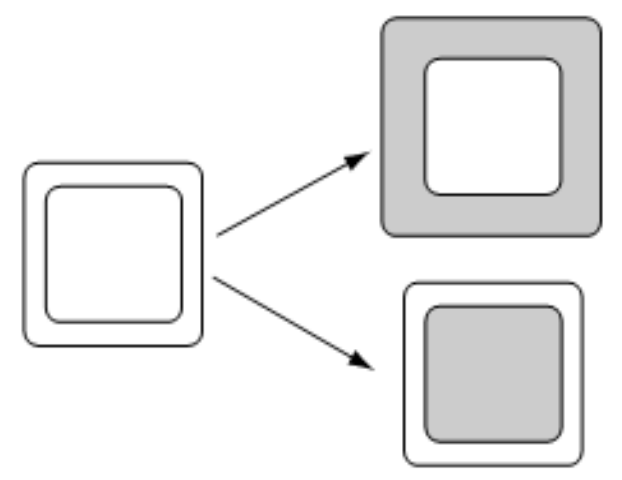

(a)

(b)

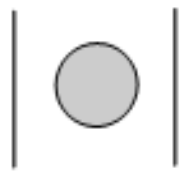

(c)

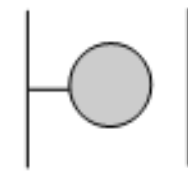

(d)

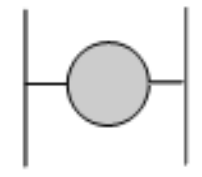

(e)

Figure 1: Mechanisms of wood modification, a: cell wall modification, b: lumen modification, c: bulking modification, $d$ : reaction with hydroxyl groups in the cell wall and e: cross-linking of hydroxyl groups in the cell wall (from Hill, 2006).

In passive wood modifications the properties of the wood are changed by simple deposition of chemicals into the cell wall (Figure 1c). These cell wall treatments usually involve the treatment of wood with a monomer solution of a certain chemical, which is able to diffuse into the cell wall and undergo polymerization in the cell wall by which it is fixed and leaching is prevented (Stamm, 1964). While PEG, sugars and salts are chemicals that can easily be impregnated into wood (if the appropriate molecular mass is used) and result in considerable bulking and, in many cases, biological durability. Furthermore they are unable to undergo polymerization and are therefore easily leached out (Kollmann et al., 1975). Phenol-formaldehyde resins, melamine-formaldehyde resins and furfuryl alcohol are examples of chemicals that can be impregnated into the wood as solutions of small molecules and afterwards condense in the cell wall. These treatments are stable towards leaching and result in considerable bulking. (Goldstein, 1955; Kollmann et al., 1975).

A different approach is the thermal modification of wood. If wood is heated to a temperature between $160^{\circ} \mathrm{C}$ to $220^{\circ} \mathrm{C}$ in absence of oxygen, cleavage and conversion of wood components lead to hydrophobation, increased dimensional stability and to improved biological resistance (Militz, 2002; Stamm, 1964). These improvements are, however, accompanied with a considerable loss in strength, which forbids the use of thermally modified wood as construction material (Militz, 2002). 
Several parameters are important to evaluate the success of a chemical modification. The wood gains weight, when chemicals are deposited in the cell walls. This weight gain is usually reported as weight percent gain (WPG) and calculated as follows:

$$
W P G(\%)=\left[\frac{m_{m}-m_{\mathrm{u}}}{m_{\mathrm{u}}}\right] \times 100
$$

where $m_{m}$ is the oven-dry mass of the modified wood and $m_{u}$ the oven-dry mass of the unmodified wood (Hill, 2006).

If a chemical consists of molecules that are smaller than the pores of the swollen cell wall, it will diffuse into the cell wall. Many attempts have been made to determine the sizes of the cell wall pores and several different methods were developed. Although different sizes for the maximum pore diameter were found depending on the method used, it can be regarded as a fact that the pores of the cell wall swollen in water have a diameter smaller than $4 \mathrm{~nm}$ (Hill and Papadopoulos, 2001). In all cases it is necessary to swell the wood to open up the pores and allow the chemical to enter the cell wall if a bulking treatment is pursued. If the chemical is not solvable in water and does not swell the wood itself, a solvent or catalyst has to be added, which is capable of opening up the pores (Rowell, 1983). It was shown, that the increase in volume of wood through the treatment with a cell wall penetrating chemical after drying (bulking) is directly related to the theoretical volume of the chemical located in the cell wall (Rowell and Ellis, 1978). When this bulked wood comes into contact with water, minor additional swelling can take place, which is the mechanism responsible for the increased dimensional stability of wood modified with a bulking treatment (Figure. 1c,d) (Rowell et al., 1976). Bulking of the cell wall is therefore an important measure to estimate the success of many active and passive wood modification treatments and is calculated as depicted in the following formula:

$$
B(\%)=\left[\frac{A_{m}-A_{\mathrm{u}}}{A_{\mathrm{u}}}\right] \times 100
$$

where $A_{m}$ and $A_{u}$ are the cross sectional areas of the modified and unmodified wood respectively.

If dimensional stability is imparted by the modification, the difference between the fully water-swollen and the oven dry cross sectional area is smaller. This increase in dimensional stability can be evaluated using the anti-shrink efficiency (ASE):

$$
\operatorname{ASE}(\%)=\left[\frac{S_{\mathrm{w}}-S_{m}}{S_{\mathrm{w}}}\right] \times 100
$$


where $S_{\mathrm{u}}$ and $\mathrm{S}_{\mathrm{m}}$ are the swelling coefficients of the unmodified and modified wood respectively (Hill, 2006). Dimensional stability i.e. a positive ASE value can only be achieved with chemicals entering the cell wall and either bulk the wood (Figure $1 \mathrm{c}, \mathrm{d}$ ), cross link it (Figure 1e) or cause a combination of both bulking and cross linking.

\section{Wood modification by acetylation and with silicon compounds}

\subsection{Acetylation}

The Acetylation of wood is one of the most studied modifications and has undergone market introduction. It involves a chemical reaction, in which the accessible hydroxyl groups of the wood components are esterified with acetic acid derivatives. Acetylation of wood was first carried out by Fuchs (1928) on spruce wood and Horn (1928) on beech wood. Stamm and Tarkow (1947) acetylated wood in a mixture of acetic anhydride and pyridine, the latter as a swelling agent and catalyst for the reaction. Although acetylation can be carried out with different chemicals, by far the most common is acetic anhydride, which can be used in liquid or vapor phase. Each molecule reacts with one hydroxyl group and in the process splits off an acetic acid molecule (Figure 2). This mechanism results in a loss of at least $50 \%$ of the reaction chemical and makes the process of acetylation very expensive. Furthermore, the resulting acetic acid partly remains in the wood after reaction and causes unpleasant smell of the wood. This can be a major drawback of acetylated wood especially for indoor use.

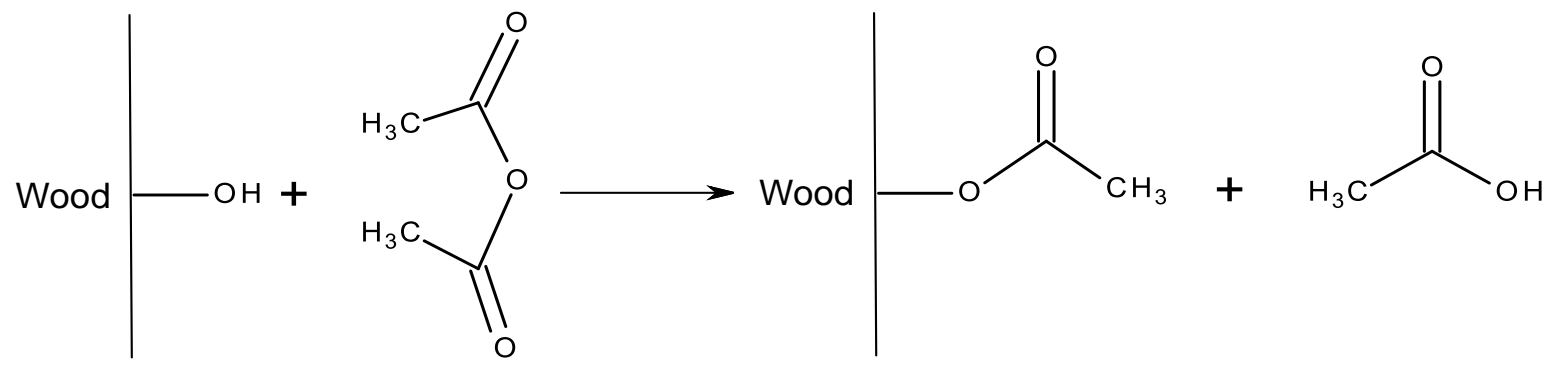

Figure 2: Acetylation of wood with acetic anhydride.

While acetylation can be catalyzed by acids or bases, it is mostly carried out without catalyst. It is a single site reaction, which means, that one acetyl group per hydroxyl group is formed, WPG of the samples can be directly related to the number of blocked hydroxyl groups (Rowell, 1983). Introduction of acetyl groups into the cell wall is accompanied with swelling of the wood (bulking) and dimensional stabilization. This dimensional stabilization is a function of the partial specific 
volume of the acetyl groups added within the cell wall (Kollmann et al., 1975) and therefore directly related to the WPG.

Acetylation to a WPG of 20-25\% results in an ASE of approx. $70 \%$ (Hill and Jones, 1996). Directly related to the WPG and bulking is an increase in fungal resistance of the treated wood, weight loss caused by fungi decreases with rising WPG until it reaches a WPG threshold value, above which no decay takes place. Typically, acetylated wood is resistant to attack by brown and white rot fungi as well as soft rot decay above a WPG of approx. 17-20\%. Hill et al. (2005) have shown that the mechanism of protection most likely is the reduction in cell wall moisture content or the blocking of the micro pores in the cell wall. Mechanical properties of wood are not significantly affected by acetylation (Hill, 2006).

\subsection{Silicon compounds}

\subsubsection{Inorganic silicon compounds}

Many different silicon compounds have been used for the treatment of wood in recent years. Silicon itself is the $2^{\text {nd }}$ most abundant element on earth following oxygen (50\%), and makes up about $25 \%$ of the earth's crust (Römpp, 2001). Silicon is mostly found in form of silicate minerals (salts or esters of silicic acid) and, less frequent, as pure silicon dioxide. It usually comprises tetravalent bonding character and is very affine to oxygen. Silicon is regarded as harmless to humans and is required for formation of bones and connective tissue (Römpp, 2001).

In nature, wood is sometimes naturally silicified in millions of years by monomeric silicic acid $\left(\mathrm{Si}\left(\mathrm{OH}_{4}\right)\right)$. The silicic acid penetrates the wood and, through polycondensation, forms silica gel. Silicified wood can further transform to quartz and opal (Selmeier, 1990).

Silicate can be brought into solution as water glass with high contents of base, such as potassium oxide or sodium oxide. These clear and colloidal solutions are highly alkaline $(\mathrm{pH}>12)$ and precipitate upon addition of acids or polyvalent metal cations (Römpp, 2001). Treatment of wood with water glass has a long history. It was first described as a fire-retarding agent for wood by Fuchs (1825) and was later intensely studied for coating of wood to render it fire retardant (Metz, 1942). To improve properties such as dimensional stability, decay resistance and water uptake, wood was treated with water glass by several authors either in a single step (Matthes et al., 2002) or in a two-step procedure (Furuno and Imamura, 1998; Furuno et al., 1991; Furuno et al., 1993; Furuno et al., 1992). In the latter cases the wood was treated with sodium water glass in the first step, which was in the second step precipitated inside the wood structure using metal salt solutions. Several different 
salts such as aluminum sulfate, calcium chloride, barium chloride, boric acid, borax, boron trioxide, potassium borate and ammonium borate were investigated (Furuno and Imamura, 1998; Furuno et al., 1991; Furuno et al., 1993; Furuno et al., 1992).

The treatment resulted in very high WPG, the silicate was found to be mainly deposited in the lumens of the cells. Because silicates as well as the metal salts are hygroscopic, the treated wood showed negative moisture excluding efficiencies. Leaching of the samples resulted in considerable loss of WPG. This was partly reduced by soaking of the specimens in 5\% acetic acid after water glass impregnation and before leaching (Furuno et al., 1992). Positive ASE values between 3\% and 69\% were found, although bulking of the specimens was rather small (Furuno et al., 1992). Fire resistance was increased except for specimens treated with barium chloride (Furuno et al., 1991; Furuno et al., 1993; Furuno et al., 1992).

Decay resistance of two step water glass treated wood to white and brown rot fungi was found to be increased by water glass treatment but highest if boron salts were introduced in a combined treatment (Furuno et al., 1992). Wood treated in a single step procedure with water glass exhibited also high decay resistance to basidiomycetes with and without leaching according to EN 84. The $\mathrm{pH}$ of the treated wood was found to be very high ( $\mathrm{pH} \mathrm{8-9),} \mathrm{which} \mathrm{can} \mathrm{explain} \mathrm{the} \mathrm{retardation} \mathrm{of}$ fungal growth (Matthes et al., 2002). In general, fungal decay tests on water glass treated wood showed high leaching of chemicals during the test and sometimes too high moisture contents (according to EN 113) of the specimens, which can also prevent colonization of the wood by fungi (Matthes et al., 2002).

Another possibility to introduce silicon into the wood is the sol-gel process using silicic acid esters. The formation of a stable gel can be divided into two steps. At first the silicic acid esters are hydrolyzed by water molecules to form silanol groups (Figure 3a). 
<smiles>CCO[Si](OCC)(OCC)OCC(O)C(C)O</smiles>

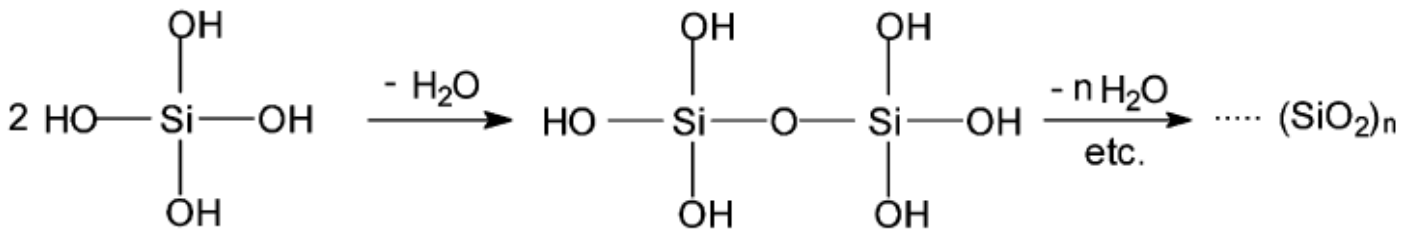

Figure 3: Mechanism of the sol-gel process (from Mai and Militz, 2004b)

These silanol groups condense further to polysilicic acid (sol) and finally to a gel of silicon dioxide (Figure 3b) (Mai and Militz, 2004b). The application of this process was studied by Saka et al. (1992) who treated hinoki wood either conditioned to different moisture contents or water saturated with alcoholic solutions of tetramethoxy-silane (TMOS), tetraethoxy-silane (TEOS) and tetrapropoxy-silane TPOS) acidified with acetic acid. The bound water inside the cell wall of the conditioned specimens was supposed to initiate the sol-gel process only, if the chemical penetrated the cell wall and thus get a deposition of silicon exclusively therein and not in the lumens of the cells. This technique worked out well; while water saturated samples exhibited deposition of silicon in the lumens without achieving any ASE, conditioned wood showed ASE of up to $42 \%$ with a WPG of $10 \%$ and no deposition of silicon dioxide in the lumens. The deposition of silicon in the cell wall was further verified by X-ray mapping (SEM-EDX) (Saka et al., 1992). WPG of specimens treated with TEOS could be increased, if an ultrasonic treatment was applied during the impregnation procedure (Ogiso and Saka, 1993).

Flammability of the treated wood was evaluated by means of the oxygen index; higher WPG resulting in an increased index (Saka et al., 1992). Further investigation revealed that $\mathrm{SiO}_{2}$ gel in the cell wall was more effective in raising the oxygen index as compared to gel deposited in the cell lumina. Thermo-gravimetric analysis showed, that the degradation temperature of the treated wood was increased; this, again, more effectively, if the $\mathrm{SiO}_{2}$ gel was deposited exclusively in the cell walls (Ogiso and Saka, 1993).

Durability of sol-gel modified wood was tested by Reinsch et al. (2002). Ovendry pine sapwood (Pinus sylvestris L.) was treated with tetraethoxy silane in a sol-gel process and incubated with the brown rot fungus Poria placenta. Weight loss of the 
specimens was decreased to $12-15 \%$ (control specimens: $40 \%$ ) depending on the WPG, but resistance was not achieved. Donath et al. (2004) treated pine sapwood (Pinus sylvestris L.) and beech wood (Fagus sylvatica L.) with TEOS either solved in pure acidified ethanol and, alternatively, prehydrolysed in acidified water-ethanol mixture. While TEOS solved in ethanol showed good penetration of the cell wall with positive bulking values and ASE of approx. 30\%, prehydrolysed TEOS was not able to impart high ASE. The treated beech wood was incubated with the white rot fungus Trametes versicolor and showed high decay resistance only, if the wood had been treated with TEOS solved in ethanol, prehydrolysed TEOS did not increase durability. This shows the importance of depositing the modification chemical into the cell wall to increase durability towards wood decaying fungi. A soil block test on treated pine and beech wood revealed only a delay of fungal decay, but no increase of resistance after 24 weeks of incubation (Donath et al., 2004). This phenomenon was also reported by Scheithauer et al. (1998), who found initial resistance of TEOS treated pine wood to the brown rot fungus Coniophora puteana; after longer exposure, this effect was lost.

Another group of inorganic silicon compounds are silica sols. If alkali from water glass is removed through ion exchange techniques in a controlled manner, the lack of stabilizing ions initiates condensation of the silicic acid molecules which then form growing colloid particles of amorphous silicon dioxide. This condensation process can be stopped at a certain stage by addition of some alkali and a sol of polysilicic acid molecules is obtained (Römpp, 2001). Silica sols are therefore alkaline and precipitate upon acidification, because the particles are stabilized by their negatively charged surface. However, silica sols can also be stabilized sterically (surface modification with silanes) or by positive charge (cationic surface of the particles) and then be stable under neutral or acidic conditions as well (Greenwood, 2010).

Götze et al. (2008) treated spruce and oak wood with commercially available, alkaline silica sol. Although the wood was partly damaged due to the alkalinity of the solution, water uptake after 6 days was reduced by $18 \%$ (oak) and accordingly $30 \%$ (pine). Yamaguchi (1994a) impregnated Japanese cedar with a monomeric silica sol, which had been prepared from water glass by ion exchange technique and, alternatively with acidified silica sol prepared by addition of phosphoric acid to a commercially available silica sol. Especially the monomeric silica sol was able to penetrate into the cell wall when applied in $5 \%$ solution and resulted in a positive ASE of approx. $30 \%$ and reduced water uptake of the wood. Fungal resistance to brown rot ( $F$. palustris) was only improved by these treatments if the wood had not 
been leached before incubation. By combining the silicic acid with boric acid, high decay resistance was achieved (Yamaguchi, 2002).

Temiz et al. (2006) treated pine sapwood (Pinus sylvestris L.) with nonfunctional alkaline silica sols with particle sizes of $15 \mathrm{~nm}$ and $30 \mathrm{~nm}$. Water uptake rate was only reduced to a minor extent and no considerable ASE was imparted to the wood. Incubation with the brown rot fungus Coniophora puteana according to EN 113 revealed increased decay resistance of treated wood only, if the samples had not been leached before. If leached samples were incubated, no increased decay resistance was observed.

While unmodified silica sols are not classified as biocidal products (Römpp, 2001) and apparently do not reduce fungal decay of wood, they can be modified by embedding soluble biocides into the silica matrix or by covalently grafting biocides to the sol particle surface (Böttcher, 2000; Böttcher et al., 1999; Haufe et al., 2005). Covalently bonded biocides are often polycationic and are assumed to interact with the negatively charged cell membranes of microorganisms. This can lead to removal of anionic phospholipids from the cell membrane and leakage of the cells (Mahltig et al., 2008; Tiller, 2011).

\subsubsection{Organic silicon compounds}

In contrast to the inorganic silicon compounds discussed in the previous chapter, organic silicon compounds can be altered in their properties by different organic groups attached to the silicon (Mai and Militz, 2004a). Methyl groups can impart high hydrophobicity to the material combined with high thermal stability, while other groups might act biocidal or affect the orientation of the molecules after application to wood.

The sol-gel process mentioned above, which applies tetraalkoxysilanes can be varied by taking organosilanes as precursors. These molecules contain up to three silicon functional alkoxy groups and one to three organo-functional groups, which can increase hydrophobicity of the gel or form covalent bonds to other constituents. Organo-silanes are used in many applications such as adhesion promotion, cross linking or surface modification (Mai and Militz, 2004a).

Schneider and Brebner (1985) used the coupling agent $\gamma$ methacryloxypropyltrimethoxysilane to treat different wood species in a sol-gel process and found ASE values of up to 70\%. Donath et al. (2004) used, besides the before mentioned TEOS, also organo functional alkoxysilanes and found good incorporation into the cell wall, when conditioned wood was impregnated with alcoholic solutions of the two silanes methyltriethoxysilane and 
propyltriethoxysilane. ASE values of up to $30 \%$ were measured, but this value decreased over time due to ageing of the gel in the cell wall. Durability of the treated wood towards the white rot fungus Trametes versicolor was increased considerably but especially, when the silane penetrated and bulked the cell wall. In a soil block test, decay was delayed, but not prevented. Further trials with the two alkylalkoxysilanes and two additional, oligomeric and water-borne silane systems revealed strong hydrophobation of the treated wood. This was more pronounced for the two oligomeric silane systems, and in addition the hydrophobation remained after several wetting and drying cycles, while it was reduced for the two alkylalkoxysilanes (Donath et al., 2006b).

Hill et al. (2004) treated pine sapwood (Pinus nigra) with the two coupling agents $\gamma$-methacryloxypropyltrimethoxysilane and vinyltrimethoxysilane. They found incorporation of the silicon material into the cell wall and ASE values of up to $40 \%$. Fungal decay tests revealed only little increase of resistance to the brown rot fungus Coniophora puteana. Incubation with the white rot fungi Trametes versicolor and Phanerochaete crysosporium displayed decay resistance of the treated wood above a WPG of approx. $40 \%$ for Trametes versicolor and approx. $40-50 \%$ for Phanerochaete crysosporium (Hill et al., 2004).

Higher decay resistance was found, if amino-functional silanes were applied. Donath et al. (2006a) treated wood with an amino-functional oligomeric silane system and found complete decay resistance of pine sapwood (Pinus sylvestris L.) to the brown rot fungus Coniophora puteana with a WPG of $16 \%$ even after prolonged incubation of 18 weeks. Beech wood (Fagus sylvatica L.) treated with the same silane and showing a WPG of $11 \%$, however, showed considerable mass loss after incubation with Trametes versicolor (Donath et al., 2006a). Weathering of pine wood (Pinus sylvestris L.) revealed, that the water repellent effect of three monomeric alkylalkoxysilanes and two oligomeric silane systems remained stable over one year. Sorption, however, was not affected and checking of the weathered samples not reduced as compared to control specimens (Donath et al., 2007).

Nami Kartal et al. (2009) treated wood with two different alkyl-alkoxyfunctional silanes in combination with boric acid to limit boron leaching from the treated wood. They were able to reduce boron leaching by approx. $40 \%$ through this combination. The treated wood showed increased resistance to fungal and termite decay compared to wood treated solely with silane or boron.

While all studies mentioned above aimed on simply depositing the silicon material in the wood, a different approach is the covalent bonding of the silicon material to the wood. Sèbe et al. (2004) treated wood with different organo- 
functional alkoxysilanes and were able to graft the silicon compounds to the hydroxyl groups of wood via carbamoylation and etherification by use of the organofunctionality and also by alcoholysis, which results in a direct reaction of the silanol with hydroxyl groups of the cell wall. The reactions were confirmed by WPG, infrared spectroscopy (FTIR) and ${ }^{13} \mathrm{C}$ and ${ }^{29} \mathrm{Si}$ NMR CP-MAS analysis. The treatment, however, resulted only in small ASE values, which decreased in a subsequent water soaking test (Sèbe et al., 2004). Further work on the carbamoylation of wood using isocyanatopropyltriethoxysilane was done by Tingaut et al. $(2005 ; 2006)$.

Besides alkoxy silanes, chlorosilanes are a group of very reactive silicon compounds. Hydrophobation of organic material (paper) by methylchlorosilanes was first observed by W. Patnode in 1940 while producing methyl-chlorosilanes in a lab. Evaporating silane hydrolyzed upon contact with the moisture in the air and reacted on and with the paper present in the lab (Rochow, 1991). This observation led to the idea of hydrophobizing materials with chlorosilanes (Patnode, 1942). During hydrolyzation of chlorosilanes, $\mathrm{HCl}$ is released, which is the major drawback of this idea, because wood, being sensitive to acid breakdown, will be degraded. Still some work was performed to treat wood with different chlorosilanes. Owens et al. (1980) treated wood with tetrachlorosilane and found increased decay resistance of the treated wood to brown and white rot fungi. Stevens (1981) used tetrachlorosilane, methyltrichlorosilane, dimethyldichlorosilane, methyldichloro-hydrogensilane and chlorotrimethylsilane to treat pine and beech wood in vapor and liquid phase. To avoid the degradation of wood by $\mathrm{HCl}$, besides hexane different basic hydrochloric acid acceptors were used as solvents (triethylamine, formamide, dimethylformamide). This time the treatments, however, did not result in high decay resistance of pine sapwood (Pinus sylvestris L.) to Poria placenta and Gloeophyllum trabeum as well as beech wood (Fagus sylvatica L.) to Trametes versicolor and Coniophora puteana. Best results (weight losses of 5-10\%) were obtained with the two materials dimethyldichlorosilane and methyldichlorohydrogensilane. Further examination of the effect on blue stains and moulds revealed only low effects of chlorosilane treatment (Stevens, 1985).

Another group of organo-silicon compounds are the silicones. These are polymeric materials with a silicon-oxygen backbone and hydrocarbon radicals attached directly to the silicon (Noll, 1968). The name silicone derives from the term silicon ketone, because the empirical formula $\left(\mathrm{R}_{2} \mathrm{SiO}\right)_{\mathrm{n}}$ is similar to the ketones from organic chemistry $\left(\mathrm{R}_{2} \mathrm{CO}\right)$ (Noll, 1968). The basic repeating unit in silicones is the siloxane, while the most common silicones are polydimethylsiloxanes (Figure 4). 
Depending on the chain length and attached functionalities, PDMS are a class of polymers ranging from fluids to elastomers.

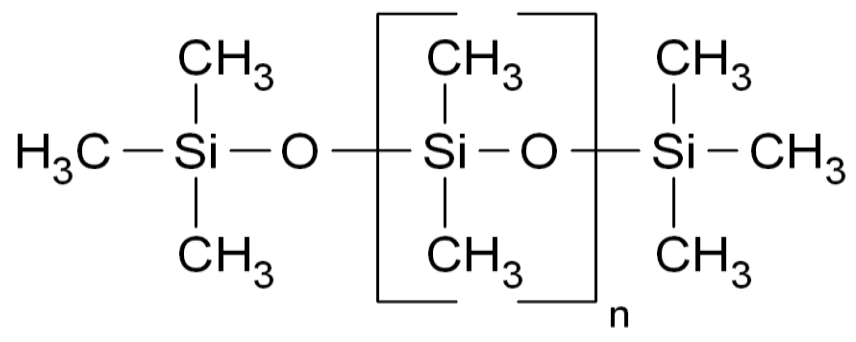

Figure 4: Unfunctional polydimethylsiloxane.

The synthesis of silicones uses methyl-chlorosilanes as precursors, which are prepared from elemental silicon by a direct synthesis found by Rochow and Müller simultaneously in 1940 (Schliebs and Ackermann, 1987) and which was the starting point for mass production of silicones:

$$
2 \mathrm{CH}_{3} \mathrm{Cl}+\mathrm{Si} \underset{300^{\circ} \mathrm{C}}{\stackrel{[\mathrm{Cu}]}{\longrightarrow}}\left(\mathrm{CH}_{3}\right)_{2} \mathrm{SiCl}_{2}
$$

These chlorosilanes are further hydrolyzed under formation of $\mathrm{HCl}$ and the resulting silanol groups subsequently polymerize to form polydimethylsiloxane (Ackermann and Damrath, 1989). Silicones are the only important polymer with an inorganic backbone, are physiological inert and hard to inflame. The methyl groups attached to the silicon have proved to be superior over other organic groups due to their small size and absence of carbon-carbon bonds which render the silicone very stable towards heat and chemicals (Rochow, 1991). That is the reason, why polydimethylsiloxane has become the most common silicone.

Recently, functionalized PDMS have attracted interest. Introduction of functional groups into the silicone structure offers the possibility to alter the properties of the silicone in specific ways, for example combine hydrophobic and hydrophilic properties. Examples for functional groups are esters, epoxides, vinyl-, allyl-, amino- and carboxy groups. Functionalized siloxanes have especially proved valuable for the combination of natural materials such as textiles and wood with PDMS. While unfunctional silicones do not interact with surfaces of textiles and wood, amino groups have proved to increase binding and orientation of PDMS on textile surfaces (Bereck et al., 2001). Due to the extreme flexibility of the siloxane backbone and the low surface energy, PDMS can spread on the surface of fibrous substrates and reduce friction of the fibers and increase hydrophobicity (Kim, 2001).

Bereck et al. (1996) studied the application of amino silicones on cotton and cotton-polyester textiles. The strongest influence on the properties of the treated 
textiles was found in the amino group content of the siloxane. The position of amino groups on the siloxane backbone was also found to have a significant effect. Softening of textiles was better for siloxane with aminogroups attached to the sides of the backbones compared to $\alpha-\omega$ functional amino silicones, while the material also became more hydrophobic.

Kim (2001) studied hydrophobation of textiles with siloxane and found amino siloxanes very effective. A strong influence on hydrophobation was found for functionality, amino content, attachement of functional group and application of siloxane. Heating of the treated textile material after application of siloxane increased orientation of the PDMS (with hydrophilic parts facing the textile) and significantly enhanced hydrophobation.

While silicone treatment of masonry to improve water repellence without reduction of water vapor permeability and to increase service life is common, treatment of wood has not gained such an importance (Hager, 1995). Rochow, who is one of the inventors of the direct synthesis of methylchlorosilanes has laid the foundation for mass production of silicones He treated his wooden house in 1958 with a coating of silicones and even 30 years later found little degradation of the coating (Rochow, 1991). This shows the potential of silicone application for the protection of wooden constructions.

To avoid the use of organic solvents, water-borne formulations are preferred for treatment of wood. SMK micro emulsions (Wacker SMK ${ }^{\circledR}$ technology) were used by Hager (1995) to impregnate wood. The technology combines silanes, siloxanes and functional polysiloxanes, which are at the same time temporary emulsifiers and co-emulsifiers. After drying the emulsifiers lose their ability and serve as adhesion promoters and catalysts. Upon mixing with water, the system emulsifies itself and forms droplets of $10-80 \mathrm{~nm}$ diameter, which are able to penetrate the wood structure and deposit the silicone in the lumens of the cells. Hager (1995) found a 70\% reduction of water uptake even after two years of outside weathering (10\% silicone treatment), showing the long term effectiveness of the silicone. Lukowsky et al. (1997) further investigated SMK type formulations of silicones and found high water repellence with long lasting stability. ASE, however, was not found and gluing of the specimens with PVAc revealed strong reduction of glue bond strength. Although the results are promising, the SMK technology has the major drawback of a short pot life of $<24 \mathrm{~h}$, which is not applicable for the use in impregnation plants. Furthermore methanol and ethanol are split off and cause further problems in the treatment and drying processes. 
Simon et al. (2011) treated wood with solvent based solutions of silicones and found strongly reduced water uptake of the treated wood. The concentrations (and WPG) that were used, however, were very high (up to 90\%) and therefore not viable in practice. De Vetter et al. (2010) treated wood with different water-borne emulsions of silicones and found no significantly improved water repellence and no ASE for low WPG of approx. 5-6\%. They concluded that only functionalized silicones may be effective enough for the treatment of wood.

The development of functional silicones, which have proved to be superior to unfunctional silicones in textiles, in combination with the similarities of the substrates cotton (textiles) and cellulose (wood) have led to the idea of using functional silicones to improve properties of wood. Weigenand et al (2007) studied the impregnation of wood with two amino-functional silicones formulated as microand macroemulsion, respectively. They found good penetration of the emulsions into the wood and also into the cell wall resulting in positive bulking values. These were higher for the micro- compared to the macroemulsion and resulted in positive ASE values. The cell wall penetration was further confirmed by $\mathrm{x}$-ray mapping (SEMEDX). Water repellence was especially high in the initial phase of water uptake, later on water repellent effectiveness (WRE) decreased.

The amino-silicone microemulsion was further investigated for its ability to impart decay resistance to the treated wood (Weigenand et al., 2008). Pine sapwood (Pinus sylvestris L.) and beech wood (Fagus sylvatica L.) was treated with 2, 5 and $15 \%$ concentrations of the amino-silicone and incubated with the brown rot fungi Coniophora puteana, Antrodia vaillantii, Gloeophyllum trabeum and Serpula lacrymans as well as the white rot fungi Trametes versicolor and Ceriporiopsis subvermispora and the soft rot fungus Hypoxylon fragiforme.

Decay in a test according to EN 113 was strongly reduced by the treatments for all fungi but the soft rot, when the wood had been treated with $15 \%$ emulsions. The resistance was mainly explained with the amino groups attached to the silicone (Weigenand et al., 2008).

The influence of silicone functionality on fungal decay of the treated wood was further evaluated by Ghosh et al. (2008). They treated pine sapwood (Pinus sylvestris L.) and beech wood (Fagus sylvatica L.) with three emulsions of commercially available silicones bearing different functionalities: alkyl-functional, aminofunctional and quaternary-ammonium-functional. While the alkyl-functional silicone did not impart any resistance to wood in a mini block test according to Bravery (1978), the two other silicones considerably reduced mass loss due to incubation with Coniophora puteana (pine) and Trametes versicolor (beech) if high treatment 
concentrations of $15 \%$ were used. In an unsterile soil bed test according to EN 807 silicone treated wood showed slightly reduced mass loss and loss of MOE compared to untreated wood. In both tests, amino-silicone showed somewhat better results than quarternary-ammonium-silicone (Ghosh et al., 2008).

The same silicone emulsions were tested on their ability to impart resistance to blue stain and mold fungi. While even treatment with $10 \%$ emulsions of alkyl- and quarternary-ammonium-functional silicone did not inhibit colonization by blue stain, amino-functional silicone did radically reduce infestation even with a concentration of $4 \%$. Treatment with $10 \%$ amino-silicone also resulted in a certain resistance to mold growth, while the other two silicones showed lower effectiveness (Ghosh et al., 2009).

Further work revealed high effectiveness of the three silicone emulsions to termite attack. A field test with the two termite species Coptotermes acinaciformis (Froggatt) and Mastotermes darwiniensis (Froggatt) resulted in complete protection, when the pine sapwood had been treated with 5\% emulsions of amino- and quarternary-ammonium-functional silicone. Alkyl-functional silicone treatment reduced mass loss, but was slightly less effective (Ghosh et al., 2012b).

As quarternary-ammonium- and amino-functional silicones showed promising results, further trials focused on these materials using different chain length. The silicones were solved in a mixture of water and organic solvents to avoid influence of the emulsifiers. Positive bulking and increased dimensional stability was found for pine sapwood; $30 \%$ treatment with amino-silicone with a chain length of 9 resulted in an ASE of approx. 60\%. Pine sapwood and beech wood showed greatly reduced mass loss after 12 weeks of incubation with Coniophora puteana (pine) and Trametes versicolor (beech). Treatment with $15 \%$ short-chained quarternaryammonium- and amino-functional silicone resulted in mass losses of less than 5\% for pine sapwood. Increasing effectiveness against decay was found for decreasing chain length of the particular silicone (Ghosh, 2009).

\subsection{Aim of the study}

The aim of this study was to assess the possibility to enhance water related properties and fungal resistance of wood by treatment with silica sols, silanes and polydimethylsiloxanes. This study can be illustrated in three sections. In the first part, wood was treated with silica sols of different $\mathrm{pH}$ and surface modification. The objectives of this part were: 
- Screening of different silica sols to gain understanding of the influence of $\mathrm{pH}$ and surface modification on penetration of the silica sols into wood and to identify silica sols for the treatment of wood.

- Study the effects of different silica sols on wood properties such as water uptake, fungal decay resistance and staining.

- Investigate, if silica sols can penetrate the cell wall and be regarded as a bulking (impregnation) modification of wood.

- Study the mode of action of silica sols.

In the second part, acetylation of wood was combined with silanes and different PDMS which were mixed into the reaction chemical acetic anhydride. While usually water is the only commercially acceptable solvent, which can be used as a delivery system for wood treatment chemicals, acetylation offers the possibility to carry chemicals into the wood by help of acetic anhydride, which is a good solvent for silicon compounds with certain functionalities. The aims of this section of the study were:

- Synthesize acetoxy-functional PDMS for the treatment of wood.

- Test acetoxy-functional silane and several PDMS with different chain length and different functionalities (acetoxy-, amino-, hydroxy- and non-functional PDMS) for the capability to be combined with acetic anhydride for the acetylation of wood.

- Study water uptake and other properties of the treated wood.

- Investigate the mode of action of the silicon compound.

The third section dealt with treatment of wood by use of short-chained functional PDMS formulated in water. The objectives of this part were:

- Screen polysiloxanes with different functionalities for treatment of wood. These were epoxy-, amino-, carbobetain- and carboxy-functionality.

- Use of water based systems and formulation by help of emulsifiers to avoid organic solvents in the impregnation process.

- Study the properties of the treated wood such as water uptake, dimensional stability and fungal resistance.

- Understand the mechanism causing water uptake reduction and fungal resistance of the treated wood. 
- Investigate, if synergistic effects can be achieved by combining carboxy- and amino-functional PDMS, which results in salt formation of the functional groups.

\section{Results and Discussion}

\subsection{Inorganic silicon compounds}

\subsubsection{Results}

In the first part of the study, different silica sols were investigated for their ability to be impregnated into wood and impart increased resistance to fungal decay and blue stain and decrease water uptake rate of the treated wood. Several typical commercially available products were used to impregnate wood with a $15 \%$ solution (Table 1).

Table 1: Commercially available silica sols used for the impregnation of wood.

\begin{tabular}{lllll}
\hline No. & Name & $\begin{array}{l}\text { Concentration } \\
\text { of stock } \\
\text { solution }(\%)\end{array}$ & Surface-modification & $\begin{array}{l}\text { pH of } \\
\text { stock } \\
\text { solution }\end{array}$ \\
\hline 1 & Levasil 200E & 20 & Unmodified & 2.9 \\
2 & Levasil 200S & 30 & Aluminum oxychloride & 3.7 \\
3 & Bindzil CC151 & 17.5 & Epoxypropylsilane & 7.6 \\
4 & Modified & 17.5 & Epoxypropylsilane & 6 \\
5 & Bindzil CC151 & & Aluminate & 10 \\
6 & Levasil 200A & 30 & Unmodified & 9.5 \\
7 & Bindzil CAT 650 & 15 & Aluminum oxychloride & 3.6 \\
\hline
\end{tabular}

Tests on penetration of the different silica sols into the wood revealed, that the neutral and acidic silica sols were able to enter the wood structure while alkaline silica sols did not penetrate the wood properly. Alkaline silica sols change their $\mathrm{pH}$ value when entering the acidic wood structure and precipitate. This may cause blocking of the penetration paths and insufficient impregnation.

After drying of the specimens, high WPG values were assessed, which were very stable towards leaching with water. Bulking, however, was not observed, which indicates, that none of the tested silica sols was able to enter the cell wall of wood. This can be explained by too large particle diameters of the silica sols compared to the nanopores in the cell wall. 
Water uptake rate was assessed on small samples in a simple submersion test. One of the tested materials, Levasil 200S, was able to reduce water uptake considerably in the first hours of the test. After $24 \mathrm{~h}$, water uptake was still approx. $15 \%$ lower than that of the control specimens. All other silica sols increased water uptake as compared to the control specimens.

Further work focused on silica sols No. 1-4 due to their more promising results. A fungal decay test according to EN 113 was performed on pine sapwood (Coniophora puteana) and beech wood (Trametes versicolor) treated with $15 \%$ solutions of the silica sols No. 1-4. Levasil 200S strongly reduced mass loss due to incubation with the fungi, while all other materials proved to be ineffective. The silica sols were mixed into the malt-agar growth medium of the two fungi in different concentrations and the petri dishes were inoculated with the fungi to assess a biocidal effect. Again Levasil 200S showed reduction in growth for both fungi if mixed into the malt-agar medium with $2 \%$ concentration, while all other silica sols did not reduce fungal growth. A laboratory blue stain test on pine sapwood treated with $15 \%$ of the silica sols No. 1-4 revealed reduced staining for wood treated with Levasil $200 \mathrm{~S}$ on the surface, that did not face the vermiculite, on the other surface, staining was equal to the control. All other silica sols did not decrease staining considerably.

A bulking test revealed slightly negative bulking values for several of the silica sols. Bulking was further examined on wood treated with Levasil 200S. It was found to become more negative with increasing drying temperature accompanied with reduced maximum swelling of the treated wood. This result indicates a thermal breakdown of the wood even at a temperature of $103^{\circ} \mathrm{C}$, leading to shrinkage and negative bulking. A reduction of the thermal decomposition temperature is often caused by fire retardant treatments. Through a layer of insulating charcoal on top of the wood formed at low temperature, burning can be inhibited and the underlying wood protected. A simple burning test was carried out on pine sapwood treated with 5, 10 and $15 \%$ concentrations of the silica sol Levasil 200S. For comparison a commercially available fire protection salt was used. Silica sol treatment was able to reduce burning speed, weight loss of the samples and burning time. Glowing of the samples after extinction of the fire was completely prevented by the treatment. Compared to the commercially available fire protection salt, the differences were rather small. Further investigation using thermo gravimetric analysis (TGA) revealed a minor reduction of pyrolysis temperature as well as a minor increase in charcoal yield after pyrolysis. Oxidation behavior of the charcoal was not altered. All these differences proved to be small compared to the commercial fire protection salt, which strongly reduced pyrolysis temperature, increased char coal yield and increased oxidation temperature of the resulting charcoal. 


\subsubsection{Discussion}

Particles of unmodified silica sols with alkaline $\mathrm{pH}$ are stabilized by negative charge. By acidification of the solution, the silanol groups, which are weak acids, are protonated and the stabilization is removed, which results in condensation and precipitation of the silica sol. The same reaction takes place if alkaline silica sols are impregnated into wood. Wood itself is an acidic material, typically exhibiting a $\mathrm{pH}$ between 4 and 6 (Kollmann, 1951). If silica sols are entering the wood structure, the wood will buffer the impregnation solution to the same $\mathrm{pH}$ value, which causes precipitation of alkaline silica sols and blocking of the main penetration pathways. If, on the other hand, the silica sols are modified in a way, that they are stabilized sterically or by positive charge and already have a neutral or acidic $\mathrm{pH}$, impregnation can be done without any precipitation and good penetration. It can be concluded, that only neutral or acidic silica sols have the potential to be used for the impregnation of wood.

The silica sol was only deposited in the lumen of the cells as can be deduced from the bulking, which was never found to be positive. For entering the cell walls of wood, the particles or molecules need to be smaller than the micro-pores of the cell wall. These have been reported to have a maximum diameter of 2-4nm (Hill and Papadopoulos, 2001). The sizes of the silica sol particles can be calculated using the surface area. Assuming a density of $2 \mathrm{gcm}^{-3}$ and a surface area of $200 \mathrm{gm}^{-2}$ (Levasil $200 \mathrm{~S}$ ) results in a mean diameter of $15 \mathrm{~nm}$, while a surface area of $650 \mathrm{~m}^{2} \mathrm{~g}^{-1}$ (Bindzil CAT 650) corresponds to a mean diameter of 5nm. Silica sols exhibit a Gaussian distribution of particle diameters around the mean value; therefore CAT 650 contains particles bigger and also smaller than $5 \mathrm{~nm}$. Still, the particles were not able to penetrate the cell wall and induce bulking, which may be due to a very narrow distribution around the mean value or due to some agglomeration of particles during the impregnation. This result corresponds to Temiz et al. (2006), who found minor penetration of silica sol into the cell wall and very low ASE values. Yamaguchi (1994a), on the other hand, was able to obtain cell wall penetration and ASE values of approx. $30 \%$ with a silica sol prepared from sodium silicate by ion-exchange technique. The silica sol had just been prepared before impregnation and was a "living" system with growing particles; obviously the particles were still small enough to enter the cell wall. However, the material gelled within a few hours (Yamaguchi, 1994b), making this material unsuitable for use in impregnation plants.

Reduction of water uptake rate was only found for Levasil 200S. Silica is a hydrophilic material which is not expected to hydrophobize the wood but only block penetration pathways of water such as ray cells or tracheids. While water glass treatments usually result in highly negative moisture exclusion efficiencies (Furuno 
et al., 1992; Matthes et al., 2002) due to hygroscopic counter ions, silica sols contain considerably smaller amounts of counter ions for stabilization. Temiz et al. (2006) found a reduced water uptake rate for wood treated with silica sols. Götze et al. (2008) treated spruce wood with silica sol and found a reduction in water uptake of $25 \%$ after 6 days of immersion. This shows, that even with a hydrophilic material it is possible to reduce water uptake rate. However, blocking of penetration pathways is a relatively ineffective way of reducing water uptake; high amounts of material are needed as can be seen from the high WPG used in this study.

Fungal decay of treated wood was considerably reduced by the cationic silica sol Leavsil 200S, while all other silica sols did not impart increased decay resistance to wood. This finding supports the assumption, that silica sol itself is a non-toxic material (Römpp, 2001). Modification of silica sols by covalently binding biocides to the surface can render silica sols biocidal. Often these biocides are polycationic and lead to removal of anionic phospholipids from the cell membrane and leakage of the cells (Mahltig et al., 2008; Tiller, 2011). The same mode of action is believed to cause the inhibition of fungal decay in the case of Levasil 200S. A further study of biocidal properties by mixing the silica sols into the malt agar growth medium revealed the (relatively low) effectiveness of Levasil $200 \mathrm{~S}$ even if not impregnated into wood. A blue stain test on Aureobasidium pullulans showed some effect on staining fungi as well, although the sensitivity of the staining fungus seemed to be very low.

While the burning test revealed some effectiveness of Levasil 200S to increase fire resistance, TGA only showed minor differences compared to control specimens. Treatment with the commercial fire retardant resulted in strongly reduced pyrolysis temperature in the TGA. The slight downshift of pyrolysis temperature of silica sol treated wood compared to the control was in contrast rather small. Pyrolysis of wood at lower temperature can be caused by acidic reaction of the fire retardant and induces the formation of a protecting charcoal layer on top of the wood which protects the wood from further burning (Rowell and LeVan-Green, 2005). The reduction of combustible volatiles is another feature of many fire retardants. A reduction of combustible volatiles is shown by a high charcoal yield after pyrolysis. In contrast to the fire retardant, the silica sol only increased the charcoal yield to a minor extent and thus did hardly reduce the amount of combustible gases (Rowell and LeVan-Green, 2005). The resulting charcoal of silica sol treated wood showed the same oxidation behavior as the charcoal of the control.

Different effects, which are not reflected in the TGA measurements, can explain the relatively strong fire retardance of Levasil 200S revealed in the burning 
test. The formation of a charcoal layer at lower temperatures was mentioned above. A second reason may be increased density accompanied with increased heat capacity of the treated wood. As a result more energy is needed to heat up the wood to a temperature where combustible gases are released (Metz, 1942). If wood is heated up, combustible gases are released, exit the wood structure through the lumen and burn outside of the wood. Through impregnation with silica sols, the release of combustible gases from the wood might be hindered through blockage of the lumens and thus flammability decreased.

The heat conductivity might be increased by the treatment with silica sols. This distributes incoming heat and prevents the wood from being heated up locally to a burning point (Metz, 1942). Moisture content of the silica sol treated wood was comparable to control samples; this can therefore not have caused increased fire resistance.

The prevention of glowing of the resulting charcoal can be explained by decreased porosity. It is know that charcoal from diffused porous wood glows easier, because air has better access to the charcoal. If the porosity of the charcoal is reduced, air cannot penetrate as easily and glowing can be reduced or prevented (Metz, 1942).

Effects of silicon compounds on fire resistance of wood have mainly been studied with tetraethoxysilane (TEOS). Saka et al. (1992) found increased fire resistance of TEOS treated wood, which was further enhanced by combining TEOS with trimethylphosphit and/or trimethylborate. Fire resistance was tested on a similar burning test compared to the test used in this study (Miyafuji and Saka, 1996). However, the chemicals used were quiet different to the silica sols used in this study. Furthermore, the silica formed by TEOS was at least partly incorporated into the cell wall (as indicated by positive bulking values), while our silica sols were only deposited in the lumens of the cells.

\subsubsection{Outlook}

According to the definition of wood modification being a change of the wood substrate itself (Hill, 2006), silica sol treatment cannot be classified as a wood modification technique. The wood substrate is not chemically changed; silica sols do not react with the wood and are therefore no active wood modification. Furthermore, the tested silica sols are not a passive wood modification either, because they are not able to enter the cell walls and induce bulking, which would also lead to a change of the wood substrate and durability towards fungi. The material is simply deposited in the lumen of the cells; effectiveness against fungal decay is based on a biocidal action of the cationic particle surface. This statement is supported by the results of 
the biocidal test in the petri dish, which showed inhibition of the fungi by cationic silica sol intermixed with the agar growth medium.

Silica sol is produced from water glass, which is a very cheap material. The synthesis of silica sol, however, makes it about ten times more expensive than water glass. While water glass is available for a price of around $0.2 € \mathrm{~kg}^{-1}$, silica sol costs around $1.8 € \mathrm{~kg}^{-1}$ to $2 € \mathrm{~kg}^{-1}$ for a $30 \%$ solution of Levasil $200 \mathrm{~S}$. If we assume a required WPG of $20 \%$ for the protection of wood against fungal decay and the density of wood being $500 \mathrm{kgm}^{-3}$, we can estimate a price for the silica sol of more than $600 € \mathrm{~m}^{-3}$ of wood, which makes silica sol treatment not competitive on the markets nowadays.

The only effective silica sol for protection of wood against fungal decay and water uptake turned out to be Levasil 200S, a cationic material, which is stabilized by cationic charge and chloride as negative counter ions.

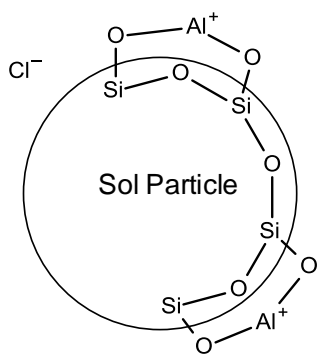

Figure 5: Idealized structure of a Levasil 200S silica sol particle.

Incineration of treated wood after service life should be possible without formation of toxic products. However, highly toxic dioxins can be formed, if chloride is present in high temperature oxidation processes of hydrocarbons (Römpp, 2001). This makes the disposal of wood treated with cationic silica sol potentially problematic and expensive. Furthermore, silica sol deposition in wood will increase wear of wood working machines and require more frequent sharpening and replacement of tools. This is another drawback of this wood treatment process.

In Summary, the costly silica sols with problematic disposal and additional machining costs render the application for wood preservation economically unattractive and therefore an unlikely product in the industry. 


\subsection{Organic silicon compounds}

\subsubsection{Results}

\subsubsection{Acetylation in combination with silicon compounds}

In a first study a polysiloxane treatment was combined with acetylation of wood. Different functional and unfunctional polysiloxanes and one silane were tested for their compatibility with acetic anhydride, the acetylation agent. Reduction of the rate of water uptake as the main goal of polysiloxane treatment was assessed for the treated wood. While all polysiloxanes did reduce water uptake rate as compared to purely acetylated wood, acetoxyfunctional siloxane proved to have the highest efficiency. Subsequently, different concentrations of acetoxyfunctional siloxane in the acetylation reagent were tested for their effect. While WPG increased due to increasing deposition of siloxane in the wood, bulking increased only very slightly. On the other hand, the acetyl content of wood acetylated with a mixture of acetanhydride and polysiloxane decreased with increasing concentration of siloxane. The water uptake rate was strongly reduced by the combination as compared to acetylated wood. While in the first test higher concentrations of up to $20 \%$ siloxane increased hydrophobation, these differences vanished in subsequent tests and $1 \%$ siloxane in the acetylation reagent seemed to be sufficient for maximum water repellence. The subsequent tests resulted in increased water repellence of the treated wood. Fungal decay resistance and mechanical properties such as bending and impact bending strength were not affected by the treatment.

\subsubsection{Treatment of wood with short chained functional polysiloxanes}

Further studies were performed on short chained polysiloxanes emulsified in water to increase water repellence and decrease fungal decay. In a first study different $\alpha-\omega$ attached functionalities were examined, these were amino-, carboxy, epoxy- and carbobetain-functionality. All siloxanes were formulated in water as $30 \%$ stock solution using three fatty alcohol ethoxylate emulsifiers. These stock solutions were diluted to $10 \%$ for the treatment of wood. The initial WPG of the treated wood was high, because the emulsifiers contributed to the weight gain. By leaching the samples, the WPG was reduced and all but carboxy-functional siloxane showed moderate leaching stability. Carboxy-siloxane showed relatively high leaching values, after two severe leaching cycles, only $22 \%$ of the material was left in the wood. For all treatments bulking was between $1 \%$ and $2.5 \%$, resulting in only negligible ASE values. Water uptake rate was reduced by the treatments in the first water uptake test, in a second test, however, carboxy-functional siloxane actually increased water uptake rate as compared to the control specimens. All other materials only induced small reductions in water uptake after $24 \mathrm{~h}$. A fungal decay test on pine 
sapwood (C. puteana) and beech (C. puteana and $T$. versicolor) showed increased fungal resistance, the most effective material being the carboxy-functional siloxane, which reduced mass loss below 3\% in two cases (pine, $C$. puteana and beech, $T$. versicolor). An unsterile soil bed test revealed decreased mass loss of the treated samples, but no resistance to soft rot.

The good effectiveness of carboxy-functional siloxane to reduce fungal decay combined with the leaching instability and absence of water repellent properties on the one hand, and amino-functional siloxane with higher effectiveness in reducing water uptake and higher leaching stability on the other hand led to the idea of combining these two materials. If amino-functional and carboxy-functional siloxanes are combined, salt formation is expected to take place between the two functionalities. This was thought to increase fixation in the wood and increase effectivity against fungi.

The two functional siloxanes were mixed in ratios of 80:20 and 20:80 and formulated in water with a siloxane content of $20 \%$. While the amino-functional siloxane was only used with a chain length of 10, carboxy functional siloxane was used with chain lengths 10 and 46. Additionally the two pure materials with chain length 10 were tested. Pine sapwood was treated with $5 \%$ and $10 \%$ emulsions of the siloxanes. Leaching stability of the mixture containing $20 \%$ carboxy siloxane was good, showing, that the salt formation was able to increase fixation to some extent. The mixture with $80 \%$ carboxy, however, showed high leaching values, the amino content being too low. Penetration into the cell wall and bulking was low, which was expected regarding the results from the first study. Water uptake rate was at first stronger reduced for the formulations containing pure or $80 \%$ carboxy-siloxane, but in a second and third experiment amino-functional siloxane and mixtures thereof with $20 \%$ carboxy-siloxane showed better results. The high water repellent effectiveness of carboxy-siloxane in contrast to the values found in the first study shows the importance of the formulation on the obtained results. A fungal decay test on pine sapwood (C. puteana) and beech (C. puteana and $T$. versicolor) revealed highest effectiveness to reduce decay for pure carboxy-functional siloxane. Synergistic effects and increased effectivity for the mixtures of the two siloxanes were not observed. Blue stain test, on the other hand, showed the opposite result, amino-functional siloxane being the most effective and carboxy-functional siloxane having no inhibiting effect on Aureobasidium pullulans.

Paintability was tested on beech wood treated with $5 \%$ and $10 \%$ of different mixtures of amino- and carboxy-siloxane. After application of the pain, paint adhesion was tested in a dolly test. Acrylic water based paint was found to show 
strongly reduced dry and wet adhesion on treated wood. Observation of the area of fracture revealed no penetration of the paint into the treated wood, while wood treated only with emulsifier or control wood showed good penetration. Alkyd based paint did not give valid test results due to insufficient adhesion between the three paint layers.

Glueability was tested on beech wood treated with the same siloxane. Most common glues for industrial application, PVAc glue, phenolic glue and PUR glue were used. No considerable reduction in bond strength was observed, although wood failure was reduced for some treatment and glue combinations.

Wood was further repeatedly impregnated with low concentrations of a mixture of $80 \%$ amino-siloxane and $20 \%$ carboxy-siloxane both with a chain length of D10. The impregnation was done with $1 * 1.6 \%, 2 * 1.6 \%$ and $3 * 1.6 \%$ and additionally also with $1 * 4.8 \%$ concentration of the emulsion. The results of water uptake clearly showed, that the highest effect is imparted by only the first $1.6 \%$ and higher loadings of siloxane have a much lower effect on water uptake rate. It was also observed, that repeated impregnation with lower concentration gives just the same results as single impregnation with higher concentration. 


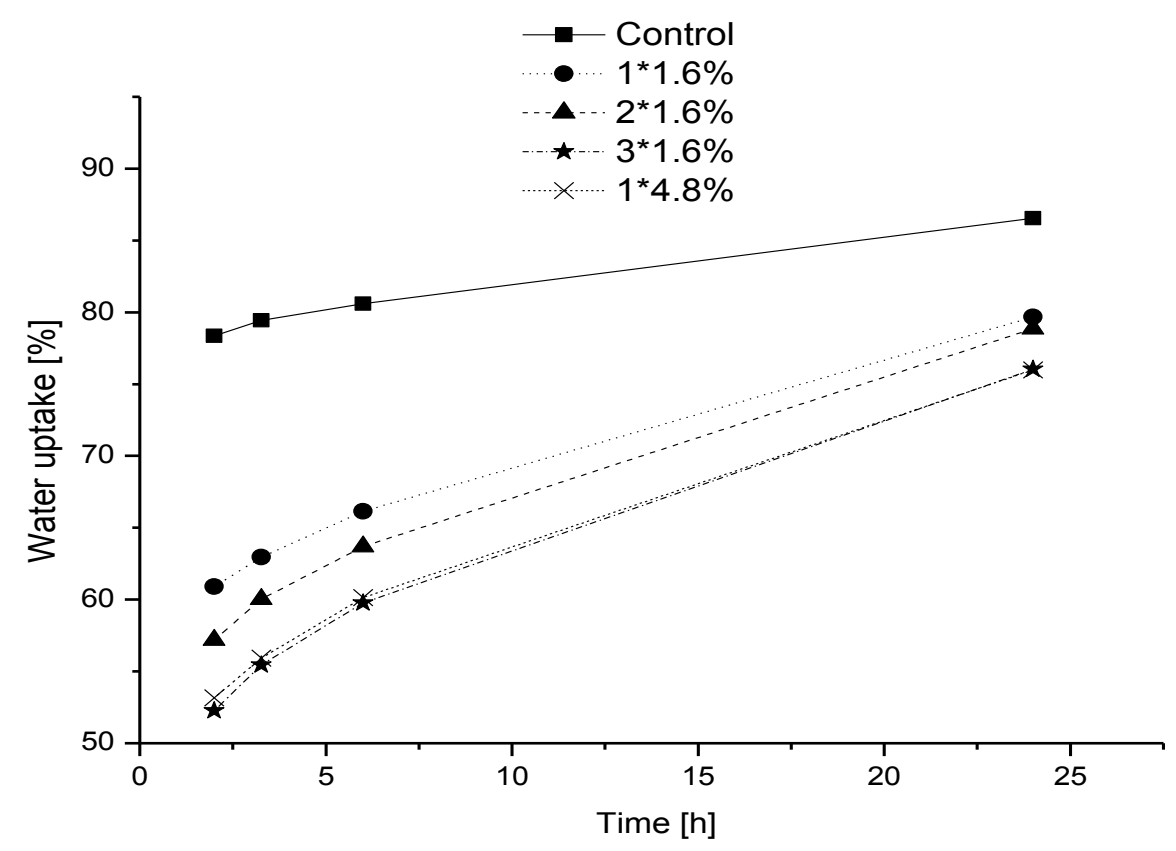

Figure 6: Water uptake of wood samples impregnated with different concentrations of polysiloxane emulsion containing amino-functional and carboxy-functional PDMS (Mean values).

\subsubsection{Discussion}

\subsubsection{Acetylation in combination with silicon compounds}

By combining acetoxyfunctional siloxane with acetic anhydride in an acetylation procedure it was possible to reduce water uptake considerably. In general two ways for the reduction of water uptake can be considered. These are a) blocking of the main penetration pathways of water and b) rendering the inner surfaces of wood hydrophobic. It was found, that even with $1 \%$ concentration of siloxane in the acetylation reagent maximum water repellence was achieved, which suggests, that the inner surfaces of wood had been rendered water repellent. Otherwise increased concentrations would have led to reduced water uptake. Furthermore, water repellence of the treated wood increased in subsequent water uptake tests which were always followed by drying at $103^{\circ} \mathrm{C}$. This phenomenon is known from other applications of siloxanes. Kim (2001) found improved water repellence of textiles treated with functional polysiloxanes, when the drying temperature was raised. This was explained with increased orientation of the PDMS in a way, that the hydrophilic parts of the chain are facing the substrate and the hydrophobic parts orient towards the outside. Amino functional PDMS have amino groups as their most hydrophilic parts, which will orient towards the wood (Bereck et al., 2001), non-functional PDMS will orient towards the wood with its siloxane-oxygen backbone while the hydrophobic methyl groups will orient outwards (Burrell et al., 2004; Kim, 2001; 
Noll, 1968; Weigenand et al., 2007). The process of increasing orientation of PDMS by heat treatment is called activation. The same mechanism of improved chain orientation should be true for wood in our case of several wetting and high temperature drying cycles.

Increased bulking accompanied with decreasing acetyl content in acetylated wood when siloxane was mixed into the reagent suggests incorporation of PDMS into the cell wall. This can also explain lower acetyl content; the PDMS may have blocked the hydroxyl groups of the cell wall and prevented acetylation. Penetration of PDMS into the cell wall was found before by Ghosh (2009), who treated wood with water-solvent based solutions of PDMS of very similar chain length and found positive bulking values. This suggests that PDMS despite their high molecular mass are able to penetrate the cell wall, but only to a small extent.

Fungal resistance of acetylated wood was solely governed by acetyl content and not altered by the introduction of PDMS. Functional PDMS was found to reduce fungal decay before (Ghosh, 2009; Weigenand et al., 2008), but in this case a reactive PDMS was introduced into the wood which is expected to polymerize upon drying and form a long chained and unfunctional siloxane structure in the wood. Many studies on PDMS have previously shown the biological inertness of PDMS with longer chain length (Ackermann and Damrath, 1989; Noll, 1968).

\subsubsection{Treatment of wood with short chained functional polysiloxanes}

Impregnation of wood with water based emulsions of PDMS of different functionality revealed great differences in the properties of treated wood. While none of the material was able to penetrate the cell wall considerably and cause high bulking values, the stability against leaching was quiet different. To be fixed in the wood, the functional PDMS can interact with functional groups of the cell wall. This is especially likely for amino-functional PDMS, the amino group being cationic under the acidic conditions of wood. Functional groups in the wood are usually anionic, for example carboxylic groups of hemicelluloses or phenolate groups in lignin. Carboxy-functional PDMS on the other hand is expected to be negatively charged and thus does not find counterparts in the cell wall to form ionic pairs. This can very well explain the high leaching of pure carboxy-functional PDMS. Combining amino- and carboxy-functional PDMS lead to increased leaching stability, if high proportions of amino-functional PDMS were present. The two functionalities can form salts and the carboxy functional PDMS can thus be fixed in the wood via an amino-functional PDMS.

Water uptake was reduced by the treatments, but strong water repellence could not be achieved. Generally the functional PDMS used are less water repellent than 
unfunctional siloxanes due to the hydrophilic properties of the functional groups, which offset the properties of the relatively short siloxane backbone. While amino functional PDMS will orient the functional groups towards the cell wall, carboxy functional PDMS will not, which causes even higher influence of functional group and less water repellence of the treated wood. Combining the two materials did not lead to improvements regarding the reduction in water uptake. If we assume salt formation between the two functionalities, the orientation of the amino PDMS will be worsened, the amino groups therefore will not strictly face the wood surface anymore. This effect exposes the functional groups to incoming water and therefore an improvement of water repellence cannot be expected by the combination of these two materials. The increase in chain length of the carboxy PDMS, which was also tested in combination with the amino PDMS, is on the other hand expected to increase water repellence. The siloxane chain is water repellent; with increasing chain length the properties of the chain should dominate over the properties of the hydrophilic functional carboxy groups and increased water repellency is therefore expected. This finding suggests a different mode of action as was discussed above for the acetylation experiments. Most likely, the PDMS in these cases blocked the penetration pathways of water inside the wood (for example ray cells and pits). This assumption is supported by the fact, that higher loadings of PDMS (5\% versus $10 \%$ ) still increased water repellent effectiveness, even though these concentrations are already high and more than sufficient to cover the inner surfaces of wood. Support comes also from the fact that water repellent effectiveness decreased in subsequent water uptake tests, which is just the opposite of what was found in the acetylation experiments. This finding can be explained by the cleaning effect the trials had on the penetration paths which in turn decreased water repellent effect of the treatment. A third hint on the mode of action is given by the results of repeating impregnation with low concentrations of PDMS. While a treatment with $1.6 \%$ siloxane reduced the water uptake strongly, the next impregnations with $1.6 \%$ showed a much lower effect. It can be concluded, that the first $1.6 \%$ acted at least partly by modification of the inner surface of wood and thus effectively reduced water uptake. Once the surfaces are covered, however, water uptake reduction takes place via pathway blocking. This mode of action makes much less efficient use of the siloxane material and therefore the reduction of water uptake with a certain amount of siloxane is low compared to the first impregnation.

To be able to evaluate the findings above and to understand, at which treatment concentration PDMS will start to block penetration paths rather than cover the inner surfaces of wood it is valuable to estimate a concentration threshold value. To alter the inner surface of wood, only a thin or even monomolecular layer of PDMS is 
needed. Because PDMS in this study did only penetrate the cell walls to a minor extent, the surface area of the tracheid lumens should therefore be regarded as a starting point. If we neglect the small proportion of resin ducts and ray cells and suppose, that the tracheid lumens are continuous cylindrical tubes, the internal surface area of our wood can be estimated. Assuming an average tracheid diameter of $\mathrm{d}=1 / 300 \mathrm{~cm}$ (Stamm, 1964) and an average density of the used pine wood of $0.5 \mathrm{~g} / \mathrm{cm}^{3}$ we get an average fractional void volume of

$$
V=1-\frac{0.5}{1.46}=0.66
$$

where 0.5 is the specific gravity of our wood and 1.46 is the specific gravity of the pure wood substance. The average lumen diameter 1 is then

$$
l=d \times \sqrt{V}=\frac{1}{300} \mathrm{~cm} \times \sqrt{0.66}=0.0027 \mathrm{~cm}
$$

and the corresponding circumference amounts to

$$
0.0027 \mathrm{~cm} \times \pi=0.0085 \mathrm{~cm}
$$

This value multiplied by $1 \mathrm{~cm}$ length and by the number of lumen in a square centimeter of a cross section $(300 \times 300=90,000)$ gives the total lumen area of one cubic centimeter of wood:

$$
0.0085 \mathrm{~cm} \times 1 \mathrm{~cm}(\text { length }) \times 90,000 \mathrm{~cm}^{-3}=765 \frac{\mathrm{cm}^{2}}{\mathrm{~cm}^{2}}
$$

Using the specific gravity of 0.5 gives $1530 \mathrm{~cm}^{2} \mathrm{~g}^{-1}$ (Stamm and Millett, 1941). This area corresponds relatively well to experimental results. Stamm and Millet (1941) used the selective adsorption of stearic acid from a benzene solution to determine the inner surface area of sugar pine wood. They determined a value of $2200 \mathrm{~cm}^{2} \mathrm{~g}^{-1}$. The wood had a density of $0.34 \mathrm{gcm}^{-3}$, which is considerably lower than that of our pine sapwood and which can explain the somewhat higher surface area. With decreasing density of the wood, ceteris paribus, inner surface area will increase.

Our amino-functional PDMS with a chain length of D10 has a molar mass of $1162 \mathrm{gmol}^{-1}$. If we roughly assume, that its length amounts to $2 \mathrm{~nm}$ and its width to $0.5 \mathrm{~nm}$, one molecule can cover a surface of $1 \mathrm{~nm}^{2}$. Our inner surface of $1530 \mathrm{~cm}^{2} \mathrm{~g}^{-1}$ is equal to $1.53^{*} 10^{17} \mathrm{~nm}^{2}$. One mol of our PDMS covers $6^{*} 10^{23} \mathrm{~nm}^{2}$. Therefore $2.55^{*} 10^{-7}$ mols or $2.96^{*} 10^{-4} \mathrm{~g}$ of siloxane are needed to cover the inner surface of our wood. A typical solution uptake of pine sapwood in a vacuum pressure impregnation process amounts to $150 \%$, which means $1.5 \mathrm{~g}$ solution per gram of wood. To impregnate the required amount of siloxane into the wood hence a concentration of approx. $0.02 \%$ is needed. 
The whole inner surface of wood which is accessible to a swelling agent such as water is, on the other hand much greater. Estimations and experimental results range from $200-400 \mathrm{~m}^{2} \mathrm{~g}^{-1}$ of wood (Kollmann, 1951; Stamm, 1964; Stamm and Millett, 1941) and are therefore approx. 1500 to 2000 times higher than the value calculated above. To cover this whole surface area, concentration of the treatment solution would therefore need to be approx. at a 30-40\% level.

These rough estimations show, in which range the concentration should be to get an effective coverage of the inner surfaces of wood. Because there was hardly any penetration of the cell walls by our treatment, the first value should be a good estimation of the amount, which is needed in practice. Even if we assume, that some PDMS is entering the cell walls and considerable amounts might be deposited in ray cells after impregnation (as these are main penetration pathways), the amount to cover the inner surface of wood is much lower than any concentrations used in our studies. To effectively alter the surface properties of wood, very low concentrations of the siloxane should therefore be used. Burell et al. (2004) investigated the orientation of $\alpha-\omega$ amino-propyl functional PDMS of several chain lengths on cellophane film by XPS. They found a preferred orientation of the amino groups towards the cellulosic surface and proposed interaction of the amino groups with the hydroxyl groups of cellulose, which was also suggested by Bereck et al. (2001). They further studied the influence of film thickness on orientation of the siloxane and found best orientation of PDMS with a film thickness close to a monolayer. Increase in film thickness resulted in significant decrease of orientation, which also indicates decreased effectivity of the PDMS material. 
(a)

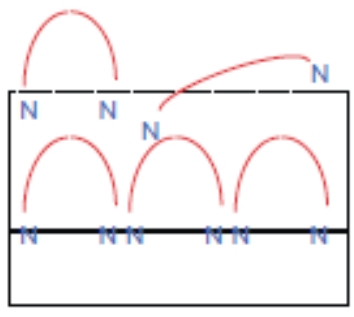

(b)
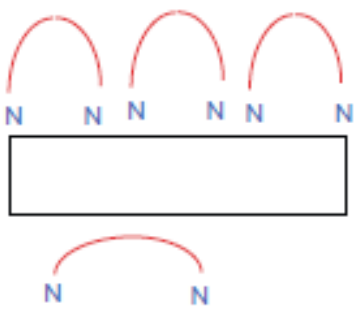

(c)

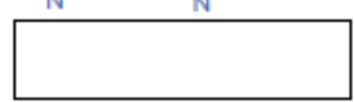

Figure 7: Model proposed for the orientation of amino-functional PDMS on cellulosic surfaces for a: thick film, b: monolayer and c: submonolayer coverage (from Burell et al., 2004).

To make most efficient use of amino-functional PDMS in reducing water uptake, treatment should therefore aim on monolayer coverage of the inner surfaces of wood. Additional material will not be oriented strictly towards the wood surface with its hydrophilic amino groups and therefore not increase water repellence, but rather decrease it. The only mode of action obtainable with high amounts is pathway blocking, which makes very poor use of the material and results in high costs and high WPG of the treated wood.

Fungal decay test revealed highest effect by the treatment with carboxy functional PDMS. While amino-functional silicon compounds have been found to be effective against fungal decay before, which was explained with the amino group content (Donath et al., 2006a; Weigenand et al., 2008), later a strict relationship between amino group content and fungal resistance was not found (Ghosh et al., 2012a). The effect was explained by penetration of the siloxane into the cell wall and micro pore blocking as well as interaction with the cell wall. Micro-pore blocking as the mode of action against fungal decay has been discussed previously for other types of chemical modification (Hill et al., 2005). Papadopoulos and Hill (2002) reacted wood with different carboxylic anhydrides and found, that not the number of reacted hydroxyl groups in the cell wall governed decay resistance, but rather the degree of bulking. Incorporation of chemicals into micro-pores alone (without reaction with the cell wall) can reduce the availability of water in the cell wall and the penetration of fungal decay agents into the cell wall and thus impart fungal resistance. In the case of PDMS treatment by Gosh et al. (2012a), however, low bulking values resulting in high fungal decay resistance make micro pore blocking 
unlikely to be the only reason for the effectiveness of functional PDMS. Interaction with the cell wall is also an unlikely explanation regarding our results, carboxyfunctional PDMS being most effective against fungi on one hand, but easily washed out and therefore not interacting strongly with the wood on the other hand.

In previous studies the charge of the functional groups of the silicon compound was regarded to be important for increasing fungal resistance (Donath et al., 2006a; Weigenand et al., 2008). In our study functional groups with different charge were tested. Besides the cationic amino group, anionic carboxy functionality and also the uncharged epoxy group (hydrolyzed to dihydroxy functionality upon contact with water) were examined. Although cationic biocides, such as quaternary ammonium compounds and others are commonly used and have proved to be effective, in this case the charge of the functional group does not seem to be the main cause of effectiveness against fungi. Especially the cationic properties of amino groups did not impart highest fungal resistance, even though cationic biocides are known to be effective. The explanation can be the orientation of the PDMS. If the amino groups are oriented strictly towards the wood and find ionic counterparts in the cell wall, the effectivity may be lost.

The combination of PDMS with amino and carboxy functionality did not show synergistic effects in the fungal decay test. The salt formation did apparently not increase resistance to fungi. Although amino groups are cationized, the salt of aminoand carboxy groups combined is neutral, which can explain, why no differences were observed.

Hydrophobation as the reason for effectiveness can be ruled out because none of the functional PDMS imparted high water repellence. Furthermore, the treated specimens after incubation showed comparable moisture content as the control specimens. This leads to the assumption, that the mobility of the siloxane chain may be responsible for effectiveness. The functionality paired with a short siloxane backbone imparting high mobility to the PDMS and thus increasing the effect on fungi. Immobile PDMS should therefore be ineffective against fungi, which was clearly shown in the combination of PDMS with acetylation.

Adhesion of acrylic based paint on wood treated with the PDMS emulsions was strongly reduced. This is most probably due to insufficient penetration of the paint into the wood. Glueability test on the other hand did not show considerably lower strength of the glue bonds of treated wood. This was true even though reduced wood failure for some of the treated wood indicated decreased penetration of the glue into the wood. Glueability of wood treated with microemulsions of PDMS was tested previously by Lukowsky et al. (1997). The wood had been treated with the SMK 
formulations mentioned above and glueability was tested using PVAc glue. Wood treatment with a $10 \%$ formulation strongly reduced tensile shear strength of the glue bond by more than 50\% compared to the control. Jusoh et al. (Jusoh et al., 2005) treated wood flakes for flakeboard production with self-emulsifying alkoxysiloxane. The flakeboards were glued with phenolic resin. Only 1\% PDMS reduced internal bond strength by approx. 37\%. Different from these studies, our formulations contained high amounts of emulsifiers and functional polysiloxanes with short chain length. As was mentioned before, these properties reduce water repellence of the material and can therefore explain the good glueability. Furthermore the emulsifiers, which stayed in the wood after treatment (wood was not leached), can promote penetration of glue into the wood and also increase glueability. In line with our findings are the results obtained by Kurt et al. (Kurt et al., 2008), who treated wood with a 5\% microemulsion of aminofunctional PDMS and found no reduced bond strength when gluing treated wood with PVAc glue. It therefore seems to be possible to glue wood treated with functional siloxanes even with typical water based glues like PVAc or phenolics. It is, however, not clear, to what extent glueability is dependent on the content of emulsifiers in the wood, which can enhance penetration of the glue.

\subsubsection{Outlook}

Water uptake rate can be reduced strongly by combining acetylation with a PDMS treatment. This is even possible with low concentrations of siloxanes, which suggests, that the inner surfaces of the wood are coated by the siloxane and very effective use is being made of the material. Other properties such as ASE, fungal resistance or mechanical properties of the wood are not affected by the combination with PDMS. It was shown, that acetoxyfunctional silane is able to acetylate wood if an acidic catalyst is present. Furthermore it was concluded, that the short chained acetoxyfunctional PDMS entered the cell wall. Therefore we can state, that treatment with acetoxyfunctional PDMS in this case is a real wood modification. It is an active wood modification, because it can react with the wood and alter the chemistry of the wood (acetylation), and at the same time a passive wood modification, because it is entering the cell wall to some extent (siloxane).

Acetylation itself is a very complex process which results in excellent wood properties. It imparts fungal resistance as well as high dimensional stability and also reduces water uptake rate. The additional reduction in water uptake by PDMS seems to be dearly bought by further increasing the complexity of the process and the price of the treatment chemicals. In addition a process for combining PDMS with the acetylation has to be developed before application. Therefore it seems to be quiet 
unlikely, that the combination of PDMS with acetylation will be widely used. Only applications in special products appear to be realistic.

Wood treatment with short chained PDMS formulated in water mainly deposits chemicals in the lumen of the wood. Penetration of the cell wall takes place to a minor extent, which is visible in small bulking and ASE values. Water uptake was reduced, but not very strongly. Furthermore, water repellent efficiency declined in subsequent water uptake tests.

Fungal resistance seems to be not imparted by altering the chemistry of the wood or reducing the available moisture in the cell wall, but rather by the PDMS itself. It is therefore concluded, that the mobility of the PDMS is an important feature for the inhibition of fungi, the PDMS acting directly against the fungi. Mobility can be increased by hydrophilic functional groups as well as by a short siloxane backbone. The most mobile siloxane (as can be seen by high leaching), the carboxy functional PDMS had the strongest effect on fungi. Reduction of chain length has been shown to increase effectivity of PDMS to inhibit fungal growth (Ghosh et al., 2012a), which supports this theory.

According to the definition of wood modification (Hill, 2006), we can consider the PDMS treatment neither an active nor a passive modification of wood. Firstly the PDMS is not able to react with the wood and alter its chemistry and it is further hardly entering the cell wall and can therefore not be regarded as a bulking treatment.

The high WPG which is required to obtain resistance to fungal decay (approx. $10 \%-15 \%)$, combined with the relative low water repellence of the treatments make PDMS treatment with the goal of protecting wood against fungal decay quiet expensive. Another approach, combining low concentrations of short chained PDMS with biocides to induce fungal decay resistance and water repellence seems to be more promising. The concentration which is needed to effectively alter the inner surface of wood was estimated above. Due to low concentrations, costs for the chemical would be much lower in this case. The treatment can be regarded closely related to the combination of PDMS with acetylation. In both cases, fungal resistance (and other features) is imparted by an additional treatment and PDMS is merely reducing water uptake and used as an internal coating for wood.

It has to be considered, however, if the approach of applying an internal water repellent is the most efficient way to protect wood from moisture uptake. The treatment is only shedding the wood from uptake of liquid water; it is not reducing swelling and shrinkage or uptake of moisture from air. To exclude liquid water from wood usually coatings or water repellents are applied to the surface (Williams, 
1999). Water repellents are non-film forming, penetrating and transparent wood finishes, which protect the wood from liquid water uptake. They usually contain a resin or drying oil, a solvent and a wax to impart water repellence (Williams, 2010). These water repellents are easily applied and do not need surface preparation prior to application. They are, however, not long lasting and are often only effective for one year (Williams, 1999). Wood in outside application needs open porous coatings to allow water vapor to escape from the wood. PDMS has shown to impart very water repellent surfaces to different construction materials (including wood) with an open porous character.

Coating of the inner surfaces of wood has some drawbacks compared to the surface treatments. First of all, these treatments involve an impregnation step. Due to the interconnection between all cell walls only small defects in the inner coating can reduce the effectivity of the coating severely. Furthermore the coating cannot be repaired, which might result in short service life. Therefore the approach of treating the surface of wood with PDMS based water repellents appears to be more promising. Research on the application of functional PDMS should focus on development of PDMS based water repellents preferably in the form of emulsions, which can easily be applied and renovated.

\section{Conclusion}

In this study treatment of wood with silanes, polysiloxanes and silica sols was investigated to evaluate their potential to be used for wood protection. In the first section, silica sols were used for the treatment of wood. Only neutral and acidic silica sols were able to penetrate the wood structure and be used for impregnation of solid wood. Even the smallest particle sizes did not result in positive bulking values, indicating, that silica sols cannot enter the cell wall. Therefore the treatment cannot be regarded as a real modification of wood because the chemicals are solely deposited in the lumen of the cells. Relatively high reduction of water uptake rate and fungal decay could be achieved with an acidic silica sol which was surface modified with aluminum-oxychloride. Fungal decay resistance was not imparted by modifying the wood itself, but rather by direct action of the cationic sol surface on the fungal organism. Further proof for this assumption was gained in a petri dish test, which analyzes the direct effect of chemicals on fungi. Even though aluminumoxychloride modified silica sol decreased the thermal degradation temperature of wood, the treated wood did only show minor enhancement of fire related properties. This indicates that the effect of the sol on thermal degradation of wood is only negligible. High WPG needed for decay resistance of the treated wood combined with relatively high price of the chemical make the treatment of wood with silica sols 
expensive. Another, in this study not further evaluated question, is disposal of the treated wood. The only effective silica sol contains chloride as stabilizing counter ions, which might prohibit the incineration of treated wood due to formation of dioxine.

In the second part of the study, acetic anhydride for acetylation was combined with a silane and different PDMS. The most promising combination of acetoxyfunctional PDMS with acetic anhydride led to actual modification of wood through acetylation and possibly (and only to a small extent) by the released silanol compound. Water uptake rate was strongly reduced by the PDMS, which was probably due to rendering the inner surfaces of the treated wood water repellent. This conclusion can be drawn from the fact that higher concentrations of PDMS did not result in increasing water repellence of the wood. Other properties of the acetylated wood as there are fungal resistance, dimensional stability and physical properties were not affected by the silicon material.

In the third part of the study, wood was treated with functional PDMS formulated in water. It was possible to increase fungal resistance and decrease the rate of water uptake by the treatment with certain PDMS. The treatment cannot be regarded as a "real" wood modification because the compounds were neither able to react with the wood (active modification) nor did they penetrate the cell walls considerably and alter the nano-structure of the wood (passive bulking modification). Action against fungi was probably related to the mobility of the siloxane chain and therefore was based on a direct effect of the chemical on fungi and not on altering the wood surface or structure as a modification would do. Water uptake reduction was probably not imparted by rendering the inner surface of the wood water repellent, but rather by blocking main penetration pathways in the wood, a relatively ineffective way of adding water repellence to wood. Support for this assumption comes from the observations, that firstly increasing concentration of the treatment chemical to very high levels still decreased water uptake rate and secondly, some water repellence was lost after each leaching cycle.

While best results in the fungal decay test were obtained with carboxyfunctional siloxane, this material did not show good leaching stability. Experiments to increase fixation via salt formation by combining it with amino-functional PDMS did not lead to promising results. Furthermore, the required WPG to impart fungal decay resistance to the treated wood seems to be too high to be competitive in the market, regarding the price of the chemical. Therefore it was concluded, that functional PDMS might be used as internal water repellents for wood in low concentration in combination with a biocide to impart required fungal resistance. If 
PDMS are used as internal coatings, very low concentrations $(<1 \%)$ should be studied to get most efficient use of the material and preferably a thin or even monomolecular coverage of the inner wood surface, which is most efficient and results in best orientation of the PDMS on the cellulosic surfaces of wood. It has to be considered, however, if internal coatings are the most effective way to impart water repellence to wood. In the case, that the PDMS treatment does not impart any valuable properties beside the exclusion of water, external water repellents applied onto the surface of wood seem to be more effective and promising. In this field, functional PDMS could be effective and compete with the mostly oil- and wax-based water repellents on the market.

\section{References}

Ackermann J., Damrath V. (1989) Chemie und Technologie der Silicone II. Herstellung und Verwendung von Siliconpolymeren. Chem unserer Zeit 23:86-99.

Bereck A., Riegel D., Matzat A., Habereder P., Lautenschlager H. (2001) Silicones in Fibrous Substrates: Their Mode of Action. AATCC review 1:45-49.

Bereck A., Riegel D., Setz A., Weber B., Münter M., Bindl J., Habereder P., Huhn K.G., Lautenschlager H., Preiner G. (1996) Einfluss von Silicon-Weichmachern auf Griff und mechanische Eigenschaften von textilen Flächengebilden. Textilveredlung 31:241-245.

Böttcher H. (2000) Bioactive Sol-Gel Coatings. Journal für praktische Chemie 342:427-436.

Böttcher H., Jagota C., Trepte J., Kallies K.H., Haufe H. (1999) Sol-gel composite films with controlled release of biocides. J Control Release 60:57-65.

Bravery A.F. (1978) A miniaturized wood-block test for rapid evaluation of wood preservative fungicides. International Research Group on Wood Preservation. Document No. IRG/WP 2113, Stockholm, Sweden.

Burrell M.C., Butts M.D., Derr D., Genovese S., Perry R.J. (2004) Angle-dependent XPS study of functional group orientation for aminosilicone polymers adsorbed onto cellulose surfaces. Appl Surf Sci 227:1-6.

EN 84 (1997) Wood preservatives - Accelerated ageing of treated wood prior to biological testing - Leaching procedure. CEN - European Committee for Standardization, Brussels, Belgium.

EN 113 (1996) Wood preservatives - Method of test for determining the protective effectiveness against wood destroying basidiomycetes - Determination of the toxic values. CEN - European Committee for Standardization, Brussels, Belgium.

EN 335 (2006) Durability of wood and wood-based products - Use classes: definitions, application to solid wood and wood-based panels. CEN - European Committee for Standardization, Brussels, Belgium.

De Vetter L., Van den Bulcke J., Van Acker J. (2010) Impact of organosilicon treatments on the wood-water relationship of solid wood. Holzforschung 64:463-468.

Donath S., Militz H., Mai C. (2004) Wood modification with alkoxysilanes. Wood Sci Technol 38:555-566.

Donath S., Militz H., Mai C. (2006a) Treatment of wood with aminofunctional silanes for protection against wood destroying fungi. Holzforschung 60:210-216. 
Donath S., Militz H., Mai C. (2006b) Creating water-repellent effects on wood by treatment with silanes. Holzforschung 60:40-46.

Donath S., Militz H., Mai C. (2007) Weathering of silane treated wood. Holz Roh Werkst 65:35-42.

Falk R.H. (2010) Chapter 01: Wood as a Sustainable Building Material, Wood Handbook, General Technical Report FPL-GTR-190. Madison, WI: U.S. Department of Agriculture, Forest Service, Forest Products Laboratory. pp. 1-1 -1-6. Chapter 1.

Falk R.H., Mc Keever D.B. (2004) Recovering wood for reuse and recycling - a United States perspective. European COST E31 Conference: Management of Recovered Wood Recycling Bioenergy and other Options: proceedings, 22-24 April 2004, Thessaloniki. Thessaloniki : University Studio Press, 2004: Pages 29-40.

Fuchs J.N. (1825) Ueber ein neues Product aus Kieselerde und Kali; und dessen nüzzliche Anwendung als Schuzmittel gegen schnelle Verbreitung des Feuers in Theatern, als Bindemittel, zu firnißartigen Anstrichen u.s.w. Dinglers polytechnisches Journal 17:465-481.

Fuchs W. (1928) Zur Kenntnis des genuinen Lignins, I.: Die Acetylierung des Fichtenholzes. Ber dtsch chem Ges (A and B Series) 61:948-951.

Furuno T., Imamura Y. (1998) Combinations of wood and silicate Part 6. Biological resistances of wood-mineral composites using water glass-boron compound system. Wood Sci Technol 32:161-170.

Furuno T., Uehara T., Jodai S. (1991) Combinations of wood and silicate I. Impregnation by water glass and applications of aluminum sulfate and calcium chloride as reactants. Mokuzai Gakkaishi 37:462-472.

Furuno T., Uehara T., Jodai S. (1993) Combinations of wood and Silicate III. Some properties of wood-mineral composites using the water glassboron compound system. Mokuzai Gakkaishi 39:561-570.

Furuno T., Shimada K., Uehara T., Jodai S. (1992) Combinations of wood and silicate II. Wood-mineral composites unsing water glass and reactance of barium chloride,boric acid,and borax and their properties. Mokuzai Gakkaishi 38:448-457.

Ghosh S.C. (2009) Wood modification with functionalized polydimethylsiloxanes, Faculty of Forest Sciences and Forest Ecology, Georg August University of Göttingen, Dissertation.

Ghosh S.C., Militz H., Mai C. (2008) Decay resistance of treated Wood with functionalised commercial Silicones. Bioresources 3:1303-1314.

Ghosh S.C., Militz H., Mai C. (2009) The efficacy of commercial silicones against blue stain and mould fungi in wood. Eur J Wood Wood Prod 67:159-167.

Ghosh S.C., Dyckmans J., Militz H., Mai C. (2012a) Effect of quat- and amino-silicones on fungal colonisation and decay of wood. Holzforschung.

Ghosh S.C., Peters P.C., Fitzgerald C.J., Militz H., Mai C. (2012b) Resistance of Scots pine (Pinus sylvestris L.) wood modified by functionalized commercial silicone emulsions against subterranean termites. Wood Sci Technol 46: 1033-1041.

Goldstein I.S. (1955) The impregnation of wood to impart resistance to alkali and Acid. Forest Prod J 5:263-267.

Götze J., Mockel R., Langhof N., Hengst M., Klinger M. (2008) Silification of wood in the laboratory. Ceramics-Silikaty 52:268-277.

Greenwood P. (2010) Surface Modifications and Applications of Aqueous Silica Sols. Department of Chemical and Biological Engineering, Chalmers University of Technology, Gothenburg, Sweden, Dissertation.

Hager R. (1995) Waterborne silicones as wood preservatives. International Research Group on Wood Protection, Irg/Wp 95-30062 Stockholm, Sweden.

Haufe H., Thron A., Fiedler D., Mahltig B., Bottcher H. (2005) Biocidal nanosol coatings. Surf Coat Int Part B-Coatings Transactions 88:55-60. 
Hill C.A.S. (2006) Wood modification - Chemical, thermal and other processes Wiley and Sons Ltd.

Hill C.A.S., Jones D. (1996) The dimensional stabilisation of corsian pine sapwood by reaction with carboxylic acid anhydride. The effect of chain length. Holzforschung 50:457-462.

Hill C.A.S., Papadopoulos A.N. (2001) A review of methods used to determine the size of the cell wall microvoids of wood. J Inst Wood Sci 90:337-345.

Hill C.A.S., Farahani M.R.M., Hale M.D.C. (2004) The use of organo alkoxysilane coupling agents for wood preservation. Holzforschung 58:316-325.

Hill C.A.S., Forster S.C., Farahani M.R.M., Hale M.D.C., Ormondroyd G.A., Williams G.R. (2005) An investigation of cell wall micropore blocking as a possible mechanism for the decay resistance of anhydride modified wood. Int Biodeterior Biodegrad 55:6976

Horn O. (1928) Zur Acetylierung des Buchenholzes. Ber dtsch chem Ges (A and B Series) 61:2542-2545.

Jusoh I.B., Nzokou P., Kamdem P. (2005) The effect of silicone on some properties of flakeboard. Holz Roh Werkst 63:266-271.

Kim B.T. (2001) Grundlegende Untersuchungen zur Hydrophobierung von Textilien mit Polyorganosiloxanen. Fachbereich 9, Chemie, Bergische Universität, Wuppertal, Dissertation.

Kollmann F. (1951) Technologie des Holzes und der Holzwerkstoffe, Vol. 1, 2nd ed. Springer Verlag, Berlin.

Kollmann F. (1955) Technologie des Holzes und der Holzwerkstoffe, Vol. 2, 2nd ed. Springer Verlag, Berlin.

Kollmann F., Kuenzi E.W., Stamm A.J. (1975) Principles of Wood Science and Technology, II. Wood Based Materials Springer, Berlin.

Kurt R., Mai C., Krause A., Militz H. (2008) Hydroxymethylated resorcinol (HMR) priming agent for improved bondability of silicone modified wood glued with a polyvinyl acetate adhesive. Holz Roh Werkst 66:305-307

Lukowsky D., Peek R.D., Rapp A.O. (1997) Water-based silicones in wood. International Research Group on Wood Protection, Irg/Wp 97-30144 Stockholm, Sweden.

Mahltig B., Swaboda C., Roessler A., Bottcher H. (2008) Functionalising wood by nanosol application. J Mat Chem 18:3180-3192.

Mai C., Militz H. (2004a) Modification of wood with silicon compounds. Treatment systems based on organic silicon compounds - a review. Wood Sci Technol 37:453-461.

Mai C., Militz H. (2004b) Modification of wood with silicon compounds. inorganic silicon compounds and sol-gel systems: a review. Wood Sci Technol 37:339-348.

Mai C. (2010) Chemical modification of wood and determination of the resulting wood properties. Habilitation at the Georg-August University of Göttingen, department of Forestry Sciences and Forest Ecology, Göttingen, pp 3-5

Matthes R., Nehring H.O., Dellith W. (2002) Wasserglas-Holzschutz im Hochbau. Proc. "Integrierter Umweltschutz im Bereich der Holzwirtschaft" 22nd-24th of january 2002, Göttingen.:104-108.

Metz L. (1942) Holzschutz gegen Feuer. 2 ed. VDI-Verlag GmbH, Berlin.

Militz H. (2002) Thermal treatment of wood: European processes and their background. . International Research Group on Wood Protection, Irg/Wp 02-40241 Stockholm, Sweden.

Militz H., Beckers E.P.J., Homan W.J. (1997) Modification of solid wood: research and practical potential. International Research Group on Wood Protection, Irg/Wp 9740098 Stockholm, Sweden. 
Miyafuji H., Saka S. (1996) Wood-inorganic composites prepared by the sol-gel process .5. Fire-resisting properties of the SiO2-P2O5-B2O3 wood-inorganic composites. Mokuzai Gakkaishi 42:74-80.

Nami Kartal S., Yoshimura T., Imamura Y. (2009) Modification of wood with Si compounds to limit boron leaching from treated wood and to increase termite and decay resistance. Int Biodeterior Biodegrad 63:187-190.

Noll W. (1968) Chemie und Technologie der Silikone. 2. ed. Verlag Chemie, Weinheim.

Ogiso K., Saka S. (1993) Wood inorganic composites prepared by sol gel process. 2. Effects of ultrasonic treatments on preparation of wood inorganic composites. Mokuzai Gakkaishi 39:301-307.

Owens C.W., Shortle W.T., Shigo A.L. (1980) Silicon tetrachloride: A potential wood preservative. International Research Group on Wood Protection, Irg/Wp 3133 Stockholm, Sweden.

Papadopoulos A.N., Hill C.A.S. (2002) The biological effectiveness of wood modified with linear chain carboxylic acid anhydrides against Coniophora puteana. Holz Roh Werkst 60:329-332.

Patnode W.I. (1942) Method of Rendering Materials Water Repellent, US Patent No. 2306222.

Reinsch S., Böcker W., Bücker M., Seeger S., Unger B. (2002) Development of woodinorganic composites with enhanced properties and environmental stability. In: Proc 4th international wood and fibre symposium, Kassel, Germany, 10-11 April 2002.

Rochow E.G. (1991) Silicium und Silicone. Springer, Berlin.

Römpp. (2001) Römpp Chemielexikon online, Thieme Chemistry, Stuttgart.

Rowell R.M. (1983) Chemical modification of wood. For Prod Abstr 6:363-382.

Rowell R.M. (2005) Handbook of Wood chemistry and wood Composites. Taylor and Francis Group, New York.

Rowell R.M., Ellis W.D. (1978) Determination of dimensional stabilization of wood using the water-soak method. Wood and Fiber 10:104-111.

Rowell R.M., LeVan-Green S.L. (2005) Thermal Properties, in: R. M. Rowell (Ed.), Handbook of Wood Chemistry and Wood Composites, Taylor \& Francis, New York.

Rowell R.M., Gutzmer D.I., Sachs I.B., Kinney R.E. (1976) Effects of alkylene oxide treatment on dimensional stability of wood. Wood Sci 9:51-54.

Saka S., Sasaki M., M. T. (1992) Wood-Inorganic composites prepared by sol-gel processing I. Wood-inorganic composites with porous structure. Mokuzai Gakkaishi 38:10431049.

Scheithauer M., Swaboda C., Böttcher H., Trepte J. (1998) Moglichkeiten des Einsatzes von Siliciumdioxid-Solen als Holzveredelungsmittel. In: Biologischer/Biotechnologischer Holzschutz. Proceedings of the meeting of the Deutsche Bundesstiftung Umwelt, Osnabrück, Germany, 9 September 1998.

Schliebs R., Ackermann J. (1987) Chemie und Technologie der Silicone I. Chemie in unserer Zeit 21:121-127.

Schneider M.H., Brebner K.I. (1985) Wood-polymer combinations - The chemical modification of wood by alkoxysilane coupling agents. Wood Sci Technol 19:67-73.

Sèbe G., Tingaut P., Safou-Tchiama R., Petraud M., Grelier S., Jeso B.D. (2004) Chemical reaction of maritime pine sapwood (Pinus pinaster Soland) with alkoxysilane molecules: A study of chemical pathways. Holzforschung 58:511-518.

Selmeier A. (1990) Anatomical studies on silicified wood. Holz Roh Werkst 48:111-115.

Simon F., Marchal F., Pochon F., Kutnik M., le Bayon I. (2011) The potential of silicone-based formulations to enhance wood properties through industrial treatment for outdoor use. International Research Group on Wood Protection, Irg/Wp 11-30578 Stockholm, Sweden. 
Stamm A.J. (1959) Dimensionsal stabilization of Wood by Thermal Reactions and Formaldehyde Cross-Linking. Tappi Journal 42:39-44.

Stamm A.J. (1964) Wood and Cellulose Science The Ronald Press Company, New York.

Stamm A.J., Millett M.A. (1941) The Internal Surface of Cellulosic Materials. J Phys Chem 45:43-54.

Stamm A.J., Tarkow H. (1947) Dimensional stabilization of wood. J Phys Colloid Chem 51:493-505.

Stevens M. (1981) Preliminary results of the treatment of wood with chlorosilanes. International Research Group on Wood Protection, Irg/Wp 3172 Stockholm, Sweden.

Stevens M. (1985) Restriction on the use of chlorosilanes as potential wood preservatives. International Research Group on Wood Protection, Irg/Wp 3345 Stockholm, Sweden.

Temiz A., Terziev N., Jacobsen B., Eikenes M. (2006) Weathering, water absorption, and durability of silicon, acetylated, and heat-treated wood. J Appl Polym Sci 102:45064513.

Tiller J.C. (2011) Antimicrobial Surfaces, in: H. G. Borner and J. F. Lutz (Eds.), Bioactive Surfaces, Springer-Verlag Berlin, Berlin. pp. 193-217.

Tingaut P., Weigenand O., Militz H., De Jeso B., Sebe G. (2005) Functionalisation of wood by reaction with 3-isocyanatopropyltriethoxysilane: Grafting and hydrolysis of the triethoxysilane end groups. Holzforschung 59:397-404.

Tingaut P., Weigenand O., Mai C., Militz H., Sebe G. (2006) Chemical reaction of alkoxysilane molecules in wood modified with silanol groups. Holzforschung 60:271-277.

Weigenand O., Humar M., Daniel G., Militz H., Mai C. (2008) Decay resistance of wood treated with amino-silicone compounds. Holzforschung 62:112-118.

Weigenand O., Militz H., Tingaut P., Sebe G., de Jeso B., Mai C. (2007) Penetration of aminosilicone micro- and macro-emulsions into Scots pine sapwood and the effect on water-related properties. Holzforschung 61:51-59.

Williams R.S. (1999) Water Repellents and Water-Repellent Preservatives for Wood. United States Departement of Agriculture, Forest Service, Forest Products Laboratory, General Technical Report FPL-GTR-109.

Williams S.R. (2010) Wood Handbook, Chapter 16: Finishing of Wood. General Technical Report FPL-GTR-190. Madison, WI: U.S. Department of Agriculture, Forest Service, Forest Products Laboratory Chapter 16:1-39.

Yamaguchi H. (1994a) Preparation and physical properties of wood fixed with silicic acid compounds. Mokuzai Gakkaishi 40:838-845.

Yamaguchi H. (1994b) Properties of silicic acid compounds as chemical agents for impregnation and fixation of wood. Mokuzai Gakkaishi 1994:830-837.

Yamaguchi H. (2002) Low molecular weight silicic acid - inorganic compound complex as wood preservatives. Wood Sci Technol 36:399-417. 


\section{Appendix}

\subsection{Published articles}

Pries M., Mai C., (2013) Fire resistance of wood treated with a cationic silica sol. Eur J Wood Prod, DOI 10.1007/s00107-013-0674-7.

Pries M., Wagner R., Kaesler KH., Militz H., Mai C. (2013) Acetylation of wood in combination with polysiloxanes to improve water-related and mechanical properties of wood. Wood Sci Technol, DOI 10.1007/s00226-013-0535-x.

Pries M., Wagner R., Kaesler KH., Militz H., Mai C. (2012) Effect of short-chain silicones bearing different functional groups on the resistance of pine (Pinus sy/vestris L.) and beech (Fagus sylvatica L.) against decay fungi. Holzforschung, DOI 10.1515/hf-20120065. (not reproduced here)

Pries M., Mai C., (2013) Treatment of wood with silica sols against attack by wood-decaying fungi and blue stain. Holzforschung, DOI 10.1515/hf-2012-0133. (not reproduced here)

\subsection{Prepared articles}

Effect of amino- and carboxy-siloxane combinations on the resistance of pine (Pinus sylvestris L.) and beech (Fagus sylvativa L.) against fungal decay and blue stain.

Painting and gluing capability of beech wood (Fagus sylvativa L.) treated with functionalized polydimethylsiloxanes. 


\title{
Fire resistance of wood treated with a cationic silica sol
}

\author{
Malte Pries $\cdot$ Carsten Mai
}

Received: 14 August 2012/Published online: 9 February 2013

(C) The Author(s) 2013. This article is published with open access at Springerlink.com

\begin{abstract}
Wood was treated with the cationic silica sol (CSS) Levasil 200S and dried at various temperatures (room temperature, 40, 60, 80 and $103{ }^{\circ} \mathrm{C}$ ). A water leaching test revealed fixation of the silica in wood even after drying at room temperature. Maximum cross sectional swelling of the specimens decreased from $15.6 \%$ (untreated control) to $13.0 \%$, when treated wood was dried at $103{ }^{\circ} \mathrm{C}$; cell wall bulking values were also negative $(-2.3 \%)$, indicating a thermal degradation of the cell wall polymers catalyzed by the CSS. Penetration of the CSS into the cell wall did not occur. A simple flammability test revealed increased fire resistance of the treated wood. Mass loss and velocity of mass loss as well as burning time were reduced; glowing of the formed charcoal was completely prevented. The effectiveness increased with increasing weight percent gain of the CSS in the wood. Thermo gravimetric analysis under nitrogen atmosphere displayed only minor reduction in the initial temperature of thermal decomposition for wood treated with CSS as compared to the control. In the presence of oxygen the resulting charcoal showed comparable thermal behaviour to the control. The yield of charcoal after pyrolysis was increased to a minor extent (from 19.9 to $23.0 \%$ ), indicating that the release of combustible gases was hardly reduced. The mode of action of enhanced fire resistance due to CSStreatment is discussed.
\end{abstract}

M. Pries · C. Mai $(\bowtie)$

Wood Biology and Wood Products, Burckhardt Institute,

Georg-August-University Göttingen, Büsgenweg 4,

37077 Göttingen, Germany

e-mail: cmai@gwdg.de

\section{Brandverhalten von mit kationisch modifiziertem Kieselsol behandeltem Holz}

Zusammenfassung Kiefernsplintholz wurde mit dem kationisch modifizierten Kieselsol Levasil 200S behandelt und bei verschiedenen Temperaturen getrocknet (Raumtemperatur, 40, 60, 80 und $103{ }^{\circ} \mathrm{C}$ ). Das Kieselsol war nach der Trocknung stabil gegenüber einer Auswaschung mit Wasser, selbst nach Trocknung bei Raumtemperatur. Die maximale Quellung der Querschnittsfläche des Holzes verringerte sich von 15,6\% (Kontrollen) auf 13,0\% bei behandeltem Holz, welches bei $103{ }^{\circ} \mathrm{C}$ getrocknet wurde. Die Querschnittsfläche im darrtrockenen Zustand verringerte sich ebenfalls (2,3\%), was auf einen thermischen Abbau des Holzes katalysiert durch das Kieselsol schließen lässt. Eine Eindringung des Sols in die Zellwand fand nicht statt. Ein einfacher Brandversuch zeigte erhöhte Feuerresistenz des behandelten Holzes. Der Gesamtmasseverlust, die Geschwindigkeit des Masseverlusts als auch die Brenndauer wurden reduziert. Das Nachglühen der entstandenen Holzkohle wurde komplett unterbunden. Die Wirkung stieg mit steigender Beladung des Holzes mit dem Kieselsol. Eine thermogravimetrische Analyse (TGA) unter Stickstoffatmosphäre ergab nur eine sehr geringe Abnahme der Pyrolysetemperatur. Die anschließende Verbrennung der entstandenen Holzkohle in Anwesenheit von Sauerstoff verlief vergleichbar zu den Kontrollproben. Die Holzkohleausbeute nach der Pyrolyse wurde durch die Behandlung nur leicht erhöht (von 19,9\% auf 23,0 \%), die Freisetzung von brennbaren Gasen aus dem Holz wurde dementsprechend unwesentlich verringert. Der Wirkungsmechanismus des kationischem Kieselsols auf das Brandverhalten des behandelten Holzes wird diskutiert. 


\section{Introduction}

Wood is a widely used building material which has, besides many advantages such as high weight-to-strength ratio, good insulating properties and favoured appearance, some natural drawbacks in use. The most important drawbacks are water related. Wood swells and shrinks under the conditions of changing ambient humidity. If unbound, liquid water is present in wood, fungal degradation can occur; insects can even destroy wood under dry conditions. Another important issue is the flammability of wood. Several attempts have been made to overcome these disadvantages; recently wood modification techniques such as acetylation, heat treatment or furfurylation have entered the market of biocide-free wood treatments (Hill 2006).

Wood is usually pressure impregnated with fire retardants, mostly inorganic salts such as mono/diammonium phosphate, ammonium sulfate, zinc chloride, sodium tetraborate and boric acid (White and Dietenberger 2010). Fire retardants can be divided into six different classes based on their modes of action, although most fire retardants operate via several mechanisms (Rowell and LeVanGreen 2005). They can, for example, increase charring of wood at lower temperature and, thus, form an insulating layer of non-flammable charcoal. In addition, they often have the side effect of diluting the flammable gases with non-combustible gases (e.g. ammonia gas from ammonium phosphate) and increasing the amount of resulting charcoal; the latter results in a diminished formation of combustible gases. Most of the fire retardant salts are not stable towards leaching out with water and can, therefore, only be used for materials used indoor. Coatings, which form insulating layers, constitute another class of fire protection agents. These coatings protect the wood by rapidly building up a thick insulating foam layer when exposed to temperatures between 180 and $200{ }^{\circ} \mathrm{C}$ (Scheer and Peter 2009). Silicon materials have long been used as fire retardants. Water glass was found to render wood fire resistant as early as 1825 (Fuchs 1825). It was later used as cheap short-term protection coating against fire especially in already erected buildings where pressure impregnation is not possible (Metz 1942). Water glass coating protects wood against fire by melting and forming an insulating foam layer on the surface of wood. Unfortunately, the water glass coating is not long-term stable due to neutralization in contact with air, which results in reduced foam formation and detachment of the coating from the substrate. Other silicon compounds have also been used to improve fire resistance of wood. Wood treated with inorganic composites based on tetraethoxysilane exhibited enhanced fire resistance (Saka et al. 1992); combination of tetraethoxysilane with trimethylphosphit/-borate led to further increase (Miyafuji and Saka 1996). Silica sols are another group of inorganic silicon compounds. They are produced by controlled removal of alkali from water glass through ion exchange techniques. This causes the silicic acid to polymerize and to form particles of amorphous silicon dioxide. To obtain a sol of polysilicic acid molecules, this polycondensation process is stopped at a certain stage by addition of alkali (Römpp 2001). Unmodified silica sols are therefore, alkaline and the colloids are stabilized by negative charge. Acidification of these sols leads to protonation of $\mathrm{Si}-\mathrm{O}$ anions and precipitation of the silica particles from the colloid. Sols can be stabilized sterically through modification of the colloid particle surface (e.g. with silanes) or by introducing positive charge (cationic groups). These modified sols are also stable under neutral or acidic conditions (Greenwood 2010). Silica sols have previously been used to impregnate wood (Böttcher et al. 1999; Götze et al. 2008; Temiz et al. 2006) in order to enhance resistance to fungi and water related properties. Influence on fire resistance has not been examined.

In a recent study, the use of various silica sols to protect wood against fungal colonization and water uptake was examined and significant improvements were found only with a cationic sol, which is modified with aluminiumoxychloride (Pries and Mai 2012). This study focuses on the fire resistant properties of wood modified with this CSS.

\section{Experimental}

\subsection{Materials}

Pine sapwood (Pinus sylvestris L.) specimens were cut from straight grained wood free of knots. Specimens to test anti-shrink-efficiency (ASE) had the dimensions $20 \times$ $20 \times 10 \mathrm{~mm}^{3}(\mathrm{~T} \times \mathrm{R} \times \mathrm{L})$, those to test fire resistance measured $13 \times 4 \times 125 \mathrm{~mm}^{3}(\mathrm{~T} \times \mathrm{R} \times \mathrm{L})$; growth rings were oriented $45^{\circ}$ with the tangential surface.

The silica sol used was Levasil 200S (Akzo Nobel, Düren, Germany) with a solid content of $30 \%$ and a pH of 3.7. Its surface is cationically modified with aluminium oxychloride; the counter ions of the cationic surface are chloride ions (Fig. 1).

Impralit F3/66 (Rütgers Organics, Mannheim, Germany), a commercial fire retardant, was used as a reference.

\subsection{Treatment of wood}

For impregnation, the specimens were placed in a desiccator and a vacuum of 7 mbar absolute pressure was applied for $15 \mathrm{~min}$. Subsequently, the solution was injected and the vacuum released. The specimens were left in the 


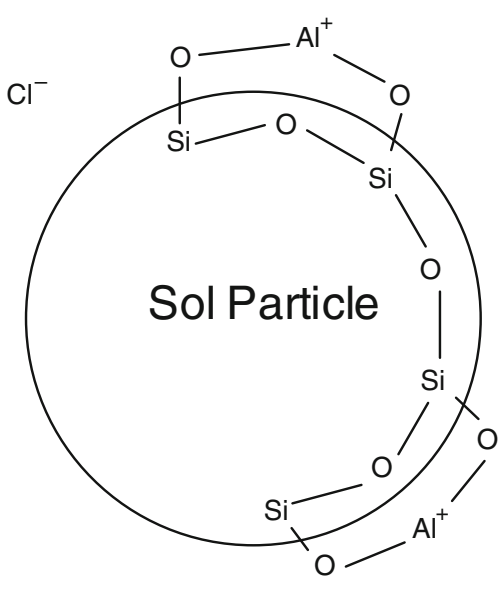

Fig. 1 Idealized cationic silica sol particle modified with aluminium oxide

Abb. 1 Idealisierter, mit Aluminiumoxychlorid modifizierter Kieselsolpartikel

solution for $2 \mathrm{~h}$ and subsequently dried as described below. The specimens were weighed after impregnation and drying to assess solution uptake and weight percent gain (WPG).

\subsection{Fixation of chemical}

ASE specimens were treated with $15 \%$ solutions (w/w) of Levasil 200S as described above. After treatment they were pre-dried at room temperature for 5 days. Subsequently eight specimens at a time were exposed to different temperatures for 3 days. The temperatures were: room temperature, 40, 60, 80 and $103{ }^{\circ} \mathrm{C}$. After this treatment the specimens were leached in water according to EN 84 (1997) and afterwards dried at room temperature and subsequently at $103{ }^{\circ} \mathrm{C}(24 \mathrm{~h}$ each $)$.

\subsection{Water uptake}

The eight ASE specimens dried at defined temperatures (fixation test) were submerged in $300 \mathrm{ml}$ water and weighted after 2, 4, 6 and $24 \mathrm{~h}$ of submersion time. After the last weighing a vacuum of approximately 40 mbar was applied for $1 \mathrm{~h}$. The specimens were left in the water for another day to ensure maximum water uptake. Water uptake was calculated based on the dry weight of the specimens before treatment (thus influence of the weight percent gain was eliminated).

\subsection{Weight percent gain (WPG), cell wall bulking} and maximum swelling

WPG and cell wall bulking (volume increase of the specimens in the dry state after chemical modification) were calculated according to the following formulas with all measurements taken in an oven dry state:

$$
\begin{aligned}
& \text { Bulking }(\%)=\frac{\operatorname{rad}_{\text {After treatment }} * \tan _{\text {After treatment }}}{\operatorname{rad}_{\text {Before treatment }} * \tan _{\text {Before treatment }}}-1 \\
& \text { WPG }(\%)=\frac{\text { Weight }_{\text {After treatment }}}{\text { Weight }_{\text {Before treatment }}}-1
\end{aligned}
$$

where "rad" is radial lengths and "tan" tangential lengths of the ASE specimens.

Maximum cross-sectional swelling was calculated from the dimensions of the fully saturated specimens of the water uptake test.

\subsection{Fire resistance}

The wood specimens were treated with 5, 10, and $15 \%$ solutions (w/w) of Levasil 200S as described above. After impregnation, the wood specimens were dried at room temperature and subsequently at $103{ }^{\circ} \mathrm{C}(24 \mathrm{~h}$ each $)$. As a reference, wood specimens were treated in the same way with a solution $(10 \%, \mathrm{w} / \mathrm{w})$ of the commercial fire retardant Impralit F3/66 (Rütgers Organics, Mannheim, Germany). Ten replicates for each treatment were used. Prior to fire resistance testing, they were conditioned at $20{ }^{\circ} \mathrm{C}$ and $65 \% \mathrm{RH}$; water leaching was not performed.

The specimens were clamped into a holder at one end forming an angle of $45^{\circ}$. The specimen holder was placed on a balance in a way that the specimen was hanging down next to the scale. The balance was tarred before clamping the specimen. From the starting mass of the specimens, the moisture content based on the original dry mass of the wood (before treatment) was calculated.

The specimens' tip was ignited with a Bunsen burner for $30 \mathrm{~s}$. In doing so the flame of the Bunsen burner was always equal in height and strength for all specimens. The weight of the specimen was recorded in $10 \mathrm{~s}$ intervals; at the same time it was assessed whether the specimen was burning or glowing. The mass loss of the specimens was related to the original dry weight (before treatment) and depicted as a function of experimental time. Total mass loss, maximum mass loss per ten-second interval (burning rate), burning time and glowing time were calculated. The test was repeated, when the specimen broke during testing.

\subsection{Thermo-gravimetric analysis (TGA)}

The treated and control specimens were milled with a centrifugal mill using a mesh of $0.5 \mathrm{~mm}$ (Retsch ZM 100, Retsch, Germany). TGA was performed using Netsch TG209 F1 IRIS (Selb, Germany); approximately $10 \mathrm{mg}$ were weighted in aluminium-oxide crucibles. The temperature program is specified in Table 1 . The flow rate of 
Table 1 Temperature program of the thermogravimetric analysis (TGA)

Tab. 1 Temperaturprogramm der thermogravimetrischen Analyse (TGA)

\begin{tabular}{lllcccc}
\hline $\begin{array}{l}\text { Segment } \\
\text { No. }\end{array}$ & Type & $\begin{array}{l}\text { Final temperature } \\
\left({ }^{\circ} \mathrm{C}\right)\end{array}$ & $\begin{array}{l}\text { Slope } \\
\left(\mathrm{K} \mathrm{min} \mathrm{min}^{-1}\right)\end{array}$ & $\begin{array}{l}\text { Time } \\
(\mathrm{min})\end{array}$ & $\begin{array}{l}\text { Oxygen purge gas } \\
\left(\mathrm{ml} \mathrm{min}^{-1}\right)\end{array}$ & $\begin{array}{l}\text { Nitrogen purge gas } \\
(\mathrm{ml} \mathrm{min}\end{array}$ \\
\hline 1 & Dynamic & 100 & 20 & 4 & 0 & 50 \\
2 & Isothermal & 100 & - & 5 & 0 & 50 \\
3 & Dynamic & 550 & 10 & 55 & 0 & 50 \\
4 & Isothermal & 550 & - & 5 & 0 & 50 \\
5 & Dynamic & 250 & -40 & 7.30 & 0 & 50 \\
6 & Isothermal & 250 & - & 5 & 0 & 50 \\
7 & Dynamic & 650 & 20 & 20 & 10 & 40 \\
8 & Isothermal & 650 & - & 5 & 10 & 40 \\
\hline
\end{tabular}

the nitrogen protective gas was $20 \mathrm{ml} \mathrm{min}^{-1}$ in each segment (Table 1).

A measurement with an empty crucible served as correction curve, which was subtracted from the sample measurements. Onset and end of the mass loss curves (Fig. 6a, b) as well as the maximum of the first derivative were recorded. The mass losses at the various segments of the program were recorded as absolute weight. To determine the percentage mass loss of the two mass loss steps (step 1: segment 3; step 2: segment 7, Table 1), all curves were shifted in a way that the final point of the thermograms was equal to the ash content of the control specimen $(0.84 \%)$. In doing so the influence of the silica add-on in the specimens, i.e., the WPG, was avoided. In order to allow for direct comparison of the percentage weight losses of all treated specimens, the starting point for the calculations ( $0 \%$ mass loss) was the begin of the 3 rd segment. In the 1 st and 2nd segment the specimens were only dried to exclude any effects of different moisture content.

\section{Results and discussion}

\subsection{Fixation of chemical}

Irrespective of the drying temperature, the weight percent gains (WPG) of CSS-treated specimens after leaching were equal (Fig. 2). This revealed that the drying temperature did not have an effect on the stability of the silica towards water leaching, when the drying time is sufficient. The treatment, which actually resulted in lowest mean value, was the treatment at $103{ }^{\circ} \mathrm{C}$ (Fig. 2).

While silica particles in sols form a colloidal solution, they agglomerate in wood upon drying and form insoluble condensation products which are apparently stable to water leaching. This process does not require elevated temperatures.

It has been suggested to fix silica in wood by covalent bonding in order to increase leaching stability of tetraethoxysilane (Ogiso and Saka 1994); this, however, is

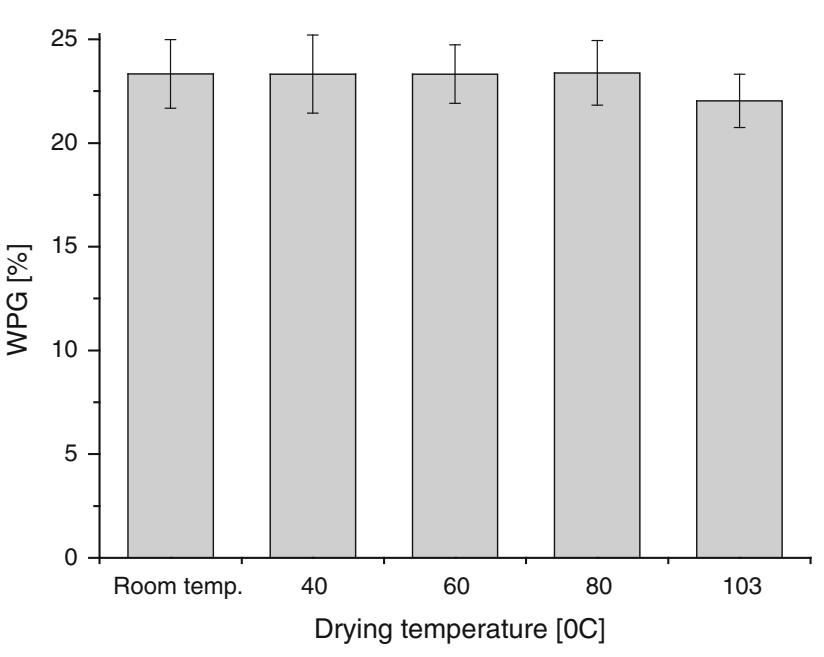

Fig. 2 WPG of ASE specimens after water leaching as a function of various temperatures; mean values and standard deviations

Abb. 2 WPG der ASE-Proben nach der Auswaschung mit Wasser in Abhängigkeit der Trocknungstemperatur nach der Behandlung; Mittelwerte und Standardabweichungen

apparently not necessary for silica sol-treatment. Water glass has also been used to treat wood and was always found to be unstable towards water leaching (Furuno et al. 1992; Matthes et al. 2002). The reason for the high solubility in water is the high content of alkali in water glass, which forms anionic silanolate groups. Water glass can be precipitated by addition of acids or by divalent ions. In wood this is achieved by ambient carbon dioxide which forms carbonic acid and causes protonation of the silanolate groups. The cationic colloid particles of the CSS used in this study, on the other hand, are only stabilized by small addition of chloride ions and are directly insoluble upon drying.

\subsection{Water uptake}

Treatment with CSS significantly decreased velocity of water uptake. Mean values of water uptake were lower for specimens, which were dried at higher temperatures (Fig. 3). Although the variation of water uptake was high, a 


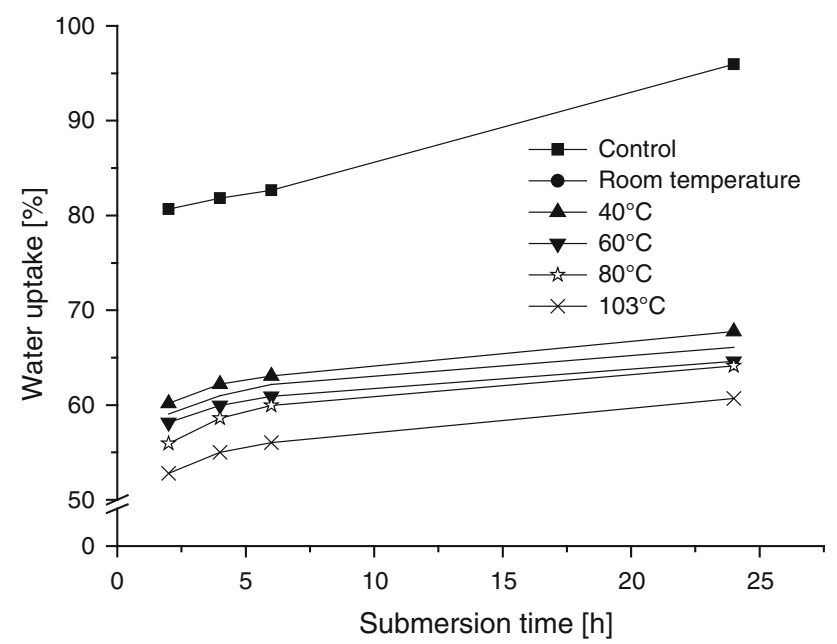

Fig. 3 Water uptake of untreated and CSS-treated wood specimens dried at various temperatures (mean values)

Abb. 3 Wasseraufnahme der Kontrollen und der mit kationischem Kieselsol behandelten Prüfkörper, welche bei verschiedenen Temperaturen getrocknet wurden (Mittelwerte)

$t$ test revealed, that the water uptake of the specimens dried at $103{ }^{\circ} \mathrm{C}$ was significantly lower (significance level 0.05 ) for the points at 4,6 and $24 \mathrm{~h}$ as compared to the specimens dried at room temperature and it was always significantly lower than water uptake of specimens dried at $40{ }^{\circ} \mathrm{C}$. Silica usually is a hydrophilic material and is therefore not expected to render wood water repellent. Especially, water glass has been reported to increase hygroscopicity of the treated wood. This was explained by the hygroscopic salts (silanolate and alkali ions) left in the wood after treatment (Furuno et al. 1992; Matthes et al. 2002). Silica sol on the other hand has previously shown to reduce water uptake. Treatment of spruce wood samples with silica sols reportedly reduced water uptake by approx. $25 \%$ after 6 days of water immersion (Götze et al. 2008). Wood treated with alkaline silica sols of two different particle sizes, 15 and $30 \mathrm{~nm}$, showed reduction in water uptake; the bigger particle size resulted in lower water uptake (Temiz et al. 2006).

It can be concluded, that the CSS Levasil 200S is better suited for reducing water uptake of wood than water glass. This can be explained by the much lower surface charge and respective lower content of counter ions in silica sols as compared to water glass. CSS reduces capillary water uptake probably by partial blocking of the main penetration paths for water such as ray cells and tracheids (Pries and Mai 2012).

\subsection{Cell wall bulking and maximum swelling}

The cross-sectional area of the specimens after treatment with CSS was lower than before treatment; thus cell wall bulking was negative. The higher the drying temperature, the

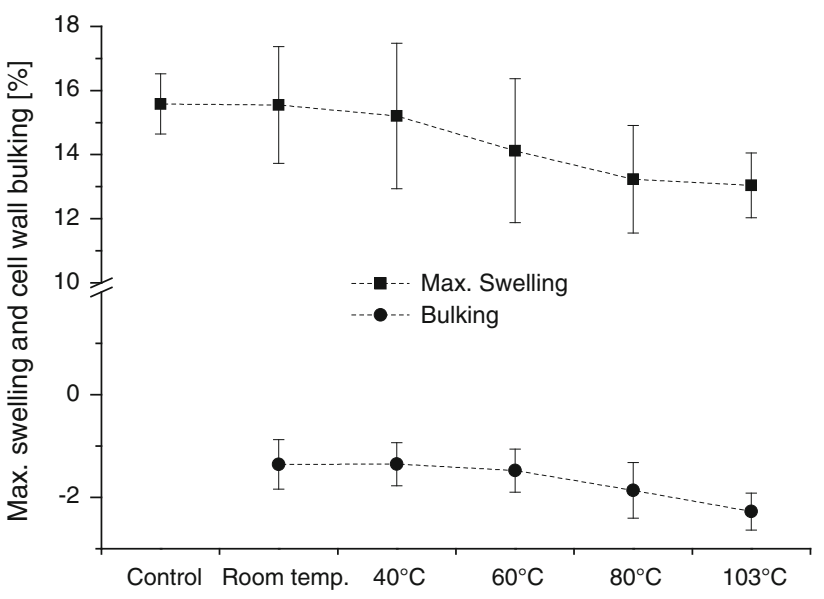

Fig. 4 Maximal cross-sectional swelling and cross-sectional bulking of specimens treated with CSS and dried at various temperatures; mean values and standard deviations

Abb. 4 Maximale Quellung der Querschnittsfläche sowie das Bulking von mit kationischem Kieselsol behandelten Prüfkörpern in Abhängigkeit der Trocknungstemperatur nach der Behandlung; Mittelwerte und Standardabweichungen

more negative was the bulking. Bulking of specimens dried at $103{ }^{\circ} \mathrm{C}$ was significantly lower than bulking of specimens dried at room temperature, 40 and $60{ }^{\circ} \mathrm{C}$ (Fig. 4). Maximum swelling in water also decreased with increased drying temperature. While the control and specimens dried at room temperature showed maximum cross-sectional swelling of approx. $15.5 \%$, specimens dried at $103{ }^{\circ} \mathrm{C}$ displayed only a mean maximum swelling of $13.0 \%$; the latter was significantly lower than the former. This is attributed mostly to the hydrolysis of hemicelluloses, which are the most susceptible wood polymers to hydrolysis (Stamm 1964), because bound aluminium chloride in Levasil 200S may act as a Lewis acid (Pries and Mai 2012).

Acid releasing chemicals can be used as fire retardants, because they induce charring of wood at low temperatures and thus form an insulating layer at the surface (White and Dietenberger 2010). CSS might therefore, act in the same way by reducing the degradation temperature of wood constituents in case of fire and thereby rendering the wood more fire retardant.

\subsection{Fire resistance and thermo-gravimetric analysis (TGA)}

The weight percent gain (WPG) of the specimens treated with CSS in the concentrations of 5,10 and $15 \%$ were 8.8, 17.2, and $27.6 \%$, respectively. Treatment with the commercial fire retardant Impralit F3/66 resulted in a WPG of $11.2 \%$.

The moisture content of the CSS-treated specimens $(12.9,15 \%$ CSS $)$ was somewhat higher than that of the controls $(11.4 \%)$. Specimens treated with the fire retardant 
were even more hygroscopic and displayed a moisture content of $14.4 \%$ (Fig. 5a).

The fire resistance test revealed a strong reduction in the maximum burning rate as compared to the untreated control (Fig. 5b). The burning rate usually reached its maximum right after removing the Bunsen burner. While the control specimens lost approx. $8.4 \%$ per $10 \mathrm{~s}$, specimens treated with $15 \%$ CSS showed only a maximum mass loss rate of $3.8 \%$ per $10 \mathrm{~s}$. Treatment with the fire retardant caused the lowest burning rate of $2.2 \%$ per $10 \mathrm{~s}$. Parallel to this reduction in the burning rate, a strong reduction in total mass loss occurred, because the treated specimens did not burn completely. While the mass loss of the controls amounted to approx. $80 \%$, specimens treated with $15 \%$ CSS underwent only a mass loss of $20 \%$; specimens treated with the fire retardant lost only $13 \%$ of their mass.

The control specimens burned completely with a mean burning time of approx. $120 \mathrm{~s}$. After burning, the specimens continued to glow with a mean glowing time of $80 \mathrm{~s}$. All treated specimens ceased to burn before complete burning of the specimen and none of the treated specimens
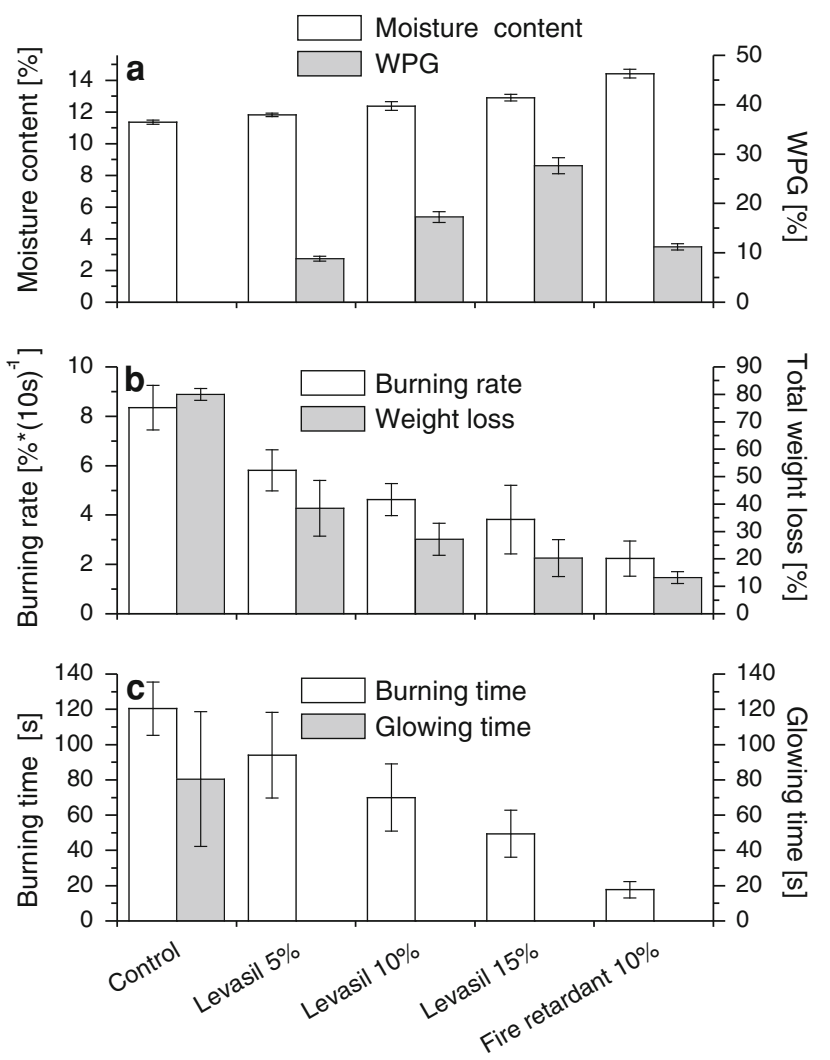

Fig. 5 Results of a burning test of untreated, CSS-treated and wood treated with a commercial fire retardant; (mean values and standard deviations) Abb. 5 Ergebnisse eines Brandversuchs der Kontrollen, der mit kationischem Kieselsol sowie der mit einem kommerziellen Feuerschutzsalz behandelten Proben; Mittelwerte und Standardabweichungen exhibited any glowing after extinction of the fire. Mean burning time of specimens treated with $15 \%$ CSS amounted to $49 \mathrm{~s}$, while specimens treated with the fire retardant burned only $18 \mathrm{~s}$.

Fire retardance of wood by chemicals can be indicated in a TGA through a decrease of the initial temperature of pyrolysis and an increase of the amount of produced charcoal which indirectly indicates a reduction of volatile, combustible gases (Rowell and LeVan-Green 2005). In the present study, TGA revealed only minor differences in the pyrolysis behaviour between the control and CSS-treated wood. The onset of mass loss in the pyrolysis of CSStreated wood was at slightly lower temperature $\left(294.4^{\circ} \mathrm{C}\right)$ than of the control $\left(304.0^{\circ} \mathrm{C}\right)$. The temperature of maximal mass loss per time (maximum of first derivative) was also shifted from $353.5{ }^{\circ} \mathrm{C}$ (control) to $339.7{ }^{\circ} \mathrm{C}$ (15\% CSS). Wood treated with the fire retardant showed an onset of pyrolysis at $264.7{ }^{\circ} \mathrm{C}$ and a temperature of maximum mass loss per time at $291.9^{\circ} \mathrm{C}$ (Figs. 6a, 7a).

After the pyrolysis, the resulting charcoal was burned in the presence of oxygen (Figs. 6b, 7a). The burning behaviour of charcoal from CSS-treated wood was very similar to that of the control. While the onset of burning in case of the control was at $438.9{ }^{\circ} \mathrm{C}$ and the maximum mass loss per time at $491.1{ }^{\circ} \mathrm{C}$, the respective points for wood treated with $15 \% \mathrm{CSS}$ were at 438.9 and $486.1^{\circ} \mathrm{C}$. The coal from wood treated with the fire retardant showed higher fire resistance with an onset at $461.7^{\circ} \mathrm{C}$ and a temperature of maximum mass loss at $522.5^{\circ} \mathrm{C}$ (Fig. 7a). The remaining charcoal is an important measure of how much burnable gas was released during pyrolysis. Charcoal yield increased only very slightly due to treatment with CSS. While the control yielded $19.9 \%$ charcoal, wood treated with $15 \%$ CSS yielded $23.0 \%$. Wood treated with the fire retardant increased the charcoal yield to $34.4 \%$ (Fig. 7b).

TGA revealed only a slight downshift of pyrolysis temperature of CSS-treated wood as compared to the control, while treatment with the commercial fire retardant resulted in strongly reduced pyrolysis temperature. Pyrolysis of wood at lower temperature can be due to acidic reaction of the fire retardant. Proton donators and Lewis acids such as zinc chloride or aluminium chloride can lower the initial temperature for thermal decomposition, which can lead to the formation of an insulating charcoal layer. Aluminium chloride has been used as a fire retardant, the performance, however, was not good enough for wider usage (Kollmann 1951; Metz 1942).

The reduction of combustible volatiles is another important feature of fire retardants. This includes the inhibition of formation of levoglucosan a breakdown product of cellulose (Rowell and LeVan-Green 2005). A reduction of combustible volatiles is shown by a high 

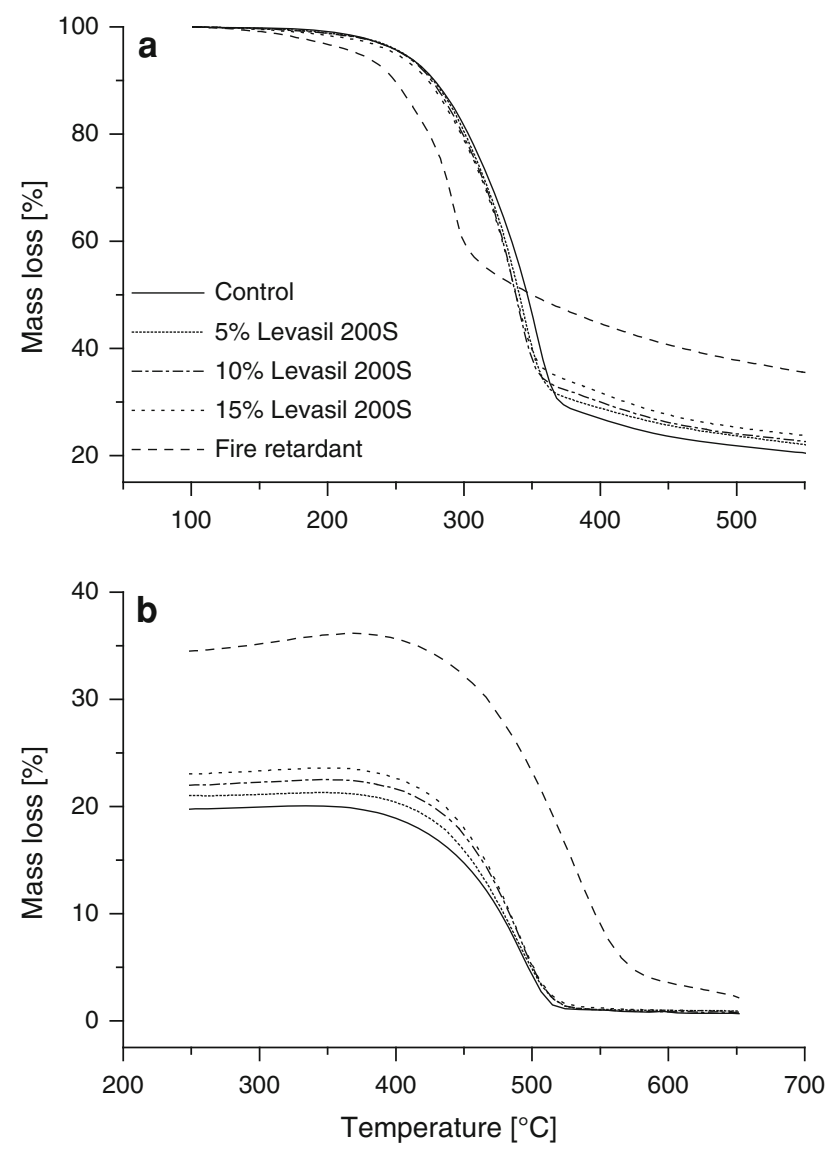

Fig. 6 Mass loss curves (thermo-gravimetric analysis) of untreated, CSS-treated and wood treated with a commercial fire retardant under nitrogen atmosphere (a segment 3 in Table 1) and subsequent burning of the resulting charcoal in the presence of oxygen (b segment 7 in Table 1)

Abb. 6 Kurven des Masseverlustes der Kontrollen, der mit Kieselsol behandelten sowie der mit einem kommerziellen Feuerschutzsalz behandelten Proben in der thermogravimetrischen Analyse: Unter Stickstoffatmosphäre (a Segment 1 in Tabelle 1) und anschließende Verbrennung der entstandenen Holzkohle in Anwesenheit von Sauerstoff (b Segment 7 in Tabelle 1)

charcoal yield after pyrolysis. In contrast to the fire retardant, the CSS only increased the charcoal yield to a minor extent and thus did hardly reduce the amount of combustible gases. The resulting charcoal of CSS-treated wood showed the same burning behaviour as the charcoal of the control.

The relatively strong fire retardance revealed in the burning test can be explained by several effects, which are not reflected in the TGA. The formation of a charred layer at lower temperatures is mentioned above. Another reason might be the increased density, which causes a higher heat capacity. As a consequence, more energy is needed to heat the wood to a temperature where combustible gases are released (Metz 1942).

Incorporation of CSS into the wood lumens might also hinder the release of volatile gases and thus reduce the combustibility. When wood is heated, combustible gases
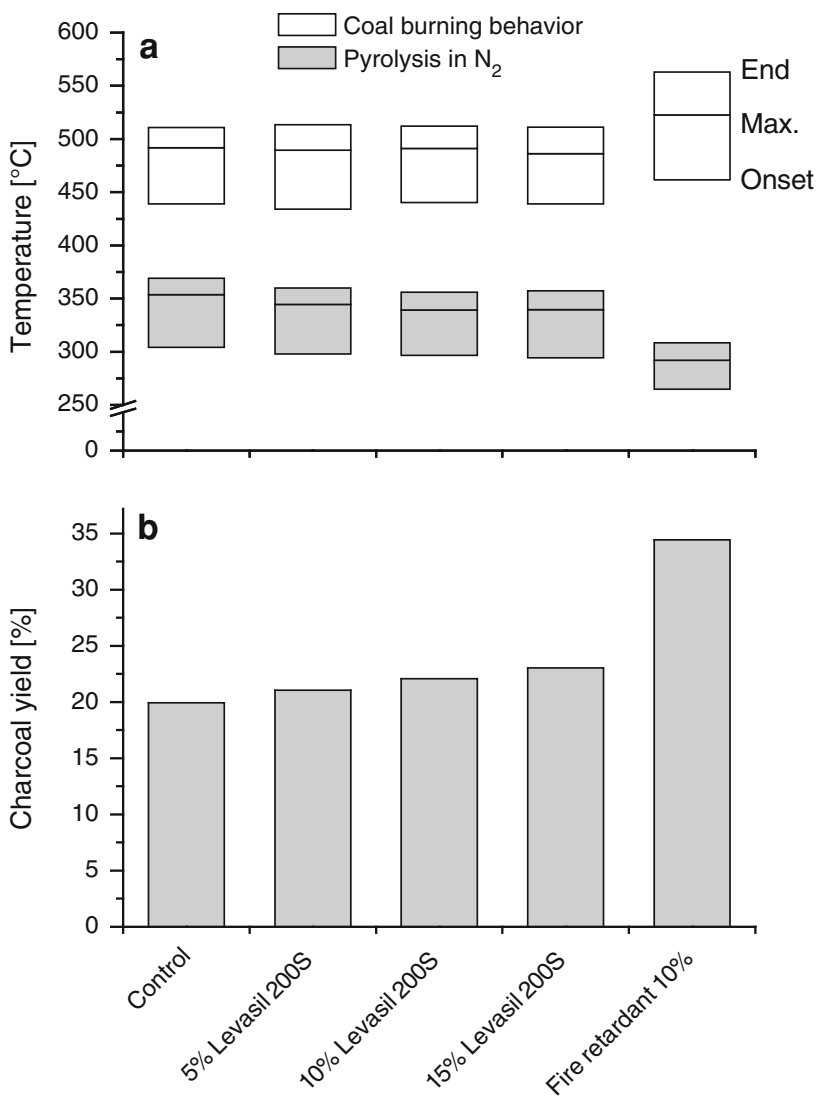

Fig. 7 Onset of mass loss, temperature of fastest mass loss and end of mass loss (a) as well as char coal yield (b) of untreated wood and wood treated with silica sol and a commercial fire retardant in the TGA under nitrogen atmosphere

Abb. 7 Beginn des Masseverlusts, Temperatur des schnellsten Masseverlustes und Ende des Masseverlusts (a) sowie Holzkohleausbeute (b) der Kontrollen, der mit Kieselsol sowie der mit Feuerschutzsalz behandelten Proben in der thermogravimetrischen Analyse unter Stickstoffatmosphäre

are released from the cell wall and exit the wood structure through the lumen to burn outside the wood. It was found that diffused porous wood burns better than ring porous wood, because the homogenous distribution of vessels facilitates diffusing of the gases to the wood surface. Ring porous wood on the other hand shows worse burning behaviour, because most vessels are small and hinder the gases from exiting. The same is true for the very small tracheids of many soft woods (Metz 1942).

CSS treatment might also influence the porosity of charcoal formed during pyrolysis. Especially the charcoal from diffused porous wood glows easier, because air has better access to the charcoal. Nonporous charcoal cannot be easily penetrated by air and the dangerous after-glowing is prevented (Metz 1942). None of the treated wood specimens exhibited any glowing after the fire stopped; this indicates that the charcoal was less porous and, therefore, air was not able to enter properly. 
Another mode of action could be that silica sol incorporated into the lumen might increase the thermal conductivity of the wood. This might lead to increased fire retardance because the wood cannot be heated up locally as easily as untreated one and thus does not inflame as fast (Metz 1942).

High moisture content due to the incorporation of hygroscopic chemicals into the wood might be another reason. The increase in moisture content of CSS-treated wood, however, was so minor that this effect was ruled out.

Effects of silicon compounds on fire resistance of wood have mainly been studied with tetraethoxysilane (TEOS) and mixtures of it. TEOS treatment alone increased fire resistance (Saka et al. 1992). This effect was enhanced by combining TEOS with trimethylphosphit and/or trimethylborate in a burning test similar to the test done in this study (Miyafuji and Saka 1996). The chemicals used by Miyafuji and Saka (1996), however, were located in the cell walls (positive bulking and ASE was observed), while silica in this study was located only in the lumens.

\section{Conclusion}

Wood treatment with CSS decreased the maximum swelling of wood, when the treated wood was dried at $103{ }^{\circ} \mathrm{C}$. This was mostly attributed to the hydrolysis of hemicelluloses. Reduction of the initial degradation temperature upon heating is known to be one mode of action of fire retardants, because it leads to the formation of an insulating charcoal layer. Fire retardant properties of CSS-treated wood were demonstrated in a simple burning test, while TGA only revealed minor changes as compared to untreated wood. CSS treatment can increase fire retardancy of wood but in general the effect is minor compared to the commercial fire retardant tested. Still, treatment of wood with CSS at $15 \%$ concentration improves some important wood properties such as low capillary water uptake and resistance to decay fungi. Increased fire retardancy, as shown in this study, is an additional positive effect of the treatment.

Open Access This article is distributed under the terms of the Creative Commons Attribution License which permits any use, distribution, and reproduction in any medium, provided the original author(s) and the source are credited.

\section{References}

Böttcher H, Jagoda C, Trepe J, Kallies KH, Haufe H (1999) Sol-gel composite films with controlled release of biocides. J Control Release 60:57-65

EN 84 (1997) Wood preservatives-Accelerated ageing of treated wood prior to biological testing-Leaching procedure. European Committee for Standardisation (CEN), Brussels, Belgium

Fuchs JN (1825) Ueber ein neues Product aus Kieselerde und Kali; und dessen nüzzliche Anwendung als Schuzmittel gegen schnelle Verbreitung des Feuers in Theatern, als Bindemittel, zu firnißartigen Anstrichen u.s.w. Dinglers polytechnisches J 17:465-481

Furuno T, Shimada K, Uehara T, Jodai S (1992) Combinations of wood and silicate II. Wood-mineral composites unsing water glass and reactance of barium chloride, boric acid, and borax and their properties. Mokuzai Gakkaishi 38:448-457

Götze J, Mockel R, Langhof N, Hengst M, Klinger M (2008) Silification of wood in the laboratory. Ceram-Silikaty 52:268-277

Greenwood P (2010) Surface modifications and applications of aqueous silica sols. Dissertation, Gothenburg

Hill CAS (2006) Wood modification. Chemical, thermal and other processes. Wiley, Chichester

Kollmann F (1951) Technologie des Holzes und der Holzwerkstoffe, vol 2, 2nd edn. Springer, Berlin

Matthes R, Nehring HO, Dellith W (2002) Wasserglas-Holzschutz im Hochbau. Proc. "Integrierter Umweltschutz im Bereich der Holzwirtschaft" 22nd-24th of January 2002, Göttingen:104-108

Metz L (1942) Holzschutz gegen Feuer, 2nd edn. VDI-Verlag GmbH, Berlin

Miyafuji H, Saka S (1996) Wood-inorganic composites prepared by the sol-gel process. 5. Fire-resisting properties of the $\mathrm{SiO}_{2}-\mathrm{P}_{2} \mathrm{O}_{5}-\mathrm{B}_{2} \mathrm{O}_{3}$ wood-inorganic composites. Mokuzai Gakkaishi 42:74-80

Ogiso K, Saka S (1994) Wood-inorganic composites prepared by solgel process. 4. Effects of chemical bonds between wood and inorganic substances on property enhancement. Mokuzai Gakkaishi 40:1100-1106

Pries M, Mai C (2012) Treatment of wood with silica sols against attack by wood decaying fungi and blue stain. Holzforschung (in press)

Römpp (2001) Römpp Chemielexikon online, Thieme Chemistry, Stuttgart

Rowell RM, LeVan-Green SL (2005) Thermal properties. In: R M Rowell (ed.), Handbook of wood chemistry and wood composites, Taylor \& Francis, New York

Saka S, Sasaki M, Tanahashi M (1992) Wood-inorganic composites prepared by sol-gel processing I. Wood-inorganic composites with porous structure. Mokuzai Gakkaishi 38:1043-1049

Scheer C, Peter M (2009) Holz Brandschutz Handbuch (3 edn). Deutsche Gesellschaft für Holzforschung, Ernst \& Sohn, Berlin

Stamm AJ (1964) Wood and cellulose science. The Ronald Press Company, New York

Temiz A, Terziev N, Jacobsen B, Eikenes M (2006) Weathering, water absorption, and durability of silicon, acetylated, and heattreated wood. J Appl Polym Sci 102:4506-4513

White RH, Dietenberger MA (2010) Wood handbook, Chapter 18: fire safety of wood construction. Department of Agriculture, Madison 


\title{
Acetylation of wood in combination with polysiloxanes to improve water-related and mechanical properties of wood
}

\author{
Malte Pries • Roland Wagner $\cdot$ Karl-Heinz Kaesler • \\ Holger Militz $\cdot$ Carsten Mai
}

Received: 25 May 2012/Published online: 2 March 2013

(C) The Author(s) 2013. This article is published with open access at Springerlink.com

\begin{abstract}
Scots pine sapwood was acetylated with ethyltriacetoxysilane using acetic acid as a solvent and sulfuric acid as a catalyst. A weight percent gain (WPG) of $14 \%$ and cell wall bulking of $7 \%$ were obtained after $5 \mathrm{~h}$ of reaction time. Pine specimens were acetylated with acetic anhydride in the presence of $1 \%$ ethyltriacetoxysilane, dihydroxy-functional siloxane, acetoxy-functional siloxane, aminofunctional siloxane and non-functional siloxane, respectively. Acetoxy-functional siloxane induced the greatest reduction in water uptake with a water repellent effectiveness after $24 \mathrm{~h}$ of up to $62 \%$ as compared to acetylated wood. WPG and cell wall bulking increased compared to solely acetylated wood with increasing concentrations of acetoxy-functional siloxane in acetic anhydride; anti-shrink efficiency, however, did not increase. Fungal resistance of pine sapwood and beech as well as mechanical strength properties did not change when $20 \%$ acetoxy-functional siloxane was added to acetic anhydride compared to solely acetylated specimens.
\end{abstract}

\section{Introduction}

Chemical modification has the potential to greatly improve properties of wood (Rowell 1983). The most studied process is by far the acetylation of wood which has undergone market introduction. Acetylation reportedly improved fungal resistance, photo-stability, dimensional stability and weathering performance of wood (Brelid et al. 2000; Chang and Chang 2001; Hill et al. 2005; Rowell 1983). The most

\footnotetext{
M. Pries $\cdot$ H. Militz $\cdot$ C. Mai $(\varangle)$

Wood Biology and Wood Products, Burckhardt Institute, Georg-August-University Göttingen, Büsgenweg 4, 37077 Göttingen, Germany

e-mail: cmai@gwdg.de

R. Wagner · K.-H. Kaesler

Momentive Performance Materials, Technology, Buildg. R20, 51368 Leverkusen, Germany
} 
abundant reaction sites in wood, the hydroxyl groups, are acetylated in the process by use of acetic anhydride (AA) under release of acetic acid. Because of the greater volume of acetyl groups compared to hydroxyl groups, cell wall bulking is observed (Stamm 1964). Reduction in capillary water uptake, however, occurs only to a minor extent.

Silicones have experienced a widespread use in many industrial applications. They are widely used in the construction sector to improve water repellence of masonry (Mayer 1998) or to improve properties of textiles (Kim 2001). Silicones have been tested on wood to enhance water repellence and showed great effectiveness in reducing water uptake (Hager 1995; Lukowsky et al. 1997). Hager (1995) used silicone micro-emulsions to treat wood and found a reduction in capillary water uptake by $80 \%$ as compared to the control after $24 \mathrm{~h}$ at $1 \%$ silicone content in the emulsion. Lukowsky et al. (1997) tested the effectiveness of similar micro-emulsions and some additional silicone formulations and found water repellent effectiveness in a submersion test of up to $50 \%$ after $24 \mathrm{~h}$. Ghosh (2009) found high water repellence when wood was treated with a water solvent-based solution of amino-functional silicones. A water repellent effectiveness of approximately $50 \%$ was reached after $24 \mathrm{~h}$ of water submersion with an amino-functional silicone comprised of 30 dimethyl siloxane units.

Silicones can therefore be used to hydrophobize wood; however, they are not easy to solubilize in water because of their strong water repellence. Real solutions can only be made by using high proportions of organic solvents in the solution which restricts the application in conventional impregnation plants. If emulsions are used, costs of emulsifiers have to be considered. In addition, the emulsifier will stay in the wood after impregnation and offset hydrophobation of the material by silicone. The micro-emulsions used by Hager (1995) and Lukowsky et al. (1997) solved this problem by using silanes and functionalized polysiloxanes as emulsifier or co-emulsifier, respectively. These emulsions, however, are not stable and a short solution stability of only approximately $24 \mathrm{~h}$ is obtained. This makes the use of these formulations not viable in impregnation plants (Lukowsky et al. 1997). Another possibility is the impregnation of solid wood with silicone using supercritical $\mathrm{CO}_{2}$ as solvent (Eastman et al. 2009).

The acetylation procedure with acetic anhydride offers the opportunity to solve silicones directly in the acetylation reagent to impregnate wood without further treatment steps. Acetoxysilanes can acetylate hydroxyl groups via transesterification and releasing silanol compounds as leaving group; release of acetic acid from the silane is therefore omitted.

\section{Materials and methods}

\section{Organo-silicon compounds}

Ethyltriacetoxysilane (TAS) was used as silicon-based acetylation chemical. A short-chained silicone (Si 200 TP 3031), containing 70-100 \% of $\alpha$ - $\omega$-functional polydimethylsiloxanediol with a mean of 6 dimethylsiloxane units (D6) and 0-30\% 
of octamethylcyclotetrasiloxane was used as a siloxane backbone, which can easily be combined with ethyltriacetoxysilane. The silicone oils M5 and M100 are nonfunctional polydimethylsiloxanes (PDMS). M5 has a mean chain length of D6-7 and M100 of D80. Amino D9 and Amino D28 are $\alpha-\omega$-functional diaminopolydimethylsiloxanes with a chain length of D9 and D28. All organo-silicon-compounds were supplied by Momentive Performance Materials GmbH (Leverkusen, Germany).

\section{Wood samples}

Pine sapwood (Pinus sylvestris L.) blocks (defined as ASE specimens) measuring $20 \times 20 \times 10 \mathrm{~mm}^{3}(r \times t \times l)$ were used to determine weight percent gain (WPG), cell wall bulking, anti-shrink efficiency (ASE) and water uptake. Blocks of beech wood (Fagus sylvatica L.) and pine sapwood (P. sylvestris L.) according to EN 113 (1996) were used for basidiomycete testing. Pine sapwood (P. sylvestris L.) stakes measuring $10 \times 10 \times 180 \mathrm{~mm}^{3}(r \times t \times l)$ were used to determine bending strength and those measuring $10 \times 10 \times 150 \mathrm{~mm}^{3}(r \times t \times l)$ to determine impact bending strength. Pine sapwood had an average density of $0.51 \mathrm{~g} \mathrm{~cm}^{-3}$, while the beech wood showed a density of $0.68 \mathrm{~g} \mathrm{~cm}^{-3}$.

Acetylation of wood with ethyltriacetoxysilane

Acetylation with ethyltriacetoxysilane (TAS) was carried out with pure TAS and in a mixture with acetic acid serving as a solvent and swelling agent for wood (Mantanis et al. 1994). The mixture consisted of $30 \%$ TAS mixed with $70 \%$ acetic acid statically dried over molecular sieves (4 ̊).

Acetylation was performed with and without catalyst. The reaction of pure TAS was catalyzed with $0.25 \% \mathrm{H}_{2} \mathrm{SO}_{4}$ (w/w of TAS), while the following catalysts were used in the mixture of $30 \%$ TAS with $70 \%$ acetic acid: $\mathrm{MgCl}_{2}(0.8 \% \mathrm{w} / \mathrm{w})$, potassium acetate $(\mathrm{KAc})$, triethylamine $(1 \% \mathrm{w} / \mathrm{w})$ and $\mathrm{H}_{2} \mathrm{SO}_{4}(0.07 \% \mathrm{w} / \mathrm{w})$. To apply KAc, the wood specimens were vacuum impregnated with $10 \%(\mathrm{w} / \mathrm{w})$ aqueous solution according to EN 113 and dried prior to the acetylation process at $103{ }^{\circ} \mathrm{C}$ (Obataya and Minato 2008). The other catalysts were directly mixed into the treatment solution.

After impregnation with the acetylation reagent (according to EN 113), the specimens were heated in the solution to $120{ }^{\circ} \mathrm{C}$ for $5 \mathrm{~h}$, while protected against moisture by a $\mathrm{CaCl}_{2}$ tube. After the reaction, the specimens were extracted in a soxhlet extractor with acetic acid for $6 \mathrm{~h}$ under exclusion of moisture by $\mathrm{CaCl}_{2}$ and subsequently with ethanol for $6 \mathrm{~h}$ to remove acetic acid. The acetylation reaction was assessed by measuring WPG, cell wall bulking and recording IR spectra.

Preparation of an acetoxy-functional polydimethylsiloxane

TAS was brought into a round-bottomed flask equipped with a reflux condenser and a dropping funnel, and Si 200 was added drop-wise until a ratio of $2 \mathrm{~mol}$ of TAS to $1 \mathrm{~mol} \mathrm{Si} 200$ was reached. During the addition, the temperature rose from 
approximately $20-38{ }^{\circ} \mathrm{C}$. After the addition, the product was confirmed by ${ }^{1} \mathrm{H}$ NMR spectroscopy in $\mathrm{CDCl}_{3}$ on a $400 \mathrm{MHz}$ spectrometer Bruker Avance 400 (Bruker, Bremen, Germany). A NMR diffusion experiment (DOSY) was applied to distinguish between ethyl groups $(0.96-1.14 \mathrm{ppm})$ attached to a silane [diffusion coefficient from $10^{-8.83} \mathrm{~m}^{2} \mathrm{~s}^{-1}$ (monomer) to $10^{-8.96} \mathrm{~m}^{2} \mathrm{~s}^{-1}$ (dimer and trimer)] and attached to a polysiloxane backbone (diffusion coefficient from $10^{-9.09}$ to $10^{-9.17} \mathrm{~m}^{2} \mathrm{~s}^{-1}$ ). After the reaction, no acetyl groups were left which were only attached to a silane. The structure of the product is depicted in Fig. 1.

Acetylation of wood in the presence of organo-silicon compounds

Impregnation of all wood specimens was done according to EN 113 (1996). The specimens were left in the solution and heated to $120{ }^{\circ} \mathrm{C}$ for $5 \mathrm{~h}$. After the reaction, the samples were dropped into deionized water to quench the reaction. They were left in water for 2 days with a water change after 1 day. Subsequently, the specimens were dried at room temperature for 2 days and finally dried at $103{ }^{\circ} \mathrm{C}$ for $24 \mathrm{~h}$. Eight ASE specimens at a time were treated with a solution of acetic anhydride (AA) and the following organo-silicon compounds:

1. $1 \%$ acetoxy-functional silane (1st educt of No. 3 ).

2. $1 \%$ Si 200 (2nd educt of No. 3).

3. $1 \%$ acetoxy-functional siloxane (product of No. 1 and 2).

4. $1 \% \mathrm{M} 5$.

5. $1 \% \mathrm{M} 100$.

6. $1 \%$ Amino D9.

7. $1 \%$ Amino D28.

In another approach, the acetoxy-functional siloxane (No. 3) was mixed with AA in various ratios $(1,3,6,10$ and $20 \%)$. These solutions were used to impregnate 16 ASE specimens at a time and to determine WPG, cell wall bulking, water uptake and acetyl content.WPG and cell wall bulking were calculated according to Xiao et al. (2010).

\section{Infrared spectroscopy}

Fourier-transform infrared (FT-IR) spectra were recorded of the cross-sections of the specimens by means of the attenuated total reflection (ATR) technique (DuraSamplIRII, SensIR Technologies, Warrington, UK), using a Vektor 22 spectrophotometer (Bruker, Bremen, Germany) (32 scans, $4 \mathrm{~cm}^{-1}$ resolution). Background spectra were collected with the empty ATR unit. Three spectra of each
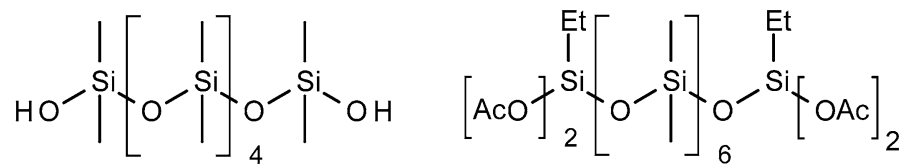

Fig. 1 Mean structure of Si200 (left) and idealized product (right) 
specimen were normalized to an absorption of 2 absorption units at $1,505 \mathrm{~cm}^{-1}$ (aromatic stretch vibration of lignin), baseline corrected using the rubber band method in the OPUS software (64 points, Bruker, Bremen, Germany) and subsequently averaged.

\section{Water uptake test}

Eight ASE specimens per treatment were submerged in approximately $300 \mathrm{ml}$ water and weighted after 2, 4, 6 and $24 \mathrm{~h}$ of submersion. Water uptake and water repellent effectiveness (WRE) were calculated according to Donath et al. (2006).

\section{Determination of the acetyl content}

Eight ASE specimens were milled in a centrifugal mill (Retsch ZM100, Retsch, Germany) using a $0.5 \mathrm{~mm}$ sieve; the milled material was soaked in water and dried subsequently at $103{ }^{\circ} \mathrm{C}$ to remove acetic acid. Approximately $0.5 \mathrm{~g}$ of each material was weighted into a flat-bottomed flask and $10 \mathrm{ml}$ of $75 \%(\mathrm{v} / \mathrm{v})$ ethanol-water mixture was added. This mixture was heated under agitation to $50{ }^{\circ} \mathrm{C}$ for $30 \mathrm{~min}$. $\mathrm{NaOH}\left(25 \mathrm{ml}, 0.5 \mathrm{~mol} \mathrm{l}^{-1}\right)$ was added and the flasks were kept at $50{ }^{\circ} \mathrm{C}$ for $30 \mathrm{~min}$. To neutralize the mixture $25 \mathrm{ml} \mathrm{H}_{2} \mathrm{SO}_{4}\left(0.25 \mathrm{~mol} \mathrm{l}^{-1}\right)$ was added, the mixture was filtered and diluted with water to $250 \mathrm{ml}$.

The acetic acid content was determined with an HPLC equipped with an RIdetector (Waters 1525 pump, Waters $717^{\text {plus }}$ auto sampler, Waters 2414 RI-detector, Waters Corporation, Milford, MA, USA) using $0.005 \mathrm{M} \mathrm{H}_{2} \mathrm{SO}_{4}$ as solvent. The acetyl content was related to the weight of the specimen tested.

\section{Fungal decay test}

Resistance to basidiomycetes was assessed according to EN 113 (1996). Twenty pine sapwood specimens and 20 beech wood samples were impregnated either with acetic anhydride or with a mixture of acetoxy-functional siloxane $(20 \% \mathrm{w} / \mathrm{w})$ in acetic anhydride as described above. Afterward the specimens were heated in the solution to $120{ }^{\circ} \mathrm{C}$. Ten specimens of each kind were heated for $1 \mathrm{~h}$ and the other ten for $2 \mathrm{~h}$. After the reaction time, the specimens were submersed into cold water and kept submerged to perform leaching according to EN 84 (1997).

After careful oven-drying $\left(103{ }^{\circ} \mathrm{C}\right)$, weighing and conditioning $\left(20{ }^{\circ} \mathrm{C}, 65 \%\right.$ $\mathrm{RH}$ ), the specimens were incubated in kolle flasks with Coniophora puteana (BAM Ebw. 15) (pine sapwood) and Trametes versicolor (CTB 863 A) (beech wood) for 16 weeks. Two treated and two untreated control specimens, respectively, were incubated in one kolle flask according to CEN/TS 15083-1 (2004). After incubation, the mass loss was determined.

Bending and impact bending test

Bending strength and modulus of elasticity were assessed according to DIN 52186 (1978) with 9 replicates per treatment (Zwick/Z010, Zwick, Ulm Germany) and 
impact bending strength according to DIN 52189 (1981) with 12 replicates per treatment (Resil Impactor, Ceast, Turin, Italy). The specimens were acetylated with pure acetic anhydride (AA) and with mixtures of 1,5 and $10 \%$ acetoxy-functional polysiloxane and AA for $6 \mathrm{~h}$ in the same way as described above. The reaction was quenched with water, and the WPG of the dry specimens was determined after 2 days of water leaching. Prior to testing, the specimens were conditioned at $20{ }^{\circ} \mathrm{C}$ and $65 \% \mathrm{RH}$, and the equilibrium moisture content (EMC) was determined.

\section{Results and discussion}

Acetylation with ethyltriacetoxysilane (TAS)

Ethyltriacetoxysilane (TAS) can acetylate hydroxyl groups of wood via a transesterification reaction (Fig. 2). The resulting silanol groups produced from TAS can form siloxane groups upon dehydration and further generate a threedimensional silicon dioxide network within the wood structure. In contrast to acetylation with acetic anhydride, this reaction principally does not release any acetic acid and the generated polysiloxane might further enhance the properties of the products.

The reaction of pure ethyltriacetoxysilane (TAS) with wood resulted only in negligible WPG and cell wall bulking. Soaking of ASE specimens in pure TAS revealed slight shrinkage $(0.04 \%$ of the cross-sectional area) after impregnation rather than swelling. This indicates that TAS does not penetrate into the cell wall and is therefore not able to react with the cell wall matrix. The minor shrinkage was probably due to complete dehydration of the specimens by the silane, which reacts with water upon formation of silanol groups and acetic acid.

The addition of $\mathrm{H}_{2} \mathrm{SO}_{4}$ as a catalyst in TAS resulted in mean bulking of $1.3 \%$ and WPG of $7.8 \%$. It therefore seems possible to acetylate wood without a solvent by using pure TAS, but effective acetylation in a reasonable time is not achievable. Swelling of the cell wall is indispensable (Rowell 1983) to acetylate wood more successfully with TAS. A $30 \%$ solution of TAS in acetic acid caused swelling of the wood to an extent comparable to water and allowed the silane to enter the cell wall. In absence of a catalyst, no reaction of TAS with wood took place. Triethylamine and $\mathrm{H}_{2} \mathrm{SO}_{4}$ induced noteworthy WPG and bulking, while magnesium
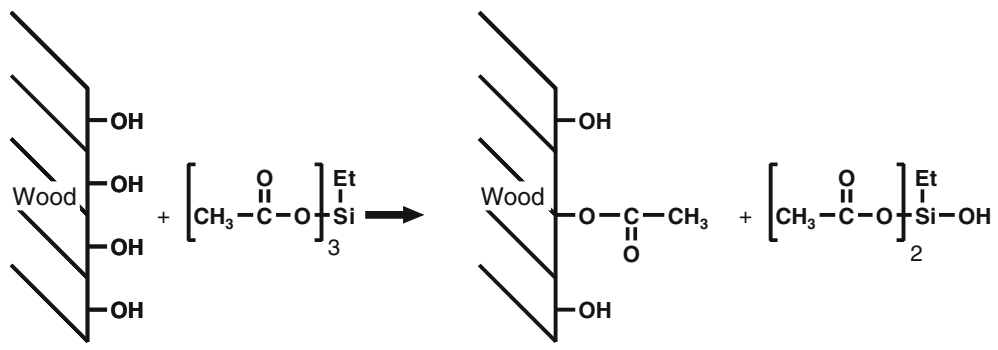

Fig. 2 Reaction of wood with ethyltriacetoxysilane 
chloride and potassium acetate did not. Using triethylamine, the treatment resulted in a WPG of $3.3 \%$ and a bulking of $2.7 \%$; acetylation in the presence of $\mathrm{H}_{2} \mathrm{SO}_{4}$ led to a WPG of $14 \%$ and a bulking of $7 \%$ after $5 \mathrm{~h}$ of reaction time.

Infrared spectra revealed successful acetylation (Fig. 3). Absorption at $1,740 \mathrm{~cm}^{-1}$ ( $\mathrm{C}=\mathrm{O}$ stretching), $1,370 \mathrm{~cm}^{-1}$ (methyl vibration), $1,220 \mathrm{~cm}^{-1}$ (C-O stretching) and $897 \mathrm{~cm}^{-1}$ (methyl vibration) were strongly increased in the specimens acetylated with a mixture of TAS, acetic acid and $\mathrm{H}_{2} \mathrm{SO}_{4}$ as compared to the control. The peak at approximately $1,000 \mathrm{~cm}^{-1}$ (assigned to $\mathrm{C}-\mathrm{O}$ stretch vibration in polysaccharides) probably increased due to the presence of siliconoxygen bonds, which were formed despite of the extraction after treatment. Acetylation catalyzed with triethylamine resulted in much smaller WPG and cell wall bulking. A slightly increased absorption appeared at 1,740 and $1,220 \mathrm{~cm}^{-1}$ assigned to acetyl groups. Other absorption peaks did not differ from those of the control.

Bulking, WPG and water uptake after modification with various combinations of polysiloxane and acetic anhydride

The two non-functional polydimethylsiloxanes (PDMS) (M5 and M100), especially M100, did not dissolve well in AA. The amino-functional siloxanes easily dissolved only in warm AA, while the other three materials, TAS, Si200 and acetoxyfunctional siloxane, easily dissolved in cold AA. WPG and bulking of all treated specimens were very similar and did not differ from the solely acetylated specimens (Fig. 4).

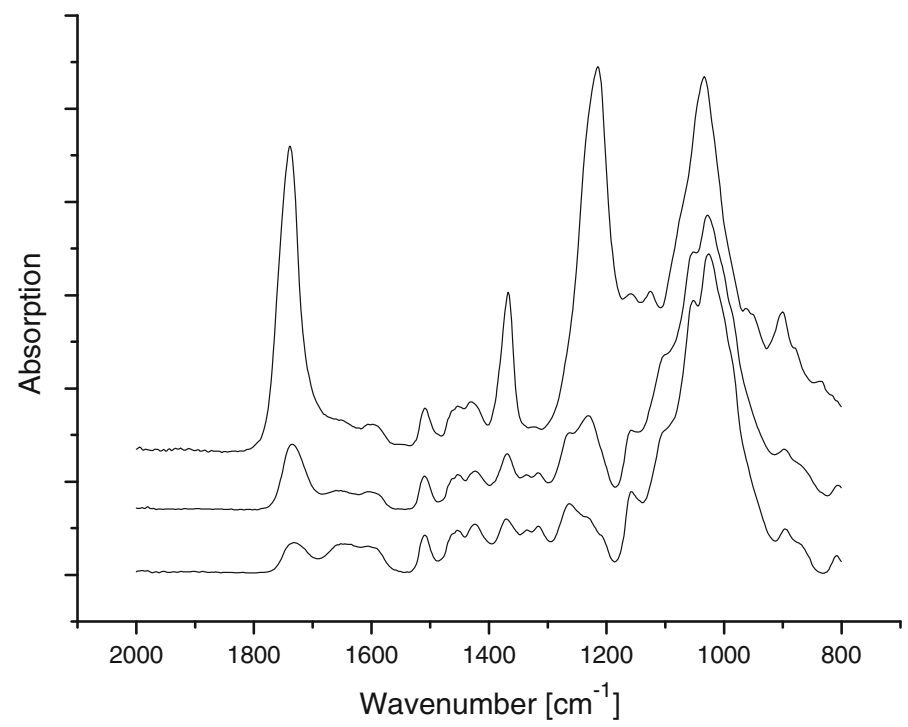

Fig. 3 FTIR spectra of control (bottom), triethylamine catalyzed acetylation (middle) and $\mathrm{H}_{2} \mathrm{SO}_{4}$ catalyzed acetylation (top) 


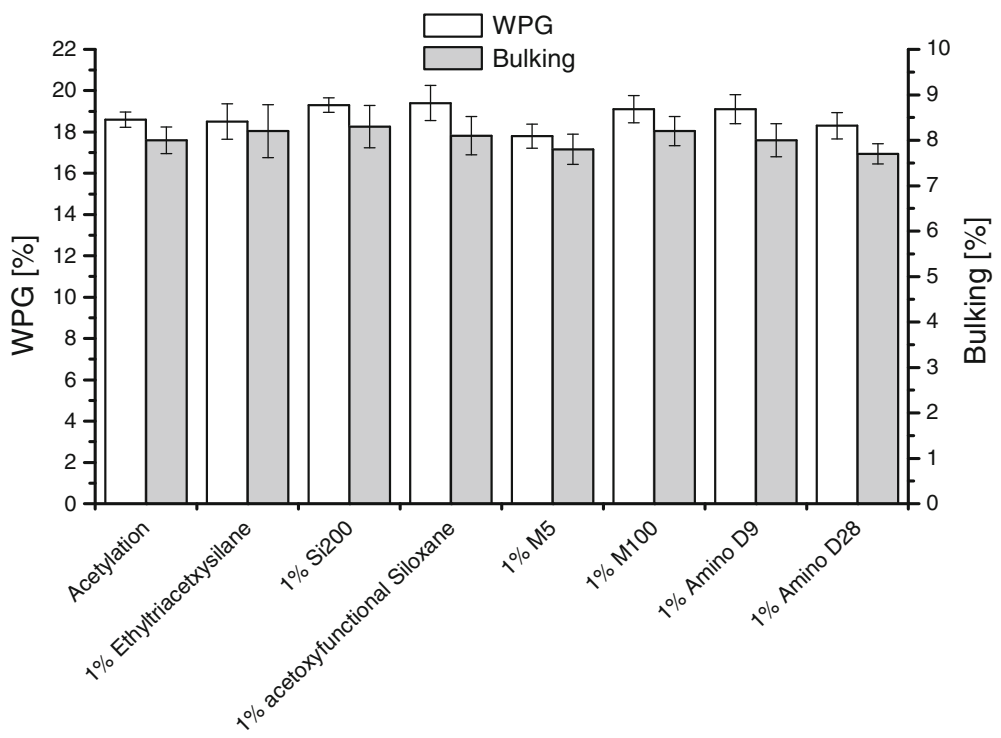

Fig. 4 WPG and bulking values of wood treated with various siloxanes in combination with acetic anhydride, mean values and standard deviations

The non-functionalized siloxane (M5 and M100) as well as the amino-functional siloxane (D9 and D28) reduced water uptake only to a minor extent compared to the acetylated control. The acetoxy-functional siloxane, however, clearly reduced the water uptake to a greater extent than all other materials (Fig. 5a) with a WRE of $33 \%$ related to acetylated wood. In subsequent water submersion tests, the two educts TAS, Si200 and their product, the acetoxy-functional siloxane, exhibited major changes. In the second test, TAS and acetoxy-functional siloxane did not differ, but in the third (not shown) and fourth tests the acetoxy-functional siloxane again reduced the water uptake more than both of its educts (Fig. 5b) with a WRE of $49 \%$ as compared to the acetylated controls.

In general, water uptake of wood can be reduced through (a) blocking of penetration pathways for capillary water uptake and (b) altering of the surface properties of the wood in a way that hinders water uptake. The gradual decrease in water uptake from the first to the fourth experiment observed with the specimens treated with acetoxy-functional PDMS, TAS and Si200 suggests an alteration of the wood surface rather than pathway blocking. The reason for the reduction in water uptake in subsequent tests may be the increasing orientation of the siloxane chain due to several steps of wetting and high-temperature drying. Kim (2001) also found a strong increase in hydrophobation of textile materials after treatment with aminofunctional siloxanes when the drying temperature was raised. The heat treatment is expected to increase the orientation of the siloxane in a way that the hydrophilic parts of the chain are facing toward the wood cell wall and the hydrophobic parts orient toward the lumens. This process is called activation (Kim 2001). In nonfunctional siloxane, the $\mathrm{Si}-\mathrm{O}-$ backbone will mostly face toward the wood matrix 

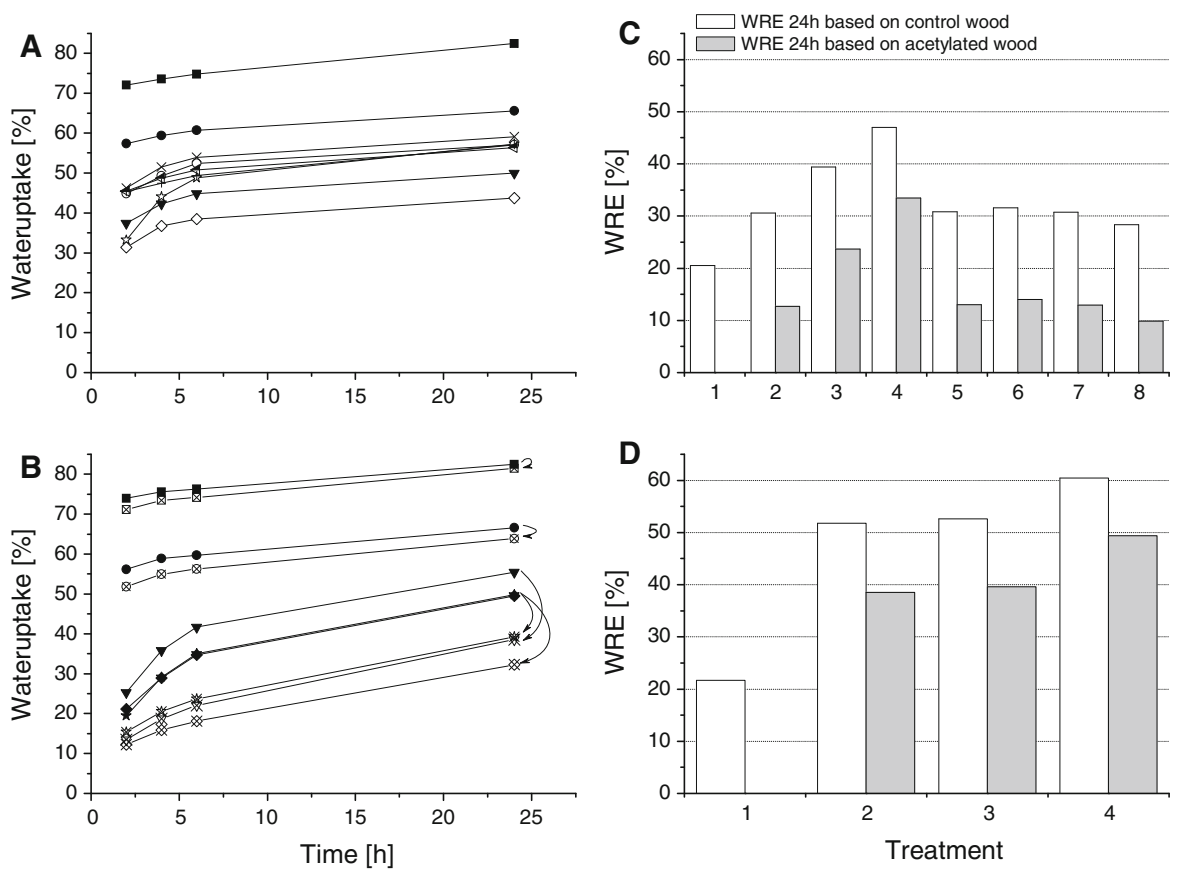

- Control; - Acetylation (1); - Acetylation + 1\% Ethyltriacetxysilane (2);

$\checkmark$ Acetylation $+1 \%$ acetoxyfunctional Siloxane (4); - - Acetylation $+1 \%$ M5 (5)

Acetylation + 1\% Si200 (3)

Acetylation $+1 \%$ Amino D9 (7); $\quad \times$ Acetylation + 1\% Amino D28 (8)

Fig. 5 Water uptake of various siloxane-treated specimens. a First submersion test, $\mathbf{b}$ second and fourth submersion of control and specimens with treatment no. 1, 2, 3, 4, c WRE in first submersion test, $\mathbf{d}$ WRE in fourth submersion test

while the hydrophobic methyl groups are directed outwards (Kim 2001; Noll 1968). In contrast to previous studies (Ghosh 2009), the amino-functional siloxane did not cause strong hydrophobation. The previously found strong reduction in water uptake by amino-functional siloxane (which is a relatively hydrophilic material) was suggested to be due to pathway blocking which prevented capillary penetration of water (Ghosh 2009; Weigenand et al. 2007). In this study, the interaction of amino groups with the wood surface (as described for textiles by Bereck et al. 2001) might be weakened because of the introduction of acetyl groups. These might interfere with the interactions which are normally formed with hydroxyl groups. In addition, acetylation of amino groups can occur in the presence of acetic anhydride (Naik et al. 2004). The following studies focused on acetoxy-functional siloxane, because best results were obtained with this material.

WPG, bulking and acetyl content after modification with combinations of acetoxy-functional siloxane and acetic anhydride

The WPG increased linearly with increasing content of the acetoxy-functional siloxane in AA (Fig. 6). Cell wall bulking increased slightly but significantly with 
increasing siloxane content in AA (Fig. 6). Analysis of variance gave a $p$ value of $<0.0001$ indicating high significance. Bulking was significantly different from the control when 6, 10 and $20 \%$ siloxane were added to AA.

Bulking of acetylated wood is caused by acetyl groups introduced into the cell wall (Rowell 1983). Therefore, the acetyl content should increase with increasing bulking. Determination of the acetyl content, however, revealed that higher bulking was not attributable to a higher degree of acetylation in case of higher PDMS content in the mixture (Fig. 7). Obviously, the siloxane was able to penetrate the wood cell wall to a certain extent and to increase bulking. Ghosh (2009) treated wood with water solvent-based solutions of siloxanes with similar chain length as used here and found considerable bulking. This suggests that siloxanes are able to penetrate the cell wall despite their high molecular mass. While the ASE of the acetylated specimens was $48.4 \%$, that of the $20 \%$ mixture amounted to $48.7 \%$ and hence did not significantly increase. The reason for this unchanged ASE was a slight increase in maximum swelling in water as compared to the untreated control and the solely acetylated specimens which offset the greater bulking.

\section{Water uptake}

The water uptake test revealed a strong hydrophobation of the wood treated with acetoxy-functional siloxane. The first submersion test still indicated differences between $1 \%$ on the one hand and 3, 6, 10 and $20 \%$ on the other hand (Fig. 8a, c). The specimens were soaked in water and dried two times at $103{ }^{\circ} \mathrm{C}$ prior to a second submersion. In this second test, the differences between the treatments nearly disappeared (Fig. 8b); the WRE ranged from $62 \%$ (1\% siloxane) to $71 \%$ (6\% siloxane) without showing a clear trend (Fig. 8d). Addition of $1 \%$ acetoxy-

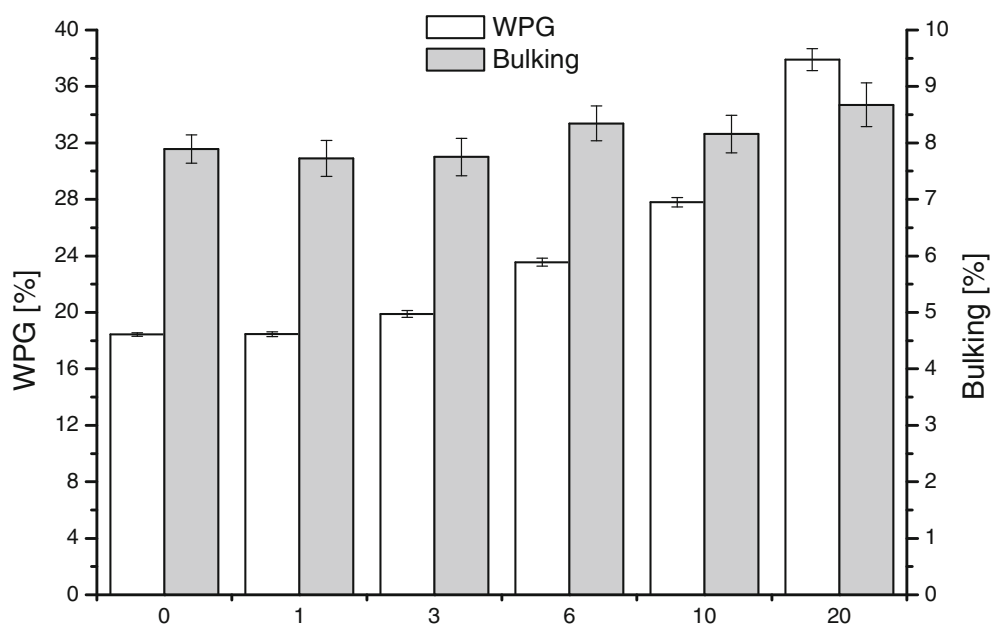

Proportion of acetoxyfunctional Siloxane to acetic anhydride [\%]

Fig. 6 WPG and bulking induced through treatment with different acetic anhydride/siloxane mixtures, mean values and standard deviations 


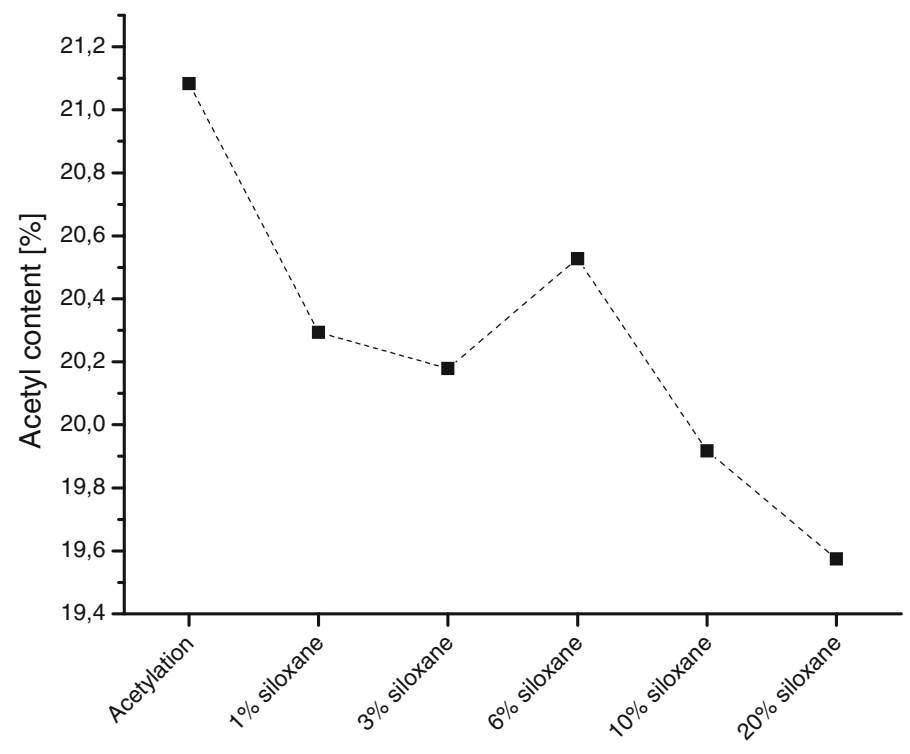

Fig. 7 Acetyl content of various acetanhydride-siloxane mixtures

functional siloxane therefore appeared to be sufficient to decrease the water uptake to a maximum extent. This result indicates that pathway blocking is not the major reason for increased hydrophobation, because it can hardly explain increasing hydrophobation in subsequent water uptake tests. Furthermore, an increased concentration of the siloxane should lead to increased pathway blocking and thus enhance hydrophobation but this was not the case. It is therefore assumed that water uptake is reduced due to alteration of the (inner) wood surface; addition of $1 \%$ siloxane seems to be sufficient for covering the inner surface of the wood. For maximum reduction in water uptake at $1 \%$ siloxane concentration, however, a more intense activation process is needed, which encompasses extended heating to enhance the orientation of the siloxane chains.

\section{Fungal decay}

In order to study the influence of the acetoxy-functional siloxane, a low degree of acetylation was established which still allowed fungal decay. The WPG of the specimens increased by addition of acetoxy-functional siloxane to AA, but the mass loss after fungal incubation was nearly the same (Table 1). A $t$ test performed, respectively, on the pairs "acetylation $(x \mathrm{~h})$ and acetylation $+20 \%$ siloxane $(x \mathrm{~h})$ " only revealed a different result between acetylation for $2 \mathrm{~h}$ in beech wood and acetylation with $20 \%$ siloxane in beech wood for $2 \mathrm{~h}$ (Table 1). Thus, the resistance to fungal decay is exclusively attributable to the acetyl content and not to the presence of siloxane chains. The significantly higher mass loss in the case of beech $(2 \mathrm{~h}$ acetylation) can be explained by a lower acetyl content which resulted 

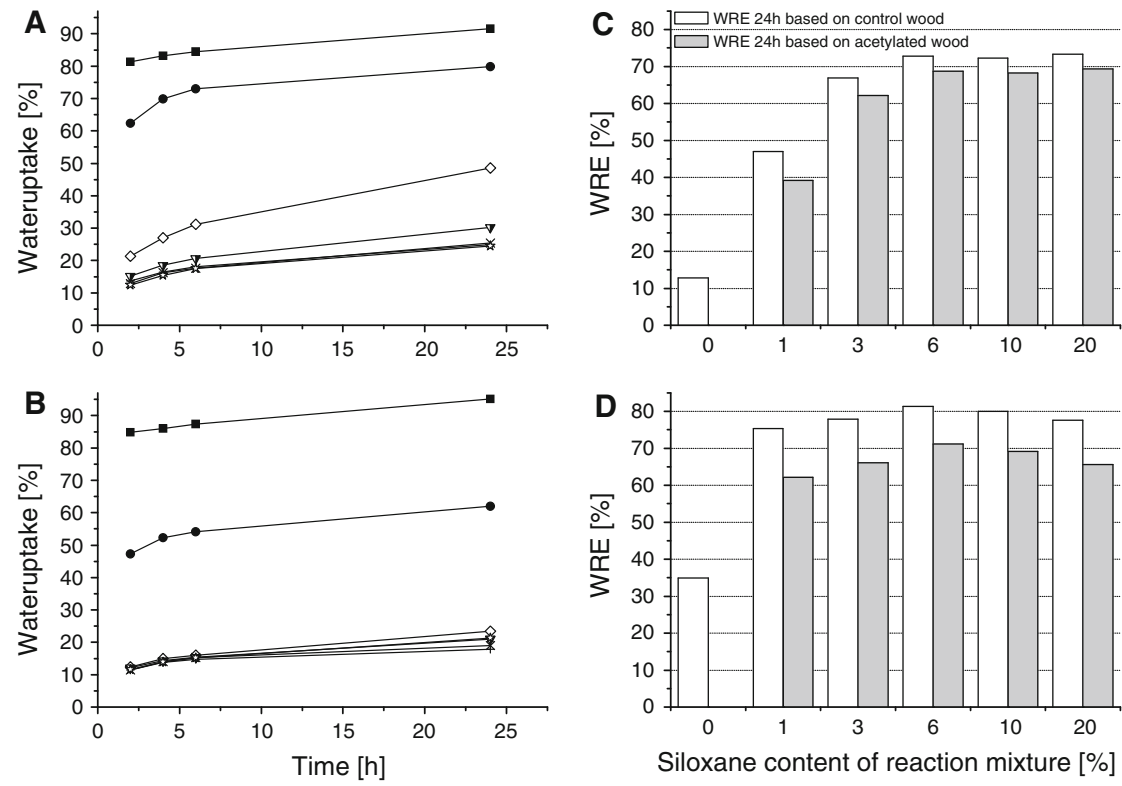

Siloxane content of reaction mixture [\%]

- Control; - - Acetylation; $\checkmark$ Acetylation $+1 \%$ acetoxyfunctional siloxane; $-\nabla-$ Acetylation $+3 \%$ acetoxyfunctional siloxane Acetylation $+6 \%$ acetoxyfunctional siloxane; $\rightarrow$ Acetylation $+10 \%$ acetoxyfunctional siloxane;

- Acetylation $+20 \%$ acetoxyfunctional siloxane

Fig. 8 Water uptake of acetylated wood in combination with different ratios of acetoxy-functional siloxane: a first submersion, b fourth submersion, c WRE in first submersion, d WRE in fourth submersion

from the high amount of siloxane in the treatment solution (see above for the decrease in acetyl content).

Micro-pore blocking was previously discussed as the main reason for fungal resistance imparted by chemical modifications such as acetylation (Hill et al. 2005). Blocking of cell wall pores can reduce the availability of water as well as the penetration of enzymes (Papadopoulos and Hill 2002). A threshold value of approximately $20 \%$ WPG was found to impart fungal resistance by acetylation,

Table 1 WPG and mass loss in a fungal decay test after 16-week incubation with $C$. puteana (pine) and T. versicolor (beech) (mean values and, in brackets, standard deviations)

\begin{tabular}{lcclcc}
\hline & \multicolumn{2}{c}{ Pine sapwood } & & \multicolumn{2}{l}{ Beech wood } \\
& WPG (\%) & Mass loss (\%) & & WPG (\%) & Mass loss (\%) \\
\hline Control & - & $28.0(9.8)$ & & - & $25.2(1.9)$ \\
Acetylation 1 h & $0.5(0.1)$ & $33.0(3.1)$ & & $2.5(0.4)$ & $20.1(1.6)$ \\
Acetylation + siloxane 1 h & $8.6(0.8)$ & $35.5(4.1)$ & & $5.5(1.2)$ & $21.5(2.0)$ \\
Acetylation 2 h & $4.5(0.3)$ & $26.0(4.9)$ & & $10.2(0.2)$ & $\mathbf{1 1 . 5 ( 0 . 9 )}$ \\
Acetylation + siloxane 2 h & $12.5(0.4)$ & $29.7(10.4)$ & & $15.6(0.9)$ & $\mathbf{1 4 . 2 ( 1 . 5 )}$ \\
\hline
\end{tabular}

Bold values are significantly different from each other with $95 \%$ confidence 
which is accompanied with cell wall bulking of approximately $8 \%$ in case of Scots pine sapwood (experimental results by the authors). A reduction in fungal decay has been reported previously for various functionalized siloxanes. Ghosh et al. (2012) attributed the effectiveness of siloxane treatment against fungal decay to the penetration of the siloxanes into the cell wall and micro-pore blocking as well as interaction with the cell wall. Treatment with amino siloxanes-induced fungal resistance to wood when a bulking value of approximately $4 \%$ was reached (Ghosh 2009). Cell wall bulking of $4 \%$, however, cannot impart complete fungal resistance if the modification chemical is biologically inactive. It is therefore assumed that amino silicones used by Ghosh et al. (2012) exhibited a certain biological effectiveness in addition to micro-pore blocking. This effectiveness probably depends on the mobility of the siloxane chain, because higher effectiveness of the materials was found, when chain length decreased (Ghosh et al. 2012). In contrast to amino siloxanes used by Ghosh et al. (2012), acetoxy-functionalized siloxanes were applied in this study, which are able to undergo condensation and form a threedimensional network within the wood. In this network, the siloxane chains are immobilised which is also evident in a completely stable WPG after severe leaching (data not shown). This immobility and the lack of functionality are the reasons why the siloxanes do not affect the physiology of decay fungi and do not prevent fungal decay. Many studies have previously shown the biological inertness of siloxanes with longer chain length (Ackermann and Damrath 1989; Noll 1968).

\section{Mechanical properties}

Specimens treated with mixtures of AA and acetoxy-functional siloxane displayed a slightly greater maximum swelling in water than solely acetylated specimens. A similar result was found by Obataya et al. (2002), combining acetylation with a bulking treatment of glucose-pentaacetate. Greater swelling can be attributed to "solving" or weakening of lignin or to a distortion of the crystalline parts of cellulose. To investigate, if this has any effect on the mechanical properties, a bending test and an impact bending test were performed (Table 2).

Analysis of variance revealed that the bending strength and the modulus of elasticity did not exhibit any significant differences at a $5 \%$ confidence level. The impact bending strength of acetylated wood was significantly higher than that of the

Table 2 Results of mechanical tests (mean values and, in brackets, standard deviations)

\begin{tabular}{lllllc}
\hline & $\begin{array}{l}\text { Bending } \\
\text { strength } \\
\left(\mathrm{N} \mathrm{mm}^{-2}\right)\end{array}$ & $\begin{array}{l}\text { Modulus of } \\
\text { elasticity } \\
\left(\mathrm{N} \mathrm{mm}^{-2}\right)\end{array}$ & $\begin{array}{l}\text { Impact bending } \\
\text { strength } \\
\left(\mathrm{kJ} \mathrm{m}^{-2}\right)\end{array}$ & WPG (\%) & $\begin{array}{l}\text { Equilibrium moisture } \\
\text { content at 20 } \\
\mathrm{RH}(\%)\end{array}$ \\
\hline Control & $119(11)$ & $13,200(1,276)$ & $30,285(7,855)$ & - & $10.6(0.1)$ \\
Acetylation & $138(22)$ & $13,183(1,510)$ & $43,513(9,992)$ & $21.0(0.3)$ & $5.2(0.1)$ \\
$+1 \%$ Siloxane & $138(25)$ & $13,000(1,669)$ & $36,310(9,733)$ & $21.6(0.3)$ & $5.2(0.1)$ \\
$+5 \%$ Siloxane & $122(26)$ & $12,256(1,516)$ & $40,047(7,381)$ & $24.1(0.2)$ & $5.2(0.1)$ \\
$+10 \%$ Siloxane & $141(17)$ & $13,583(1,164)$ & $34,758(11,945)$ & $28.7(0.4)$ & $5.2(0.0)$ \\
\hline
\end{tabular}


control specimens with $95 \%$ confidence. There were, however, no differences between the solely acetylated wood and acetylated wood combined with siloxane.

\section{Conclusion}

Combining acetylation with polysiloxane treatment can enhance the water repellence of acetylated wood without any apparent drawbacks. ASE, mechanical properties and fungal resistance were not changed by the treatment. Small amounts of siloxane are sufficient to reduce water uptake to a great extent, because only the inner surfaces of the wood need to be covered by the siloxane. Fungal resistance of acetylated wood is solely brought about by the acetyl content; fungal resistance is not increased by introduction of acetoxy-functional siloxane probably because of the immobility of the condensed siloxane in the wood.

Acknowledgments The authors would like to acknowledge the contribution of Momentive GmbH, Leverkusen, Germany, for supplying the polysiloxanes and technical information.

Open Access This article is distributed under the terms of the Creative Commons Attribution License which permits any use, distribution, and reproduction in any medium, provided the original author(s) and the source are credited.

\section{References}

Ackermann J, Damrath V (1989) Chemie und Technologie der Silicone II. Herstellung und Verwendung von Siliconpolymeren. Chem unserer Zeit 23:86-99

Bereck A, Riegel D, Matzat A, Habereder P, Lautenschlager H (2001) Silicones in fibrous substrates: their mode of action. AATCC Rev 1:45-49

Brelid PL, Simonson R, Bergman O, Nilsson T (2000) Resistance of acetylated wood to biological degradation. Holz Roh Werkst 58:331-337

Chang ST, Chang HT (2001) Comparisons of the photostability of esterified wood. Polym Degrad Stab 71:261-266

DIN 52186 (1978) Testing of wood; bending test. Deutsches Institut für Normung e.V, Berlin

DIN 52189 (1981) Testing of wood; determination of impact bending strength. Deutsches Institut für Normung e.V, Berlin

DIN EN 113 (1996) Prüfverfahren zur Bestimmung der vorbeugenden Wirksamkeit gegen holzzerstörende Basidiomyceten. Deutsches Institut für Normung e.V, Berlin

DIN EN 84 (1997) Beschleunigte Alterung von behandeltem Holz vor biologischen Prüfungen. Deutsches Institut für Normung e.V, Berlin

Donath S, Militz H, Mai C (2006) Creating water-repellent effects on wood by treatment with silanes. Holzforschung 60:40-46

Eastman S, Lesser A, McCarthy $\mathrm{T}$ (2009) Supercritical $\mathrm{CO}_{2}$-assisted, silicone-modified wood for enhanced fire resistance. J Mater Sci 44:1275-1282

Ghosh SC (2009) Wood modification with functionalized polydimethylsiloxanes. Dissertation, Georg August University of Göttingen

Ghosh SC, Dyckmans J, Militz H, Mai C (2012) Effect of quat- and aminosilicones on fungal colonisation and decay of wood. Holzforschung 66(8):1009-1015

Hager R (1995) Waterborne silicones as wood preservatives. International Research Group on Wood Protection, IRG/WP 95-30062 Stockholm, Sweden

Hill CAS, Forster SC, Farahani MRM, Hale MDC, Ormondroyd GA, Williams GR (2005) An investigation of cell wall micropore blocking as a possible mechanism for the decay resistance of anhydride modified wood. Int Biodeterior Biodegradation 55:69-76 
Kim BT (2001) Grundlegende Untersuchungen zur Hydrophobierung von Textilien mit Polyorganosiloxanen. Dissertation, Faculty University of Wuppertal

Lukowsky D, Peek RD, Rapp AO (1997) Water-based silicones in wood. International Research Group on Wood Protection, IRG/Wp 97-30144 Stockholm, Sweden

Mantanis GI, Young RA, Rowell RM (1994) Swelling of wood.2. Swelling in organic liquids. Holzforschung 48:480-490

Mayer H (1998) Masonry protection with silanes, siloxanes and silicone resins. JOCCA—Surf Coat Int 81:89-93

Naik S, Bhattacharjya G, Talukdar B, Patel Bhisma K (2004) Chemoselective acylation of amines in aqueous media. Eur J Org Chem 2004:1254-1260

Noll W (1968) Chemie und Technologie der Silikone, 2nd edn. Verlag Chemie, Weinheim

Obataya E, Minato K (2008) Potassium acetate-catalyzed acetylation of wood: extraordinarily rapid acetylation at $120^{\circ} \mathrm{C}$. Wood Sci Technol 42:567-577

Obataya E, Masaki S, Bunichiro T (2002) Dimensional stability of wood acetylated with acetic anhydride solution of glucose pentaacetate. J Wood Sci 48:315-319

Papadopoulos AN, Hill CAS (2002) The biological effectiveness of wood modified with linear chain carboxylic acid anhydrides against Coniophora puteana. Holz Roh Werkst 60:329-332

prCEN/TS 15083-1 (2004) Durability of wood and wood based products-determination of the natural durability of solid wood against wood-destroying fungi-test methods part 1: basiodiomycetes. European committee for standardization, Brussels

Rowell RM (1983) Chemical modification of wood. Forest Prod Abstr 6:363-382

Stamm AJ (1964) Wood and cellulose science. The Ronald Press Company, New York

Weigenand O, Militz H, Tingaut P, Sebe G, de Jeso B, Mai C (2007) Penetration of amino-silicone microand macro-emulsions into Scots pine sapwood and the effect on water-related properties. Holzforschung 61:51-59

Xiao Z, Xie Y, Militz H, Mai C (2010) Effect of glutaraldehyde on water related properties of solid wood. Holzforschung 64:483-488 


\title{
Effect of amino- and carboxy-siloxane combinations on the resistance of pine (Pinus sylvestris L.) and beech (Fagus sylvativa L.) against fungal decay and blue stain
}

\begin{abstract}
Pine sapwood and beech wood were treated with water-based emulsions of polysiloxanes, which were amino- or carboxy-functional. Amino-functional siloxane had a chain length of 10 dimethylsiloxane units (D10), while carboxy-functional siloxane had a chain length of D10 or D46. The emulsions contained either polysiloxanes of one functionality or combinations of the two in ratios of 20:80 and 80:20. Even with a weight percent gain (WPG) of approx. 20\%, cell wall bulking of pine sapwood was low and led to negligible anti shrink efficiency (ASE). Water uptake rate in the first submersion cycle was lowest for pure carboxy siloxane. In the second and third submersion cycle, however, amino siloxane and mixtures of 80:20 with carboxy showed lower water uptake rates. Synergistic effects between the two materials, which reduced water uptake, were not found. Leaching of carboxy siloxane and mixtures containing $80 \%$ carboxy siloxane was high, fixation of carboxy siloxane was enhanced by combination with amino siloxane in a ratio of $80 \%$ amino and $20 \%$ carboxy siloxane. Mass loss in a fungal decay test after 16 weeks of incubation with Coniophora puteana and Trametes versicolor according to EN 113 (1996) and CEN TS 15083-1 (2004) was reduced by the treatments; the most effective material turned out to be pure carboxy siloxane. Synergistic effects were not found. Staining of wood due to attack by Aureobasidium pullulans was reduced by amino-functional siloxane, while carboxy-functional siloxane did not cause inhibition. Again there were no synergistic effects further enhancing the inhibition of blue stain.
\end{abstract}

\section{Introduction}

The search for alternative wood preservation is growing due to increasing restrictions for the use of conventional and toxic wood preservatives. It has been proved possible to protect wood from fungal decay through use of non-toxic chemicals simply by incorporating these into the cell wall and blocking the micro pores as well as decreasing the availability of water in the cell wall (Stamm, 1964). While some wood 
modifications such as the acetylation have undergone market introduction, research for other modification techniques are ongoing (Evans, 2003).

Organo-silicon compounds have previously been used to protect and modify wood (Donath et al., 2004; Donath et al., 2006a; Hill et al., 2004; Mai et al., 2003). The most important groups of organo-silicon compounds for the treatment of wood are silanes and polydimethylsiloxanes (silicones). Silicones are found in many industrial applications and are also widely used in construction to improve water repellence of masonry (Mayer, 1998). Water repellence of wood can also be enhanced by the treatment with silicones (Hager, 1995; Lukowsky et al., 1997). Weigenand et al. (2008) treated Scots pine sapwood with an emulsion of amino silicones of 300-400 dimethylsiloxane units (DMS) and found high decay resistance to white and brown rot fungi, when the silicones were applied in high concentrations. Penetration of silicones into the cell wall was found to be higher, when the silicones were formulated as a micro- instead of a macro-emulsion (Weigenand et al., 2007). These results demonstrate the possibility to achieve fungal decay resistance and dimensional stabilization by polysiloxane treatment. Gosh et al. (2008) found effectiveness against wood-decaying fungi with quarternary-ammonium-functional and especially amino-functional siloxane. Effectiveness against fungi and increasing dimensional stability of the treated wood was detected with decreasing chain length of the polysiloxanes down to a chain length of 7 DMS. Water uptake in a submersion test, on the other hand, increased with decreasing chain length, reflecting the rising importance of the functionality for very short polysiloxane chains (Ghosh, 2009). Quarternary-ammonium compounds are used in commercial wood preservatives and known for their effectiveness against fungal colonization of wood (Pernak et al., 1998; Worley and Sun, 1996; Zabielska-Matejuk et al., 2004). The more surprising was the finding of higher effectiveness of amino-functional siloxanes against wood decaying fungi and also against discoloration of treated wood (Ghosh et al., 2012).

Silanes bearing amino-functionality were found to be effective against wood decaying fungi (Donath et al. (2006a). Apparently, functionality of the silicone material plays a crucial role in the effectiveness of the material. Several mechanisms are considered for the high fungal resistance: a) hydrophobation of the wood substrate due to interaction of the silicone-functional group with the wood surface; b) micro-pore blocking in the wood cell wall with cell wall penetrating chemicals 
that may reduce water availability in the wood cell wall and hinder the intrusion of low molecular weight agents released by the fungi to degrade wood (Hill et al., 2005; Papadopoulos and Hill, 2002).

In a previous study we investigated polysiloxanes with different functionalities for the protection of wood against decaying fungi. Two functionalities have proved to be effective, amino-functionality and carboxy-functionality. However, the most effective material, which was carboxy-functional, easily leached out of the wood and caused high water uptake rates. The less effective amino siloxane on the other hand, showed good stability and reduced water uptake rates (Pries et al. 2012). In this study we investigated the combination of these two functionalities to improve water-related and fungal properties of the treated wood and avoid problems such as leaching by salt formation of the two functionalities. Amino- and carboxy-functional siloxanes were mixed in different ratios, formulated in water and wood was treated with these emulsions. Water uptake, dimensional stability, decay resistance and resistance to blue stain were assessed.

\section{Materials and Methods}

\section{Preparation of silicone emulsions}

Silicones with $\alpha-\omega$ carboxy- and amino-functionality were synthesized.

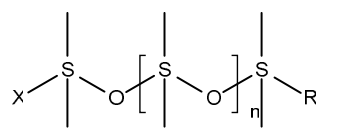

With $R=$

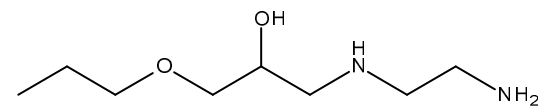

(a)<smiles>CCCOCC(O)COC(=O)CCC(=O)O</smiles>

(b)

Figure 1: Siloxane chain with a: aminofunctionality and b: carboxyfunctionality.

While amino-functional siloxane was only synthezised with a chain length of 10 dimethylsiloxane units (DMS), carboxy-functional material was synthesized with chain length of 10 and 46 DMS (D10, D46). The materials were mixed in different 
ratios and then formulated in water using acetic acid and three different emulsifiers. The formulations, all with a siloxane concentration of $20 \%$, are depicted in Table 1 .

Table 1: Siloxane formulations for the treatment of wood.

\begin{tabular}{|l|c|c|c|c|c|c|c|c|}
\hline Siloxane & $\begin{array}{c}\text { Amino } \\
\text { D10 }\end{array}$ & $\begin{array}{c}\text { Carboxy } \\
\text { D10 }\end{array}$ & $\begin{array}{c}\text { Carboxy } \\
\text { D46 }\end{array}$ & Water & $\begin{array}{c}\text { Acetic } \\
\text { acid }\end{array}$ & $\begin{array}{c}\text { Imbentin } \\
\text { T30 }\end{array}$ & $\begin{array}{c}\text { Imbentin } \\
\text { T60 }\end{array}$ & $\begin{array}{c}\text { Imbentin } \\
\text { T120 }\end{array}$ \\
\hline A & $20.0 \%$ & & & $64.0 \%$ & $6.0 \%$ & $5.0 \%$ & $3.0 \%$ & $2.0 \%$ \\
\hline B & $16.0 \%$ & $4.0 \%$ & & $64.0 \%$ & $6.0 \%$ & $5.0 \%$ & $3.0 \%$ & $2.0 \%$ \\
\hline C & $16.0 \%$ & & $4.0 \%$ & $64.0 \%$ & $6.0 \%$ & $5.0 \%$ & $3.0 \%$ & $2.0 \%$ \\
\hline D & $4 \%$ & $16.0 \%$ & & $64.6 \%$ & $4.0 \%$ & $2.0 \%$ & $6.4 \%$ & $3.0 \%$ \\
\hline E & $4.0 \%$ & & $16.0 \%$ & $64.0 \%$ & $2.0 \%$ & $2.0 \%$ & $8.0 \%$ & $4.0 \%$ \\
\hline F & & $20.0 \%$ & & $60.0 \%$ & & & $13.6 \%$ & $6.4 \%$ \\
\hline
\end{tabular}

Prior to treatment of wood, the formulations were diluted to the required concentrations with deionised water. Tests were conducted according to a three factor full factorial design with the factors: a: Ratio of amino to carboxy, b: Chain length of carboxy-siloxane and c: Concentration. Additionally, the two pure materials with chain length D10 were tested for comparison (Table 2).

Table 2: Experimental plan for siloxane treatment of wood.

\begin{tabular}{|l|c|c|c|}
\hline ExperimentlFactor & a & b & c \\
\hline $\mathbf{1}$ & Ratio 16:4 & Carboxy D10 & $5 \%$ Concentration \\
\hline $\mathbf{2}$ & Ratio $4: 16$ & Carboxy D10 & $5 \%$ Concentration \\
\hline $\mathbf{3}$ & Ratio $16: 4$ & Carboxy D46 & $5 \%$ Concentration \\
\hline $\mathbf{4}$ & Ratio 16:4 & Carboxy D10 & $10 \%$ Concentration \\
\hline $\mathbf{5}$ & Ratio 4:16 & Carboxy D46 & $5 \%$ Concentration \\
\hline $\mathbf{6}$ & Ratio $4: 16$ & Carboxy D10 & $10 \%$ Concentration \\
\hline $\mathbf{7}$ & Ratio 16:4 & Carboxy D46 & $10 \%$ Concentration \\
\hline $\mathbf{8}$ & Ratio $4: 16$ & Carboxy D46 & $10 \%$ Concentration \\
\hline $\mathbf{9}$ & - & Amino D10 & $5 \%$ Concentration \\
\hline $\mathbf{1 0}$ & - & Amino D10 & $10 \%$ Concentration \\
\hline $\mathbf{1 1}$ & - & Carboxy D10 & $5 \%$ Concentration \\
\hline $\mathbf{1 2}$ & - & Carboxy D10 & $10 \%$ Concentration \\
\hline
\end{tabular}




\section{Wood samples}

Scots pine (Pinus sylvestris L.) sapwood specimens $\left(25 \times 25 \times 10 \mathrm{~mm}^{3} \mathrm{R} \times \mathrm{T} \times \mathrm{L}\right.$, “ASE samples") were used to assess WPG, bulking and water uptake. Specimens according to EN 113 (1996) were cut from Scots pine (Pinus sylvestris L.) and European beech (Fagus sylvatica L.) to determine WPG and resistance to basidiomycetes. Scots pine (Pinus sylvestris L.) sapwood specimens $\left(5 \times 40 \times 40 \mathrm{~mm}^{3} ; \mathrm{R} \times \mathrm{T} \times \mathrm{L}\right.$, growth rings oriented at $45^{\circ}$ with the tangential face) were used to assess resistance to Aureobasidium pullulans.

\section{Silicone treatment}

Impregnation of wood was done in a vacuum-pressure process. The oven dried specimens were placed in plastic containers and weights were put on top to prevent floating. Afterwards the emulsions were poured into the containers. A vacuum of approx. 100 mbar was applied for $1 \mathrm{~h}$, then released and a pressure of $11 \mathrm{bar}$ applied for another $2 \mathrm{~h}$. The specimens were then weighed, pre-dried for one week at $20^{\circ} \mathrm{C} / 65 \% \mathrm{RH}$ and finally dried at $103^{\circ} \mathrm{C}$ for two days.

\section{Weight percent gain (WPG), cell wall bulking}

After drying, the weight of the specimens was determined to calculate the weight percent gain (WPG), theoretical WPG and cross-sectional bulking according to Pries et al. (2012).

\section{Water uptake}

ASE samples were immersed in approximately $300 \mathrm{ml}$ of water and the weight was determined after 2, 4, 6, and $24 \mathrm{~h}$. To establish maximum water uptake, a vacuum of approx. 40 mbar was applied for $1 \mathrm{~h}$ and afterwards the specimens were kept in the water for one more day. The water uptake was related to the oven dry weight of the specimens prior to the silicone treatment. Water repellent effectiveness (WRE) was calculated according to Donath et al. (2006b).

\section{Resistance to white and brown rot fungi}

The treated wood specimens were subjected to accelerated ageing according to EN 84 (1997), dried (to determine leaching) and conditioned at $20^{\circ} \mathrm{C} / 65 \% \mathrm{RH}$ until 
they reached equilibrium moisture content. They were sterilized at $121^{\circ} \mathrm{C}$ for $20 \mathrm{~min}$ and inoculated on 4\% malt and 1.5\% agar in kolle flasks according to EN 113 (1996). Two treated and accordingly two untreated specimens were inoculated together in one flask as described in the standard CEN-TS 15083.1 (2004). Ten replicates were used per treatment. Treated and untreated specimens of Scots pine (P. sylvestris) were tested with C.puteana (CTB 863A). Treated and untreated specimens of European beech ( $F$. sylvatica) were tested with C.puteana and T. versicolor (BAM Ebw. 15).

\section{Blue stain testing}

Blue stain specimens were treated with siloxane emulsions as described above, subjected to accelerated ageing according to EN 84 (1997), dried at $103^{\circ} \mathrm{C}$ and subsequently conditioned at $20^{\circ} \mathrm{C} / 65 \% \mathrm{RH}$. They were sterilized at $121^{\circ} \mathrm{C}$ for $20 \mathrm{~min}$ and then dipped in a spore suspension of Aureobasidium pullulans (de Barry). Afterwards the samples were placed in plastic containers on stainless steel sample holders over $120 \mathrm{ml}$ sterilized vermiculite and $45 \mathrm{ml}$ of water inoculated with $15 \mathrm{ml}$ spore suspension. Ten untreated samples of the same dimensions were used as controls. Two samples from each treatment were placed in one plastic container; 10 replicates were used per treatment. The inoculated samples were incubated for 6 weeks in a climate chamber at $22^{\circ} \mathrm{C} / 70 \% \mathrm{RH}$. The blue stained area was analysed using an Epson Expression 10000XL scanner (Seiko Epson Corp., Nagano-Ken, Japan) and GIMP image processing software (GNU General Public Licences). For this analysis the front and reverse side were scanned and converted to black and white pictures by adjusting a threshold value in a way that the stained areas were converted to black and the unstained areas to white. This way it was possible to determine the percentage of the surface that was stained by the fungus.

\section{Results and discussion}

\section{WPG and Bulking}

WPG of the specimens after treatment exceeded the theoretical WPG. This was due to the emulsifier content, which contributes to the WPG (Figure 2). Leaching of the samples according to EN 84 (1997) removed the water soluble emulsifiers and 
probably some siloxane. WPG of the samples after leaching was close to the theoretical WPG.
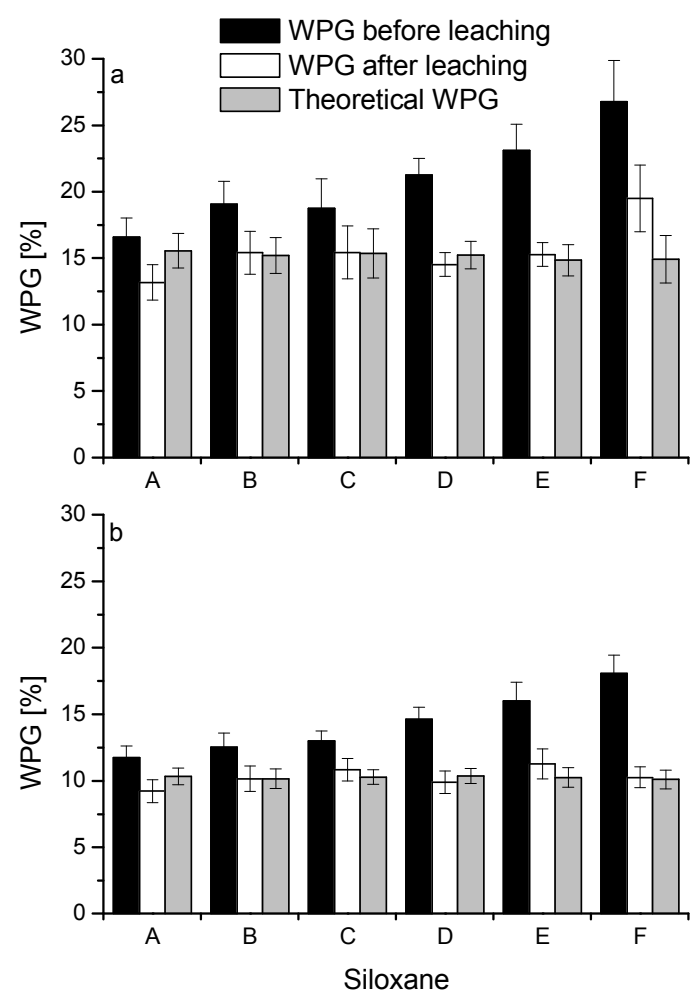

Figure 2: Weight percent gain (WPG) of EN 113 specimens, a: pine sapwood (Pinus sylvestris L.) and b: beech wood (Fagus sylvatica $L$.) treated with $10 \%$ emulsions of various combinations of amino- and carboxy-functional siloxanes.

ASE samples showed a similar picture after treatment (Figure 3a). After three water uptake and leaching cycles, WPG especially of the wood treated with the materials $\mathrm{D}, \mathrm{E}, \mathrm{F}$ was strongly reduced. The leaching in ASE samples was much more severe compared to EN 113 samples due to vast cross sectional-area to volume ratio. Pure carboxy siloxane and also material D showed the lowest leaching stability, apparently the 20:80 mixture of amino-carboxy siloxane did not improve fixation of the material. Leaching was a little lower when the chain length of carboxy was longer (material E), but it showed in general the same picture. Amino-functional siloxane, on the other hand, turned out to be much more stable against leaching. Pries et al. (2012) studied treatment of wood with different functional siloxanes and also found good stability of amino-functional siloxane and high leaching of carboxyfunctional siloxane. Ghosh (2009) treated wood with amino siloxanes and explained 
fixation of amino siloxane with cationic properties of the functional group as well as with possible covalent bond formation of primary amino groups with the polysaccharides in wood. While amino groups brought into wood are expected to be positively charged, carboxy groups are expected to be either negatively or uncharged. The cell wall, on the other hand, contains mainly negatively charged groups (e.g. phenolate groups, carboxy groups) to interact with the siloxane functionalities. Therefore the amino-functional siloxane can interact strongly with the cell wall and be kept from leaching, while carboxy siloxane is easily leached out. Salt formation of the two siloxanes, which is expected to take place in the emulsions containing both functionalities, did apparently stabilize the carboxy-functional siloxane in materials $\mathrm{B}$ and $\mathrm{C}$, but the amino-siloxane content was too low to stabilize materials $\mathrm{D}$ and $\mathrm{E}$ and fix the siloxane in the wood. 

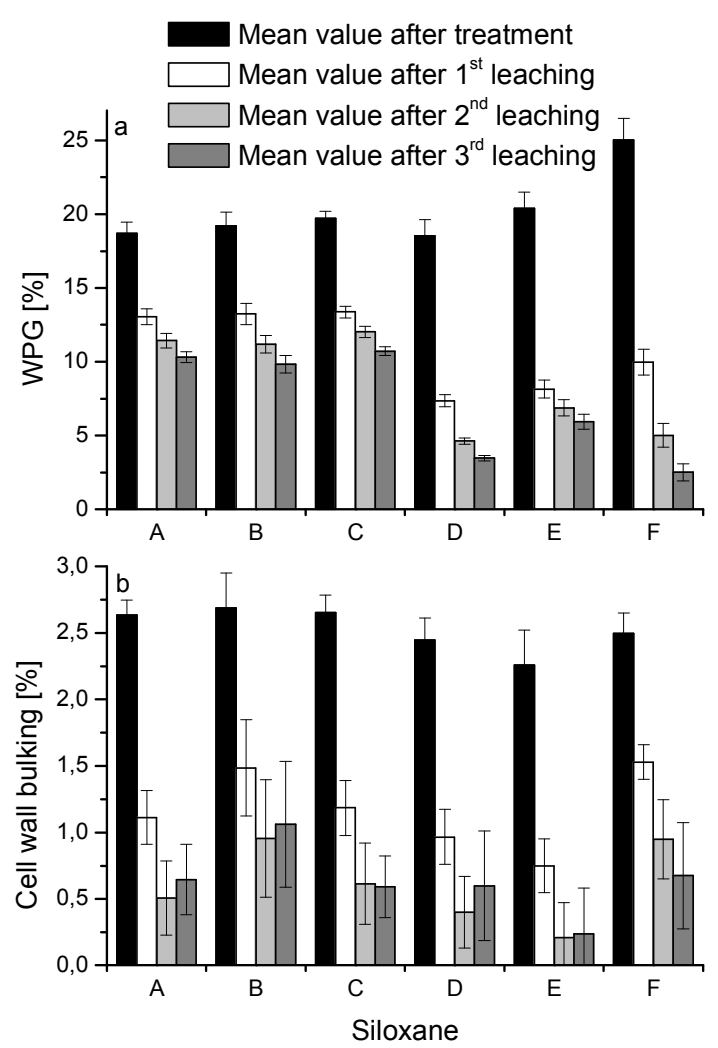

Figure 3: Weight percent gain (WPG) (a) and cell wall bulking (b) of ASE specimens treated with various siloxane emulsions.

Bulking after the treatment was very similar for all siloxanes (Figure 3b). Leaching of the samples strongly reduced bulking. In total, bulking values were too low to effectively reduce swelling and resulted only in negligible anti-shrink-efficiency.

\section{Water uptake}

Water uptake was reduced by all treatments compared to the control samples. Two groups of materials can be identified, if the water repellent effectiveness (WRE) after $24 \mathrm{~h}$ is regarded (Figure 4). Materials A, B and C showed a very low WRE in the first water uptake, which increased to a maximum in the second water uptake and then started to decrease. Materials D, E and F showed the highest WRE in the first water uptake, WRE decreased in the following water uptake tests. These two behaviours are due to the different formulations. While materials $\mathrm{A}, \mathrm{B}$ and $\mathrm{C}$ had the same emulsifier mixture, $\mathrm{D}, \mathrm{E}$ and $\mathrm{F}$ contained different ratios of the three emulsifiers. The values of the first water uptake can be regarded as strongly affected 
by the emulsifier in the wood. After leaching, the effect of the pure siloxane becomes more important.

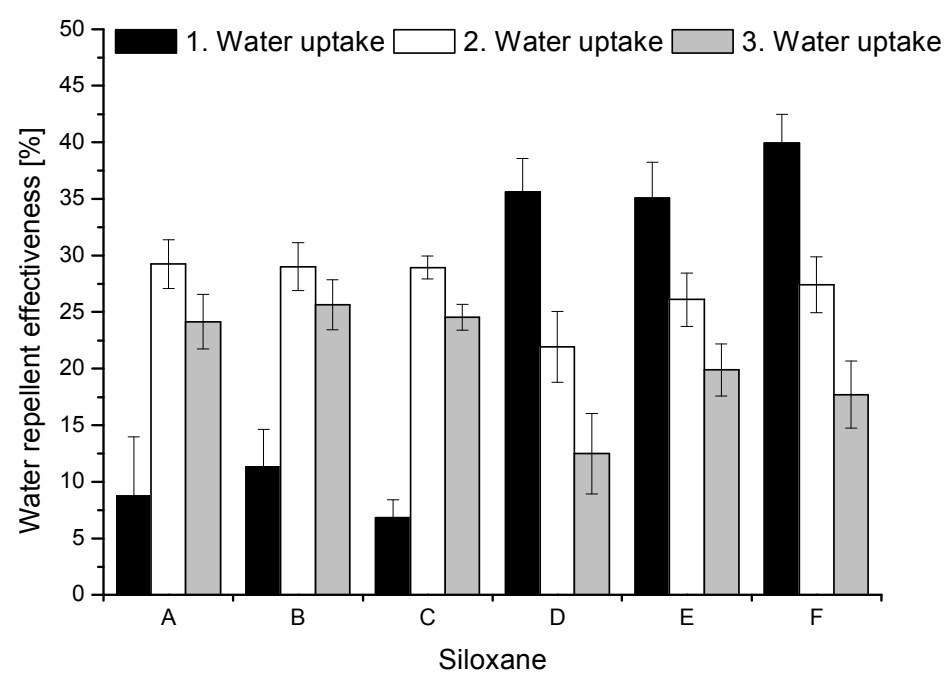

Figure 4: Water repellent effectiveness (WRE) after $24 \mathrm{~h}$ of pine sapwood treated with various siloxane emulsions.

The high WRE values for materials containing high amounts of carboxy-functional siloxane were unexpected based on earlier results. Pries et al. (2012) found stronger reduction of water uptake with amino-functional siloxane as compared to carboxyfunctional siloxane. The reason for these differences can be attributed to the different formulations. While Pries et al. (2012) formulated the material to 30\% stock solutions, a different formulation was used in this study with only $20 \%$ concentration of siloxane and higher amounts of emulsifier. This reflects the importance of the formulation on the properties of treated wood. Apparently the material was distributed differently in the wood and was therefore not able to effectively reduce water uptake in the former study.

A synergistic effect of amino and carboxy siloxane on water uptake was not found. Material A, containing only amino siloxane showed similar or better results in the second and, especially, in the third water uptake test compared to all other materials.

While unfunctional siloxanes can very effectively reduce water uptake of wood (Hager, 1995; Lukowsky et al., 1997), functional groups such as the ones used here increase the polarity of the siloxanes and reduce hydrophobation of the treated 
wood. When the chain length decreases, properties of the functional groups become even more important, with the result of more polar siloxanes. In this study, the chain length of the siloxanes was very short (D10 and D46); hydrophobation of the wood was therefore low. The results are, however, comparable to Ghosh (2009), who found similar values of WRE after $24 \mathrm{~h}$ when amino-functional siloxanes in a solution of water and organic solvents were impregnated into wood.

Two ways of water uptake reduction can be distinguished; first, altering the inner surfaces of the wood to become water repellent and, second, blocking of the penetration paths of water. Amino-functional siloxanes can very effectively render textile materials water repellent, if the polar amino groups are oriented towards the cell wall surface. In this way, the surface properties are changed (Bereck et al., 2001). The polar siloxanes in this study probably do not greatly alter the surface of the wood but block the penetration paths of water and thus reduce water uptake rate (Weigenand et al., 2007). This assumption is supported by the fact that the treatments with 5\% siloxane showed lower WRE values (not shown) as compared to those with $10 \%$. For covering the inner surfaces of the wood, however, concentrations of only a few percent are sufficient and any additional material will not reduce water uptake rate any more (Pries et al., 2013). Apparently, effective orientation of the amino siloxane, as described by Bereck et al. (2001), has not taken place; only just enough amino groups were oriented towards the wood surface to stabilize the material against leaching.

\section{Fungal decay}

The control specimens reached a mean mass loss of more than $20 \%$ indicating a sufficient virulence of the fungal cultures used. In the case of pine sapwood incubated with $C$. puteana (Figure 5a) the concentration of the treatment emulsion had a strong effect. While 5\% treatment only resulted in a high decay resistance when pure carboxy siloxane was used, all treatments resulted in a mean mass loss of lower than 5\%, when $10 \%$ siloxane emulsions were used. A synergistic effect of the combination of the two materials was not observed.

In general, the effectiveness of all materials was much lower in beech wood (Figure $5 \mathrm{~b}$ and $\mathrm{c}$ ). This can be explained with the higher density of beech wood, which resulted in lower WPG values. The effect of concentration was strong, 
samples treated with 5\% siloxane often revealed higher mass losses than the control specimens. In most cases increasing ratio of carboxy siloxane in the emulsion resulted in lower mass losses, synergistic effects could not be seen.
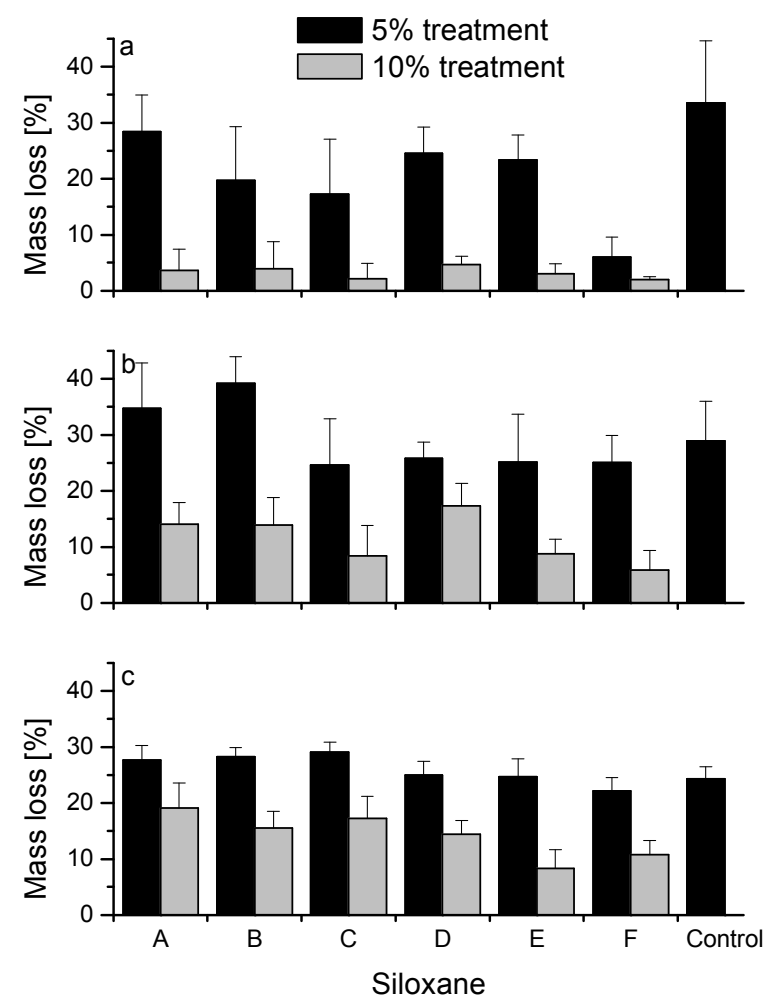

Figure 5: Mass loss of a: pine sapwood, b: beech wood after incubation with Coniophora puteana and c: beech wood after incubation with Trametes versicolor. Mean values and standard deviation.

Amino-functional silicon based materials have shown to be effective against wooddecaying fungi in several studies. Ghosh et al. (2008) treated wood with different commercially available polysiloxanes and found amino-functionality to be effective against fungal decay. Furthermore they found increasing effectiveness of aminofunctional siloxane with decreasing chain length (Ghosh et al., 2012). The aminofunctionality was previously regarded as the main factor to reduce fungal decay (Donath et al., 2006a; Weigenand et al., 2008), but this suggestion was not supported by results of Ghosh et al. (2012) and it was concluded, that fungal resistance is mainly imparted by interaction with the cell wall and micro-pore blocking. In this study, amino-functional siloxane did show major reduction of fungal decay in pine 
sapwood, but the effectiveness in beech was low, indicating that high WPG are required to obtain protection against fungal decay.

Carboxy-functional siloxane, on the other hand, was only recently found to be even more effective than amino-functional siloxane (Pries et al. 2012). Because the carboxy-functionality itself is thought to be non-toxic and should not have any inhibiting effect on the fungus, it was concluded, that it may enhance mobility of the siloxane. This might be crucial for effectiveness against decay. Different from amino functionality, which can interact with negatively charged counterparts in the cell wall, e.g. carboxy groups or phenolate groups, the carboxy functionality cannot interact strongly with the cell wall. This lack of interaction, on the other hand, has the disadvantage of low fixation of the material in the wood and leaching instability. To overcome this problem, carboxy-siloxane was combined with amino-functional siloxane in this study to induce salt formation and thus improve leaching properties. Amino-groups are thought to prevent fungal attack only if cationised (Donath et al., 2006a) which can be promoted by addition of carboxy siloxane. Carboxy siloxane, on the other hand, may be fixed in the wood and prevented from leaching by addition of amino-functional siloxane (Donath et al., 2006b) and furthermore increase fungal resistance of the treated wood. This goal was not achieved and no synergistic effects were seen. While water uptake reduction and leaching stability was highest with materials containing high amounts of amino siloxane, fungal resistance was highest with pure carboxy siloxane; mixtures of the two functionalities in no case showed better results than the pure materials.

\section{Blue stain colonisation}

The blue stain test revealed reduction of staining by Aureobasidium pullulans only for amino siloxane containing formulations, while pure carboxy siloxane did not show any reduction of staining (Table 3 ). None of the materials, however, was able to prevent staining completely. Best results were obtained with pure amino siloxane and with materials containing high amounts of amino siloxane (Materials A, B, C). Synergistic effects of the two siloxane materials were not observed; there was a clear trend to higher reduction of staining with increasing amino siloxane content of the treatment emulsion. There was not a clear trend for higher resistance against staining with increasing concentration of the siloxane emulsion. Materials A and B showed 
very similar results for both concentrations, while material $\mathrm{C}$ even showed lower colonisation areas for the $5 \%$ treatment. In most cases, the bottom side of the specimens showed stronger staining than the top side; the staining fungi apparently started to grow from the surface facing the vermiculite. This can be explained with higher moisture content between wood and vermiculite and also by the high concentration of spores in the vermiculite (Ghosh et al., 2009).

Table 3: Blue stain colonisation, mean stained area and, in brackets, standard deviations.

\begin{tabular}{|c|c|c|c|}
\hline \multirow[t]{2}{*}{ Concentration } & \multirow[t]{2}{*}{ Material } & \multicolumn{2}{|c|}{ Mean area of staining $(\%)$} \\
\hline & & Bottom & Top \\
\hline \multirow{6}{*}{$5 \%$} & $\bar{A}$ & $9.9(4.3)$ & $0(0)$ \\
\hline & $\mathbf{B}$ & $7.6(7.0)$ & $0(0)$ \\
\hline & $\mathrm{C}$ & $13.8(15.7)$ & $0.5(1.5)$ \\
\hline & D & $34.3(13.3)$ & $23.9(20.0)$ \\
\hline & $\mathbf{E}$ & $34.9(13.9)$ & $10.7(10.3)$ \\
\hline & $\mathbf{F}$ & $84.6(15.8)$ & $79.4(13.6)$ \\
\hline \multirow{6}{*}{$10 \%$} & $\mathbf{A}$ & $8.8(6.4)$ & $0(0)$ \\
\hline & B & $9.9(6.1)$ & $1.9(3.5)$ \\
\hline & $\mathbf{C}$ & $19.0(10.3)$ & $0(0)$ \\
\hline & D & $58.2(12.0)$ & $60.4(20.0)$ \\
\hline & $\mathbf{E}$ & $20.1(7.9)$ & $4.3(2.5)$ \\
\hline & $\mathbf{F}$ & $85.2(7.0)$ & 70.9 (13.1) \\
\hline \multicolumn{2}{|l|}{ Control } & $75.9(22.3)$ & $72.6(13.5)$ \\
\hline
\end{tabular}

It was previously shown, that silicone treatment of wood can reduce staining by A. pullulans. Ghosh et al. (2009) treated wood with commercially available functionalised silicones and found strong reduction of staining when wood was treated with amino siloxane emulsions. Ghosh et al. (2012) treated wood with solutions of functional siloxane in water and organic solvents. This way, the influence of the emulsifier was avoided. It was found, that quat- and aminofunctional siloxane both reduce staining by A. pullulans to a great extent. In both studies, the side facing the vermiculite was stained stronger than the top side of the 
specimens, which is in line with our findings. But in both studies there was also a clear trend for greater reduction of staining with higher concentration of the treatment formulation which was not found in this study. It is certain, that this trend has to exist to some degree below our lowest concentration. Probably 5\% treatment concentration was sufficient in this study to cover the inner surfaces of the wood and prevent staining to a maximum extent; higher concentrations of siloxane did not reduce staining any further. These results indicate a totally different mode of action for the inhibiting of $A$. pullulans by siloxanes as compared to the inhibition of white and brown rot fungi. While the mobility of the siloxane chain was concluded to be important for the inhibition of wood decaying fungi and therefore carboxy-functional siloxane being most effective (Pries et al. 2012), inhibition of A. pullulans seems to be caused by the amino groups or the alteration of the inner surface of wood and therefore resulting in amino-functional siloxane to be the most effective material (Ghosh et al., 2012).

\section{Conclusion}

Wood was treated with water-based emulsions of amino and carboxy siloxanes. The two functionalities were combined to obtain synergistic effects in fungal decay protection, improved fixation of carboxy siloxane in wood and at the same time strong reduction of water uptake rate.

Fixation of carboxy siloxane was achieved only when low concentrations of carboxy siloxanes were present in the material (80:20 mixture). When carboxy siloxane represented the major part of the mixture (20:80 mixture), fixation of the material was low.

Water uptake rate was reduced most effectively by pure amino siloxane and 80:20 mixtures with carboxy siloxane. No synergistic effects of the two materials reduced water uptake rate any further, when mixtures of the siloxanes were used.

Mass loss due to fungal decay was reduced most effectively by pure carboxy siloxane. The idea that the combination of the two functionalities with resulting salt formation might enhance fungal resistance was not verified. Mixtures of carboxy siloxane with amino siloxane showed equal or worse results than pure carboxy siloxane. Staining was most effectively inhibited by pure amino siloxane, while all 
mixtures showed equal or worse results and especially pure carboxy siloxane did not inhibit staining fungi at all. Again synergistic effects to improve resistance to staining were not found.

\section{References}

Bereck A., Riegel D., Matzat A., Habereder P., Lautenschlager H. (2001) Silicones in Fibrous Substrates: Their Mode of Action. AATCC review 1:45-49.

CEN/TS 15083-1 (2004) Durability of wood and wood based products - Determination of the natural durability of solid wood against wood-destroying fungi - test methods Part 1: Basiodiomycetes. European committee for standardization, Brussels, Belgium.

Donath S., Militz H., Mai C. (2004) Wood modification with alkoxysilanes. Wood Sci Technol 38:555-566. DOI: $10.1007 / \mathrm{s} 00226-004-0257-1$.

Donath S., Militz H., Mai C. (2006a) Treatment of wood with aminofunctional silanes for protection against wood destroying fungi. Holzforschung 60:210-216. DOI: 10.1515/hf.2006.035.

Donath S., Militz H., Mai C. (2006b) Creating water-repellent effects on wood by treatment with silanes. Holzforschung 60:40-46. DOI: 10.1515/hf.2006.008.

EN 84 (1997) Wood preservatives - accelerated ageing of treated wood prior to biological testingLeaching procedure. CEN - European Committee for Standardization, Brussels, Belgium.

EN 113 (1996) Wood preservatives - Method of test for determining the protective effectiveness against wood destroying basidiomycetes - Determination of the toxic values. CEN European Committee for Standardization, Brussels, Belgium.

Evans P. (2003) Emerging technologies in wood protection. Forest Prod J 53:14-22.

Ghosh S.C. (2009) Wood modification with functionalized polydimethylsiloxanes, Faculty of Forest Sciences and Forest Ecology, Georg August University of Göttingen, Dissertation.

Ghosh S.C., Militz H., Mai C. (2008) Decay resistance of treated wood with functionalised commercial Silicones. Bioresources 3:1303-1314.

Ghosh S.C., Militz H., Mai C. (2009) The efficacy of commercial silicones against blue stain and mould fungi in wood. Eur J Wood Wood Prod 67:159-167. DOI: 10.1007/s00107-008-02967.

Ghosh S.C., Dyckmans J., Militz H., Mai C. (2012) Effect of quat- and amino-silicones on fungal colonisation and decay of wood. Holzforschung. DOI 10.1515/hf-2012-0024.

Hager R. (1995) Waterborne silicones as wood preservatives. International Research Group on Wood protection, Irg/Wp 95-30062, Stockholm, Sweden, 1995. pp. 1-11.

Hill C.A.S., Farahani M.R.M., Hale M.D.C. (2004) The use of organo alkoxysilane coupling agents for wood preservation. Holzforschung 58:316-325.

Hill C.A.S., Forster S.C., Farahani M.R.M., Hale M.D.C., Ormondroyd G.A., Williams G.R. (2005) An investigation of cell wall micropore blocking as a possible mechanism for the decay resistance of anhydride modified wood. Int Biodeterior Biodegr 55:69-76.

Lukowsky D., Peek R.D., Rapp A.O. (1997) Water-based silicones in wood. International Research Group on Wood Protection, IRG/Wp 97-30144, Stockholm, Sweden, 1997.pp. 1-11.

Mai C., Donath S., Militz H. (2003) Modification of wood with silicon compounds, in: J. Van Acker and C. A. S. Hill (Eds.), European Conference on Wood modification, Ghent, Belgium. pp. 239-251.

Mayer H. (1998) Masonry protection with silanes, siloxanes and silicone resins. JOCCA - Surf Coat Int 81:89-93.

Papadopoulos A.N., Hill C.A.S. (2002) The biological effectiveness of wood modified with linear chain carboxylic acid anhydrides against Coniophora puteana. Holz Roh Werkst 60:329-332. 
Pernak J., Zabielska-Matejuk J., Urbanik E. (1998) New quaternary ammonium chlorides - wood preservatives. Holzforschung 52:249-254. DOI: 10.1515/hfsg.1998.52.3.249.

Pries M., Wagner R., Kaesler K.H., Militz H., Mai C. (2012) Effect of short-chain silicones bearing different functional groups on the resistance of pine (Pinus sylvestris L.) and beech (Fagus sylvativa L.) against decay fungi. Holzforschung, DOI 10.1515/hf-2012-0065.

Pries M., Wagner R., Kaesler K.H., Militz H., Mai C. (2013) Acetylation of wood in combination with polysiloxanes to improve water-related and mechanical properties of wood. Wood Sci Technol, DOI: 10.1007/s00226-013-0535-x.

Stamm A.J. (1964) Wood and Cellulose Science. The Ronald Press Company, New York.

Weigenand O., Humar M., Daniel G., Militz H., Mai C. (2008) Decay resistance of wood treated with amino-silicone compounds. Holzforschung 62:112-118. DOI: 10.1515/hf.2008.016.

Weigenand O., Militz H., Tingaut P., Sebe G., de Jeso B., Mai C. (2007) Penetration of aminosilicone micro- and macro-emulsions into Scots pine sapwood and the effect on water-related properties. Holzforschung 61:51-59. DOI: 10.1515/hf.2007-009.

Worley S.D., Sun G. (1996) Biocidal polymers. Trends Polym Sci 4:364-370.

Zabielska-Matejuk J., Urbanik E., Pernak J. (2004) New bis-quaternary ammonium and bisimidazolium chloride wood preservatives. Holzforschung 58:292-299. DOI: 10.1515/hf.2004.045. 


\title{
Painting and gluing capability of beech wood (Fagus sylvativa L.) treated with functionalized polydimethylsiloxanes
}

\begin{abstract}
Beech wood (Fagus sylvatica L.) was treated with different water-based emulsions of short-chained amino- and carboxy-siloxanes. Thereafter the painting capability of the treated wood was tested with typical acrylic water-based and alkyd solvent-based paints. While no valid test results were obtained for alkyd-based paint, acrylic-based paint showed strongly reduced adhesion on treated wood in a self-aligning Posi-Test. The glueing capability was tested on the treated wood using three typical adhesives; PVAc-D4 adhesive, phenolic resin and PUR adhesive. With the PVAc-adhesive none of the treatments reduced bond strength, although silicone with high amino-content reduced wood failure, indicating some interaction of basic amino groups with the polyvinyl acetate. Bond strength of phenolic resin and PUR adhesive was reduced in some cases, but generally the reductions were relatively small and do not seem to impede the use of these adhesives for wood treated with these functional polysiloxanes.
\end{abstract}

\section{Introduction}

Due to regulations and environmental concerns, new alternatives for the treatment of wood with biocides are sought for (Evans, 2003). Aside from other treatments, organo-silicon treatments have been studied for the protection of wood against fungal decay in a number of studies (Donath et al., 2006; Mai and Militz, 2004; Weigenand et al., 2008). While certain silicon materials can inhibit fungal growth, they usually render the wood more water repellent (Hager, 1995; Lukowsky et al., 1997). This attribute is mostly desired, because moisture causes shrinkage/swelling and fungal degradation of wood, but can cause problems in painting and gluing. Wood used in outside applications is susceptible to weathering and attack by microorganisms. While attack by microorganisms can be prevented by biocides or wood modification, weathering and degradation by UV light can only be prevented by pigmented coatings. Common wood coatings can be divided based upon the two most important binding agents which are water-borne latexes (acrylic or vinyl-acrylic polymers) and solvent-borne oil-alkyd paints (Williams, 2010). Coating performance is greatly 
affected by the wood substrate; high extractive contents, including resins, and swelling/shrinkage of wood can reduce adhesion and service life of coatings (Williams, 2010). For proper adhesion, the paint has to penetrate into the wood. While oil-alkyd-based paints are expected to penetrate into the cell wall as well as into the lumens, aqueous acrylic binders have emulsion particles which are too big to enter the cell wall, therefore only penetrate into the lumens of the cells and mechanically interlock with the wood (Williams, 2010). Treatment with siloxanes can render wood water repellent and, at the same time, act abherent (oleophobic) which can also cause problems regarding paint adhesion and coating performance. Especially water borne coatings are expected to show poor wetting of the water repellent surface. Proper penetration into the wood may therefore be prevented by pretreatment with siloxanes and thus prevent proper adhesion of paints to the treated wood.

For efficient use of wood resources, gluing of wood is becoming increasingly important. It is closely related to the topic of paint adhesion. Adhesion is governed by chemical and mechanical factors. One mechanism of adhesion is mechanical interlocking. It takes place when the adhesive penetrates into the wood structure beyond surface debris and damaged fibers (Frihart and Hunt, 2010). Attractive forces between the adhesive and wood also contribute to bond strength. To achieve a strong bond, adhesive and wood molecules must come into close contact with each other. Extractives or impregnated chemicals can prevent close contact or proper wetting of the surface and hereby reduce bonding strength. Many types of wood adhesive are water-based and expected to show worse wetting and bonding qualities when wood is treated with siloxanes. Lukowsky et al. (1997) treated wood with water-based silicone emulsions and found greatly reduced adhesion strength of PVAc. Jusoh et al. (2005) treated wood for flake board production with siloxanes and found severe reduction of bonding strength, when the flakes were glued with phenolic resin. Kurt et al. (2008), on the other hand, did not find any reduced bonding strength in dry state for wood that had been treated with amino-functional siloxane and was glued with PVAc. Performance of adhesives seems to be strongly dependent on the type of siloxane that is used for the treatment of wood.

In this study, we investigated the possibility to coat and glue wood that had been treated with different short-chained functional siloxanes formulated in water. 
Typical types of paints and adhesives were tested with regard to their adhesion properties. While adhesives were tested for shear strength, paints were tested in a pull-off test in dry and wet state.

\section{Materials and Methods}

\section{Wood}

Glueability test (EN 302-1, 2004): Beech wood (Fagus sylvatica L.) samples of size $130 \times 10 \times 300 \mathrm{~mm}^{3}(\mathrm{R} \times \mathrm{T} \times \mathrm{L})$ were prepared and treated with the polysiloxane emulsions. After drying and conditioning, the boards were freshly planed to $5 \mathrm{~mm}$ thickness and two boards of equal treatment were immediately glued together. After 7 days of drying, 10 specimens of size $20 \times 10 \times 145 \mathrm{~mm}^{3}$ were cut out of these boards for glueability testing. In the middle of these specimens, cuts with the saw were made perpendicular to the fiber direction on both sides with a depth of $10 \mathrm{~mm}$ to obtain an overlapping zone of $20 \mathrm{~mm} \times 10 \mathrm{~mm}$ for testing of bond strength.

Paintability testing (ASTM 4541; Pr-ENV 927-8): Beech wood samples of size $50 \times 4 \times 300 \mathrm{~mm}^{3}(\mathrm{R} \times \mathrm{T} \times \mathrm{L})$ were prepared for paintability testing.

\section{Chemicals}

Polysiloxanes with two different $\alpha$ - $\omega$-functionalities were synthesized. The functionalities contained diamino-groups and carboxyl-groups (Figure 1).

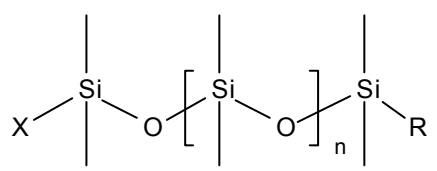

With $\mathrm{R}=$<smiles>[R]CCOCC(O)CNCCN</smiles><smiles>CCCOCC(O)COC(=O)CCC(=O)O</smiles>

Figure 1: Siloxane chain with a: aminofunctionality and b: carboxyfunctionality. 
Silicones with the following numbers (n) of dimethyl-siloxane (DMS) units were synthesized for the respective functionalities:

Diamino-functional (a): 10

Carboxy-functional (b): 10, 46

The silicones were dispersed in water using acetic acid and three commercially available surfactants; Imbentin T120, T060 and T030 (Kolb, Hedingen, Switzerland). All emulsions contained 20\% (w/w) of the polysiloxanes (Table 1$)$.

Table 1: Composition of the formulations of different functional siloxanes.

\begin{tabular}{|l|c|c|c|c|c|c|c|c|c|}
\hline \multicolumn{1}{|c|}{ Label } & $\begin{array}{c}\text { Amino } \\
\text { D10 }\end{array}$ & $\begin{array}{c}\text { Carboxy } \\
\text { D10 }\end{array}$ & $\begin{array}{c}\text { Carboxy } \\
\text { D46 }\end{array}$ & Water & $\begin{array}{c}\text { Acetic } \\
\text { acid }\end{array}$ & $\begin{array}{c}\text { Imbentin } \\
\text { T30 }\end{array}$ & $\begin{array}{c}\text { Imbentin } \\
\text { T60 }\end{array}$ & $\begin{array}{c}\text { Imbentin } \\
\text { T120 }\end{array}$ & $\begin{array}{c}\text { Treatment } \\
\text { concentration }\end{array}$ \\
\hline Amino & $20 \%$ & & & $64 \%$ & $6 \%$ & $5 \%$ & $3 \%$ & $2 \%$ & $10 \%$ \\
\hline $80: 20$ & $16 \%$ & $4 \%$ & & $64 \%$ & $6 \%$ & $5 \%$ & $3 \%$ & $2 \%$ & $5 \%$ \\
\hline $20: 80$ & $4 \%$ & $16 \%$ & & $64.6 \%$ & $4 \%$ & $2 \%$ & $6.4 \%$ & $3 \%$ & $10 \%$ \\
\hline Carboxy & & $20 \%$ & & $60 \%$ & & & $13.6 \%$ & $6.4 \%$ & $5 \%$ \\
\hline $80: 20$ long & $16 \%$ & & $4 \%$ & $64 \%$ & $6 \%$ & $5 \%$ & $3 \%$ & $2 \%$ & $5 \%$ \\
\hline $20: 80$ long & $4 \%$ & & $16 \%$ & $64 \%$ & $2 \%$ & $2 \%$ & $8 \%$ & $4 \%$ & $5 \%$ \\
\hline $\begin{array}{l}\text { Emulsifier } \\
\text { control }\end{array}$ & & & & $84 \%$ & $6 \%$ & $5 \%$ & $3 \%$ & $2 \%$ & $10 \%$ \\
\hline
\end{tabular}

\section{Impregnation of wood}

The specimens were dried at $103^{\circ} \mathrm{C}$ for $48 \mathrm{~h}$ and the dry weight was determined. Subsequently the specimens were placed in the solutions stated above. A vacuum of approx. 100 mbar was applied for $1 \mathrm{~h}$ and afterwards a pressure of $13 \mathrm{bar}$ for $2 \mathrm{~h}$ (all pressures in absolute values). The samples were weighed in the wet state, slowly dried to prevent cracking and finally oven dried at $103^{\circ} \mathrm{C}$. The dry weight was determined and the samples were then conditioned at $20^{\circ} \mathrm{C} / 65 \% \mathrm{RH}$ prior to painting and gluing. The weight percent gain (WPG) was calculated according to Pries et al. (2012).

Due to material shortage a non-orthogonal experimental design was used. Table 1 lists the different treatments and concentrations (right column). 


\section{Paints and application of paint}

Two different paints were used:

Rubbol Ventura Satin plus (Akzo Nobel, Amsterdam, Netherlands)

Rubbol WF 361 (Akzo Nobel, Amsterdam, Netherlands)

Sikkens Rubbol Ventura Satin plus is a typical alkyd-based paint solved in organic solvents. It can be applied in three layers without a special primer. In the first test, treated and untreated control specimens were conditioned at $20^{\circ} \mathrm{C} / 65 \% \mathrm{RH}$ and the surface was sanded with 240 grit sand paper. The paint was applied in three layers with a quantity of approx. $90 \mathrm{ml} \mathrm{m}^{-2}$ per layer. After application of each layer, the samples were left to dry for $24 \mathrm{~h}$, the paint was lightly sanded and dust removed before the next layer was applied. In the second test, the conditioned specimens were planed directly before application of paint. The paint was applied in three layers with a quantity of approx. $90 \mathrm{ml} \mathrm{m}^{-2}$ per layer. The paint was left to dry for $3 \mathrm{~h}$ before the next layer was applied. This procedure was done to ensure maximum adhesion between the paint layers.

Rubbol WF 361 is a typical acrylic-based paint dispersed in water. It can be applied without special primer in three layers. The treated and untreated conditioned $\left(20^{\circ} \mathrm{C} / 65 \%\right.$ RH) wood specimens were sanded with 240 grit sand paper immediately before application of the paint; three layers of paint were applied with a quantity of approx. $70 \mathrm{ml} \mathrm{m}^{-2}$ per layer. After application of each layer, the samples were left to dry for $24 \mathrm{~h}$, the paint was lightly sanded and dust removed before the next layer was applied.

\section{Adhesives and procedure of gluing}

Three different adhesives were tested:

Prefere 6415 (Dynea, Helsinki, Finland)

Prefere 4040 with hardener Prefere 5839 (Dynea, Helsinki, Finland)

PUR 1968 (Akzo Nobel, Amsterdam, Netherlands)

Treated and untreated conditioned $\left(20^{\circ} \mathrm{C} / 65 \% \mathrm{RH}\right)$ wood specimens were planed immediately prior to application of the adhesives. 
Prefere 6415 is a one-component polyvinylacetate (PVAc) adhesive for D4 application according to European standard EN 204 (2001). Approx. 200g m² were applied one-sided and always two samples of the same polysiloxane treatment were pressed together for $12 \mathrm{~h}$ with a constant pressure of $1.2 \mathrm{~N} \mathrm{~mm}^{-2}$ in a hydraulic press.

Prefere 4040 is a phenol-resorcinol resin, which was mixed with hardener in a quantity of 5 parts adhesive to 1 part hardener. Approx. $200 \mathrm{~g} \mathrm{~m}^{-2}$ of resin were applied on each side of two samples with the same polysiloxane treatment $\left(400 \mathrm{~g} \mathrm{~m}^{-2}\right.$ in total). Two specimens were pressed for $12 \mathrm{~h}$ with a constant pressure of $1.0 \mathrm{~N} \mathrm{~mm}^{2}$ in a hydraulic press.

PUR 1968 is a one-component polyurethane adhesive. Approx. $200 \mathrm{~g} \mathrm{~m}^{-2}$ of resin was applied on each side of two samples with the same polysiloxane treatment $\left(400 \mathrm{~g} \mathrm{~m}^{-2}\right.$ in total). Specimens were pressed together for $12 \mathrm{~h}$ with a constant pressure of $0.8 \mathrm{~N} \mathrm{~mm}^{-2}$ in a hydraulic press.

\section{Paint adhesion}

The paint adhesion test was carried out according to ASTM D 4541 and Pr ENV 927-8. After conditioning the coated specimens at $20^{\circ} \mathrm{C} / 65 \% \mathrm{RH}$, five aluminum dollies per wood specimen were glued onto the coating using a two component epoxy resin (Araldite 2011, Huntsman, Michigan, USA). After three more days in the climate, a slot was cut into the film around the dollies until the surface of the wood substrate was visible and the dollies were pulled off in a dry state. Five dollies for each paint-siloxane/emulsifier combination and five control dollies were tested for dry adhesion.

In another test, the slot around the dolly was filled with water and kept for $2 \mathrm{~h}$ to moisten the interface of the film along with the wood substrate and then the dollies were removed. The measurements were only taken as valid, if the coating broke between the wood and the first paint layer. Five dollies for each paintsiloxane/emulsifier combination and five control dollies were tested for wet adhesion.

\section{Glueability}

Glueability was tested according to EN 302-1 (2004), alternative A1, table 1. After cutting the specimens, they were conditioned at $20^{\circ} \mathrm{C} / 65 \% \mathrm{RH}$ and subsequently 
shear strength was tested on a Zwick /Z010 (Zwick, Ulm, Germany). Strain was increased with a speed of $2 \mathrm{kN} \mathrm{min}$. The percentage of wood failure was estimated. Ten specimens for each glue-siloxane/emulsifier combination and ten control specimens were tested.

\section{Statistics}

Significant differences of the treated wood compared to the control were examined by use of t-tests, comparing control and treated samples. Significance is reported, if the p-value is below 0.05 .

\section{Results and Discussion}

\section{Weight percent gain (WPG)}

WPG of the samples was caused by siloxane and emulsifier. Water and acetic acid was expected to evaporate completely during drying. Specimens treated with $5 \%$ formulations had a mean WPG of $7-10 \%$. Carboxy D10 imparted the highest WPG due to the highest emulsifier content. The $10 \%$-treatment resulted in a WPG of approx. 16\%. Pure emulsifier caused a WPG of approx. 5\%. All WPG values were slightly lower than expected; the theoretical WPG caused by pure siloxane was calculated based upon the solution uptake (Figure 2).

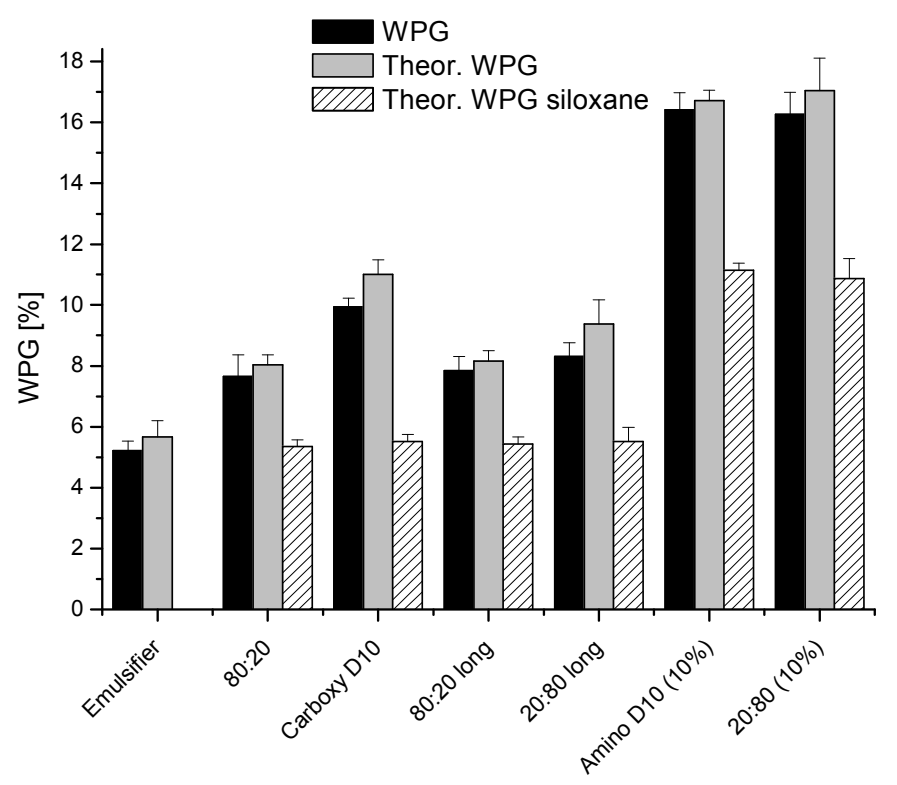

Figure 2: WPG of siloxane treated samples and theoretical WPG (retention) based on solution uptake. Mean values and standard deviations $(n=10)$. 


\section{Paintability}

\section{Rubbol WF 361}

While the influence of the emulsifier on the dry pull-off strength was minor and insignificant, the siloxane treated samples showed a significantly reduced paint adhesion (Figure 3). The influence of the concentrations appeared to be minimal; specimens treated with "Amino D10" at 10\% concentration even exhibited a higher pull off strength than those treated with " $80: 20 "$ at $5 \%$ concentration.

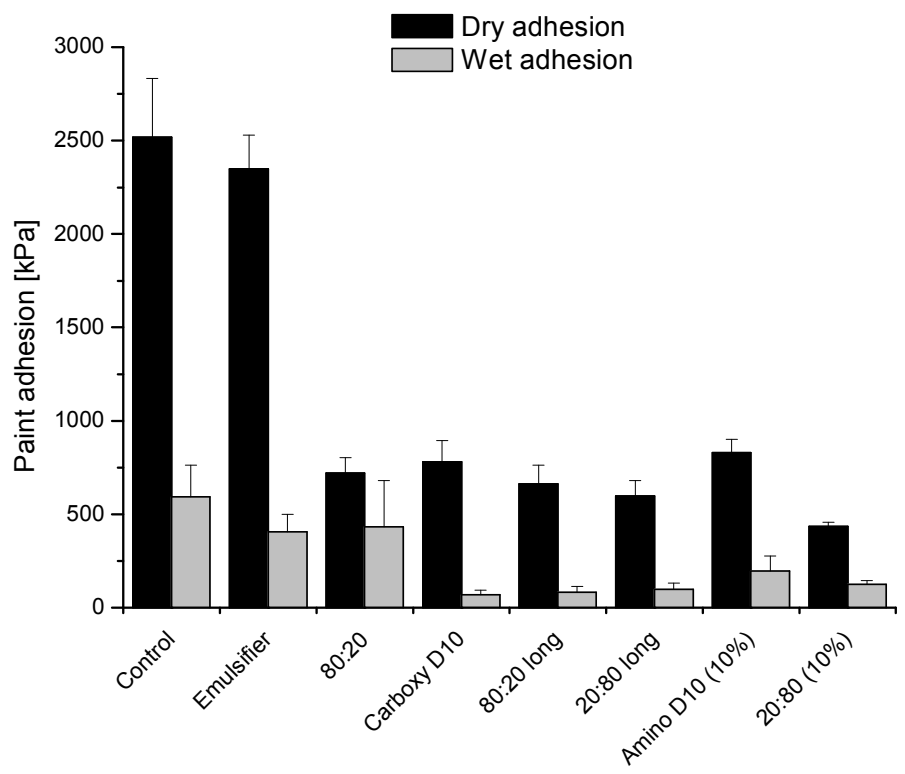

Figure 3: Dry and wet paint adhesion in a pull-off test on siloxane treated beech wood. Sample annotations are to be found in table 1 . Mean values and standard deviations $(n=5)$.

The reason for the low paint adhesion can be attributed to the minor penetration of the paint into the wood. The untreated control samples and the samples treated with pure emulsifier both broke between paint and wood, but the paint had penetrated the untreated wood as was noticeable by the white color of the wood. The siloxanetreated samples on the other hand did not show any penetration of paint into the wood. (Figure 4). 

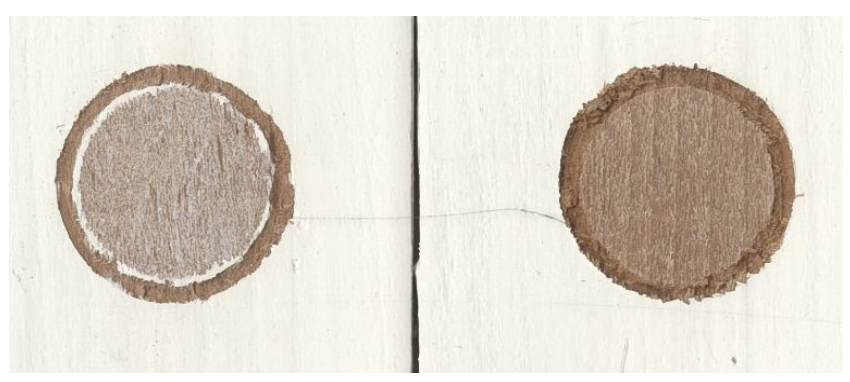

Figure 4: Comparison between untreated control (right) and treated sample after pull-off test.

Wet adhesion testing showed in general the same results. The control samples, however, did not give valid test results according to the requirements of the standard, because the paint always broke in between the paint layers. It can be assumed, that the values reported for the control are estimates for the lower limit of adhesion strength. Testing of samples treated with the emulsifier was valid and did not result in significant differences to the controls, although the emulsifiers were expected to enhance water uptake of the wood. Treatment with 5\% concentration of " $80: 20$ " did also not reduce wet adhesion strength significantly as compared to the control. All other treatments reduced wet adhesion significantly. Three of these treatment formulations contained high amounts of carboxy-functional siloxane, which is a very hydrophilic material. In addition, these formulations had the highest emulsifier contents. Both can increase the velocity of water uptake and thus decrease wet adhesion. Reduction in penetration depth of paint caused by all treatments can also strongly reduce wet adhesion, because incoming water can penetrate between paint and wood and destroy the bond between these materials. Furthermore siloxanes can act abherent (oleophobic) and can thereby reduce adhesion of the coating.

\section{Rubbol Ventura Satin plus}

In a first test, where Rubbol Ventura Satin plus was applied in three layers with drying of the layers in between the application steps did not result in valid tests. In all cases, the paint broke in between the applied layers and therefore the adhesion between wood and paint was not assessed. That is why a second test was done with application of the next layer of paint, when the former one was still wet. This, again, did not result in valid test results, because the bottom layers were sealed by the top layers and could not dry completely, even after extended drying times of several months. 


\section{Glueability}

Bond strength of treated samples glued with phenolic resin was significantly reduced by the four treatments with "Amino D10", "20:80", "80:20 long” and "20:80 long”. Even in these cases the reduction was minor and none of the treatments clearly reduced bond strength (Figure 5A). Wood failure did also not differ among the treatments and amounted to $100 \%$ in all but the " $20: 80$ "-treatment. This indicates a relatively good penetration of the adhesive into the wood despite of the siloxane treatment and no abherent properties of the siloxane towards phenolic resin (Figure 5A). 


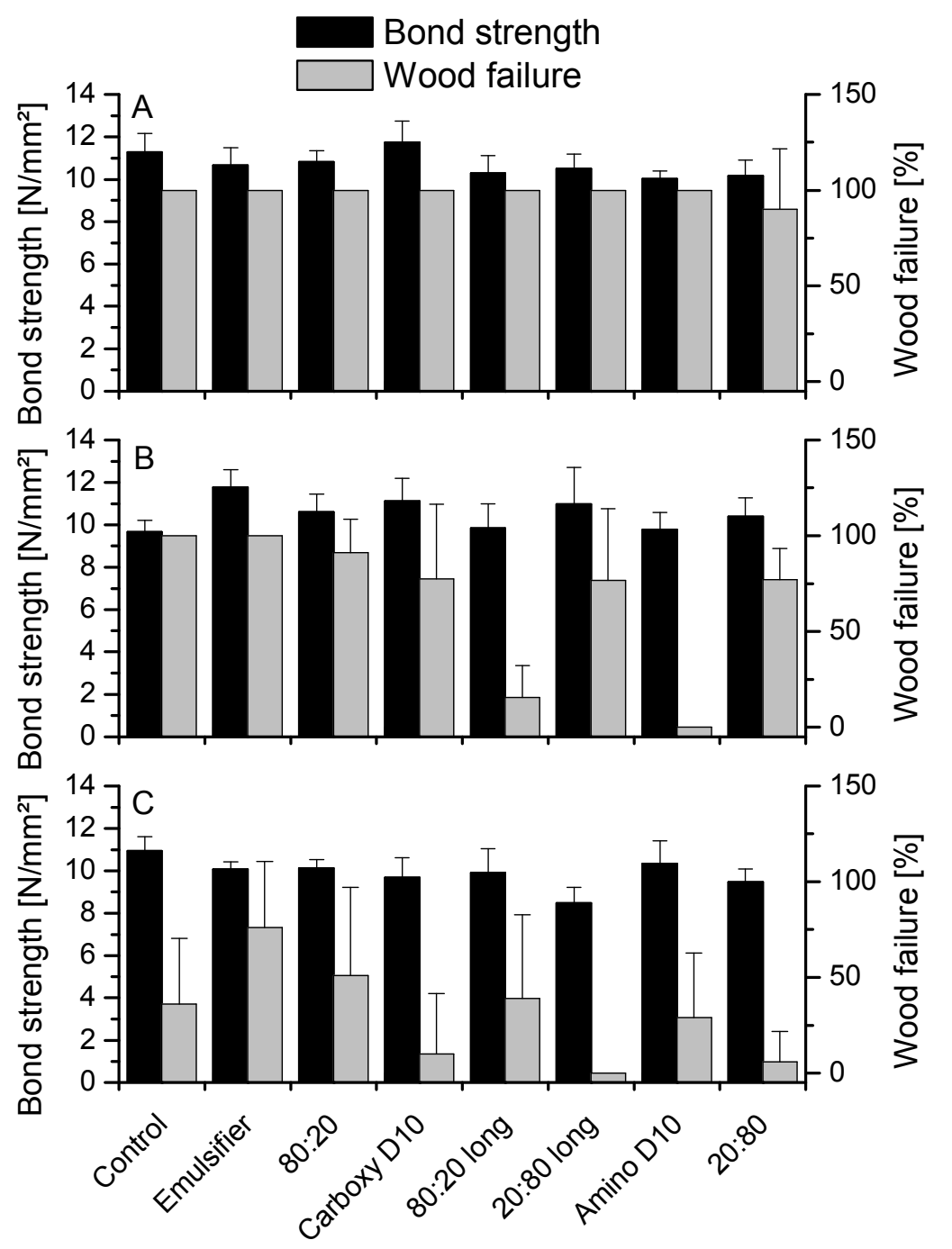

Figure 5: Bond strength and proportion of wood failure of siloxane treated specimens glued with A: phenolic resin, B: PVAc glue and C: PUR glue. Mean values and standard deviations $(\mathrm{n}=10)$.

Samples glued with polyvinylacetyte (PVAc) showed a slightly different picture (Figure 5B). None of the treatments resulted in reduced bond strength. Four treatments; pure emulsifier, "Carboxy D10", "80:20" and "20:80" all significantly increased bond strength as compared to the controls. With regard to wood failure, two treatments differed strongly from the control; these were treatment with "Amino D10" and "80:20 long". Both formulations mainly consist of amino functional siloxane. Reduction of wood failure with PVAc can be attributable to the alkaline amino-groups. The amino-funcional siloxane is acidic after impregnation of 
wood. During the drying process the main part of the acetic acid evaporates leaving behind deprotonated alkaline amino groups. These alkaline amino-groups might contribute in saponification of the ester groups of vinyl acetate to polyvinyl alcohol and thus change the adhesive properties. Polyvinyl alcohol is water sensitive and hydrophilic. While the ratio of amino to carboxy groups in "80:20 long" is very high, the ratio in "80:20 short" is much lower and the treated wood in this case did not show a great decrease in wood failure.

Bonding of wood with polyurethane (PUR) adhesive revealed significant reduction in bond strength for all but the treatment with "Amino D10" as compared to the control (Figure 5C). Even the control samples did not exhibit wood failure, indicating some penetration problems of the adhesive. Once more, emulsifier treatment seems to enhance adhesion. In total, reduction in bond strength by siloxane treatments was minor.

Glueability of siloxane-treated wood was previously assessed on wood treated with micro-emulsions of silicones (Lukowsky et al., 1997). The silicones in this study were formulated using emulsifiers and co-emulsifiers, which were both simultaneously active ingredients and consisted of silanes and short-chained polysiloxanes. This offers the possibility to formulate the silicones without any emulsifiers as is the case in this study. On the other hand, it makes the formulations stable for only a short time. Treatment resulted in highly hydrophobic properties of the wood. Glueability of the wood treated with $10 \%$ formulations of such materials was problematic; tensile shear strength decreased by more than $50 \%$ compared to control when PVAc was used (Lukowsky et al., 1997). Jusoh et al. (2005) treated wood flakes for flakeboard production with a self-emulsifying alkoxysiloxane. Manufactured flakeboards glued with phenolic resin were tested for bonding strength. The controls displayed an internal bond strength of $0.41 \mathrm{MPa}$, while those manufactured from flakes treated with $1 \%$ polysiloxane showed internal bond strength of $0.26 \mathrm{MPa}$; this is a decrease of approx. $27 \%$. Our study differed in several aspects from the former: Functionality of the silicones, shorter chain length and the high amount of emulsifier. The functionality of the silicones combined with the short chain has an impact on water related properties of the material. In general, the siloxane chain is water repellent and can, at the same time, act oleophobic. With decreasing chain length, the properties are influenced more and more by the 
functionality of the siloxane. Amino-groups and carboxy-groups are both hydrophilic and therefore render the siloxane more hydrophilic. Emulsifiers, which remain present in the wood after treatment increase the hydrophilic properties of the material. These two combined effects induce a high bond strength and glueability of the siloxane treated wood, when water-based adhesives (phenolic and PVAc) are used. Kurt et al. (2008) treated wood with a 5\% micro-emulsion of amino-functional siloxane and tested the glueability with PVAc. They did not find reduced bond strength of treated wood as compared to the control when tested in dry state. This result is very similar to the results obtained in this study. It seems as if wood treated with functional siloxanes can be glued with typical water-based adhesives such as PVAc or phenolic resins. One must not overlook the fact that testing was only done in dry state. According to EN 302-1 (2004) table 1, several wet adhesion experiments must be carried out before a final conclusion can be drawn. It was further not evaluated, to which extent glueability was influenced by the emulsifiers, which were left inside the wood after treatment and can enhance penetration of the adhesives.

\section{Conclusion}

Paintability with acrylic-based paint showed insufficient penetration of paint into the wood and low paint adhesion in both the dry and wet state. It can be concluded, that penetration of the paint was inhibited by the siloxane (because pure emulsifier treatment did not reduce penetration). Abherent properties of the siloxane may also be responsible for low paint adhesion. Water-based acrylic paint can therefore not be used to coat wood treated with siloxane emulsions of the type tested in this study. Further testing of paints, especially siloxane containing coatings, should be done in order to identify candidates for coating of siloxane treated wood.

Glueability was not as severely affected by siloxane treatment. While some treatments reduced bond strength significantly for phenolic and PUR adhesives, no reduction was so severe that it seemed to prevent the use of these adhesives. PVAc revealed increased bonding strength in some cases but also reduced wood failure in two others. It was concluded, that amino-groups in the functional siloxane may cause saponifcation of ester groups in PVAc. Despite reduced wood failure, the bond strength was not reduced and gluing of siloxane treated wood with PVAc seems to be possible. 
Gluing of wood treated with certain siloxane-emulsions can easily be done with the most common adhesives for solid wood. The reduction in wood failure in some cases does not seem to affect bond strength. Emulsifiers remaining in the wood may enhance penetration of adhesives into the wood structure. However, tests were only done on conditioned wood. For final evaluation, glueability needs to be tested in wet state as described in EN 302-1, table 1.

\section{References}

ASTM D4541 (2009) Standard test method for pull-off strength of coatings using portable adhesion testers. ASTM international, West Conshohocken, USA.

Donath S., Militz H., Mai C. (2006) Treatment of wood with aminofunctional silanes for protection against wood destroying fungi. Holzforschung 60:210-216. DOI: 10.1515/hf.2006.035.

EN 204 (2001) Classification of thermoplastic wood adhesives for non-structural applications. CEN European Committee for Standardization, Brussels, Belgium.

EN 302-1 (2004) Adhesives for load-bearing timber structures - Part 1: Determination of longitudinal tensile shear strength. CEN - European Committee for Standardization, Brussels, Belgium.

Pr-ENV 927-8 Pull-off test for the assessment of the wet adhesion of exterior wood coatings. CEN European Committee for Standardization, Brussels, Belgium.

Evans P. (2003) Emerging technologies in wood protection. Forest Prod J 53:14-22.

Frihart C.R., Hunt C.G. (2010) Wood Handbook, Chapter 10: Adhesives with Wood Materials - Bond Formation and Performance. General Technical Report FPL-GTR-190. Madison, WI: U.S. Department of Agriculture, Forest Service, Forest Products Laboratory, Chapter 10:10-1 - 1024.

Hager R. (1995) Waterborne silicones as wood preservatives. International Research Group on Wood protection, Irg/Wp 95-30062, Stockholm, Sweden, 1995. pp. 1-11.

Jusoh I.B., Nzokou P., Kamdem P. (2005) The effect of silicone on some properties of flakeboard. Holz Roh Werkst 63:266-271.

Kurt R., Mai C., Krause A., Militz H. (2008) Hydroxymethylated resorcinol (HMR) priming agent for improved bondability of silicone modified wood glued with a polyvinyl acetate adhesive. Holz Roh Werkst 66:305-307.

Lukowsky D., Peek R.D., Rapp A.O. (1997) Water-based silicones in wood. International Research Group on Wood Protection, IRG/Wp 97-30144, Stockholm, Sweden, 1997.pp. 1-11.

Mai C., Militz H. (2004) Modification of wood with silicon compounds. Treatment systems based on organic silicon compounds - a review. Wood Sci Technol 37:453-461. DOI: 10.1007/s00226004-0225-9.

Pries M., Wagner R., Kaesler K.H., Militz H., Mai C. (2012) Effect of short-chain silicones bearing different functional groups on the resistance of pine (Pinus sylvestris L.) and beech (Fagus sylvativa L.) against decay fungi. Holzforschung, DOI 10.1515/hf-2012-0065.

Weigenand O., Humar M., Daniel G., Militz H., Mai C. (2008) Decay resistance of wood treated with amino-silicone compounds. Holzforschung 62:112-118. DOI: 10.1515/hf.2008.016. 
Williams S.R. (2010) Wood Handbook, Chapter 16: Finishing of Wood. General Technical Report FPL-GTR-190. Madison, WI: U.S. Department of Agriculture, Forest Service, Forest Products Laboratory, Chapter 16:16-1 - 16-39. 


\section{Lebenslauf}

Malte Pries

Obere Roßstaig 5

71579 Spiegelberg

Telefon: 07194/5086363

Email: maltepries@gmx.de

\section{Persönliche Daten}

Geboren am 19.08.1983 in Vechta, Niedersachsen.

verheiratet, deutscher Staatsbürger.

\section{Praktische Tätigkeit}

10/2012-heute Mitarbeiter der Fa. Häussermann, Sulzbach/Murr

10/2009-9/2012 Wissenschaftlicher Mitarbeiter am Institut für Holzbiologie und Holzprodukte der Universität Göttingen.

\section{Ausbildung}

10/2009-9/2012 Promotion bei Herrn Professor Militz am Institut für Holzbiologie und Holzprodukte der Universität Göttingen zum Thema „Holzmodifizierung mit Siliziumverbindungen“.

10/2005-6/2012 Wirtschaftswissenschaftliches Studium an der Fernuniversität in Hagen. Abschluss Diplom Volkswirt: 6/2012

Abschluss Diplom Kaufmann: 11/2010.

10/2006-1/2009 Masterstudium der Forstwissenschaften mit dem Schwerpunkt „Holzbiologie und Holztechnologie“ an der Universität Göttingen.

Abschluss: Master of Science

4/2008-10/2008 Masterarbeit an der University of Maine, Orono, Maine, USA.

10/2003-9/2006 Bachelorstudium der Forstwissenschaften an der Universität Göttingen. Abschluss: Bachelor

7/2002-3/2003 Wehrdienst beim Gebirgsjägerbataillon 232 in Bischofswiesen/Bayern.

05.06.2002 Abitur an der Alten Landesschule in Korbach, Hessen.

Spiegelberg, den 11.11.14 